JOINT TRANSPORTATION RESEARCH PROGRAM

FHWA/IN/JTRP-2010/24

\author{
Final Report
}

\title{
A LABORATORY STUDY OF BENDWAY WEIRS AS A BANK EROSION COUNTERMEASURE
}

Dennis A. Lyn

R. Cunningham

November 2010 


\section{TECHNICAL Summary}

INDOT Research

Technology Transfer and Project Implementation Information

TRB Subject Code:

Publication No.: FHWA/IN/JTRP-2010/24, SPR-3011

November 2010

Final Report

\section{A Laboratory Study of Bendway Weirs as a Bank Erosion Countermeasure}

\section{Introduction}

Bendway weirs are being considered by INDOT as a potential alternative countermeasure for bank erosion at channel bends that might be more environmentally sensitive than the traditional riprap. These are linear structures extending riverwards from the bank to be protected, but unlike the more familiar spur structure, they are intended to be overtopped. The flow over the weir crest is supposed to be directed perpendicular to the plane of the weir, and so by appropriate placement of the weir(s), the flow can be directed away from the bank, thus protecting it.

Design guidelines for such structures are available in HEC-23 (Lagasse et al., 2009), but these have not received much detailed scrutiny regarding their performance. Also, the HEC-23

\section{Findings}

Compared to the initial geometry, the HEC-23-based weir protected the toe of the outer bank, but, under design conditions, still allowed significant erosion in the upper part of the outer bank. This remained the case even when the weir crest height was increased above the level recommended in HEC-23, and only the case where the weir crest was above the water surface was there any noticeable improvement in protection of the upper outer bank. Higher approach velocities were also found associated with an increased rate of erosion, and so when higher velocities are expected, a more design is independent of approach velocity. A laboratory study was conducted to examine the effectiveness of bendway weirs based on the HEC23 guidelines in protecting the outer bank of $90^{\circ}$ bend, characterized by a single ratio of radius of curvature to top width of 3.3. The laboratory model had both erodible bed and banks. Experiments were conducted with and without weirs, with three different weir crest heights (including one that was essentially not overtopped), and two approach velocities. Measurements of erodible boundary elevations as well as point velocities were made. Effectiveness was assessed by comparison with the corresponding no-weir case, and with the initial 'artificial' channel geometry.

conservative design would be preferred. The point velocity measurements did not give strong evidence that the overtopping flow had substantial erosion potential. They did suggest that erosion could occur even where the local velocities were markedly below the critical velocity associated with equilibrium straightchannel flows, even where slope effects were included. Mass failure or slumping rather than direct shear erosion seems a more plausible mechanism for much of the observed bank retreat. 


\section{Implementation}

Based on the laboratory study, the following recommendations may be made regarding the suitability of bendway weirs as a bank erosion countermeasure:

- in cases where no erosion of the upper bank can be tolerated, then, at this stage of knowledge of the hydraulics of bendway weirs and their associated erosion response characteristics, the
HEC-23 based structures should not be considered.

- if it is sufficient that the toe of the bank be protected, and that retreat of only the upper part of the outer bank can be tolerated, then bendway weirs may be more seriously considered, but their effectiveness would require close monitoring.

\section{Contact}

For more information:

Prof. Dennis Lyn

Principal Investigator

School of Civil Engineering

Purdue University

West Lafayette, IN 47907

Phone: (765) 494-9615

lyn@purdue.edu

\author{
Indiana Department of Transportation \\ Division of Research \\ 1205 Montgomery Street \\ P.O. Box 2279 \\ West Lafayette, IN 47906 \\ Phone: (765) 463-1521 \\ Fax: (765) 497-1665
}

\section{Purdue University}

Joint Transportation Research Program

School of Civil Engineering

West Lafayette, IN 47907-1284

Phone: (765) 494-9310

Fax: (765) 496-1105 
Final Report

FHWA/IN/JTRP-2010/24

\title{
A LABORATORY STUDY OF BENDWAY WEIRS AS A BANK EROSION COUNTERMEASURE
}

\author{
by \\ D. A. Lyn and R. Cunningham \\ School of Civil Engineering \\ Joint Transportation Research Program \\ Project No. C-36-62-S \\ File No. 09-08-19 \\ SPR-3011 \\ Conducted in Cooperation with the \\ Indiana Department of Transportation \\ and the U.S. Department of Transportation \\ Federal Highway Administration
}

The contents of this report reflect the views of the authors, who are responsible for the facts and the accuracy of the data presented herein. The contents do not necessarily reflect the official views or policies of the Indiana Department of Transportation or the Federal Highway Administration at the time of publication. The report does not constitute a standard, specification, or regulation.

\author{
Purdue University \\ West Lafayette, IN 47907 \\ November 2010
}


TECHNICAL REPORT STANDARD TITLE PAGE

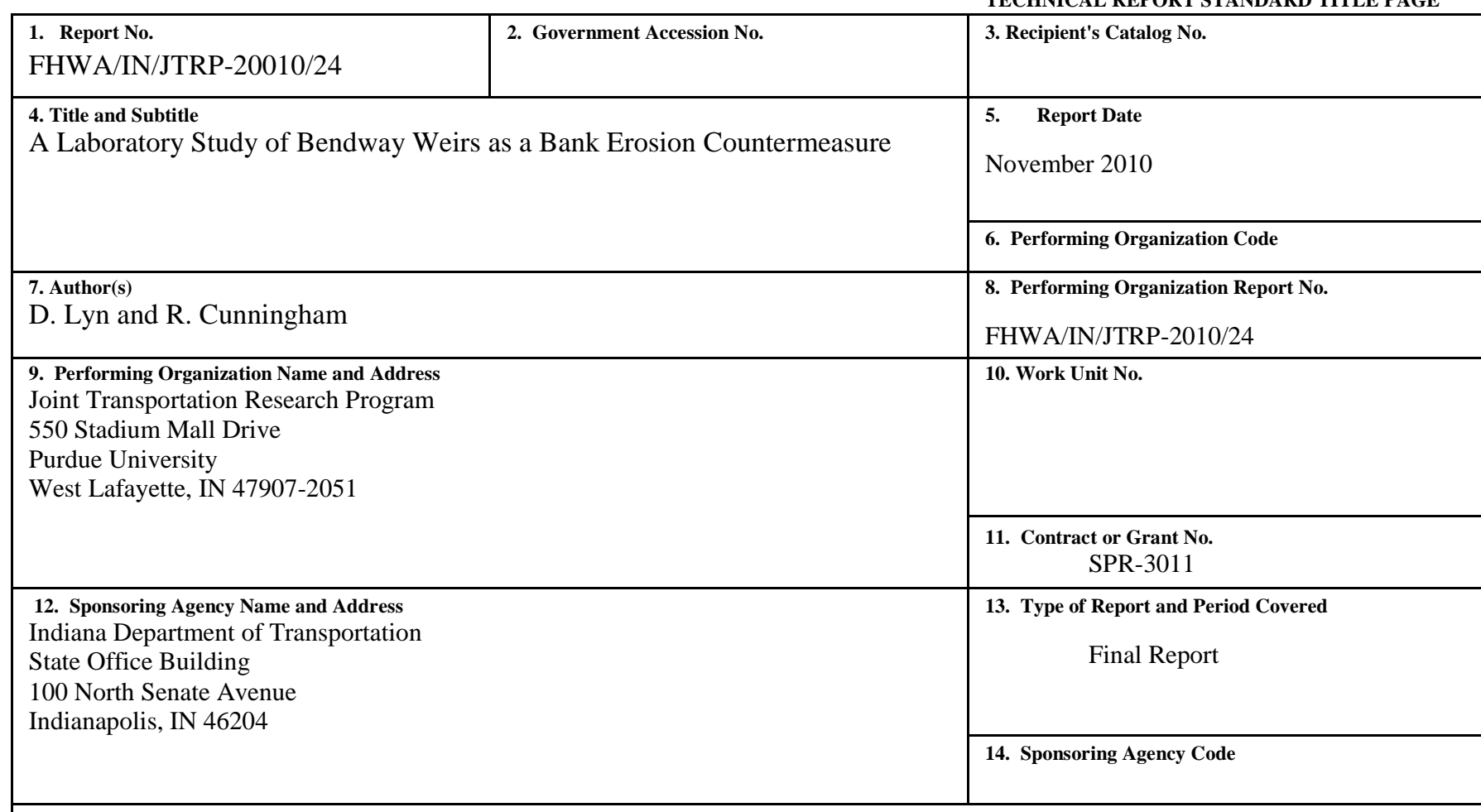

\section{Supplementary Notes}

Prepared in cooperation with the Indiana Department of Transportation and Federal Highway Administration.

16. Abstract

Bendway weirs are being considered by INDOT as a potential alternative countermeasure for bank erosion at channel bends that might be more environmentally sensitive than the traditional riprap. These are linear structures extending riverwards from the bank to be protected, but unlike the more familiar spur structure, they are intended to be overtopped by the design flow. The flow over the weir crest is supposed to be directed perpendicular to the plane of the weir, and so by appropriate placement of the weir(s), the flow can be directed away from the bank, thus protecting it.

Design guidelines for such structures are available in HEC-23 (Lagasse et al., 2009), but these have not received much detailed scrutiny regarding their performance. Also, the HEC-23 design is independent of approach velocity. A laboratory study was conducted to examine the effectiveness of bendway weirs based on the HEC-23 guidelines in protecting the outer bank of $90^{\circ}$ bend, characterized by a single ratio of radius of curvature to top width of 3.3. The laboratory model had both erodible bed and banks. Experiments were conducted with and without weirs, with three different weir crest heights (including one that was essentially not overtopped), and two approach velocities. Measurements of erodible boundary elevations as well as point velocities were made. Effectiveness was assessed by comparison with the corresponding no-weir case, and with the initial 'artificial' channel geometry.

Compared to the initial geometry, the HEC-23-based weir protected the toe of the outer bank, but, under design conditions, still allowed significant erosion in the upper part of the outer bank. This remained the case even when the weir crest height was increased above the level recommended in HEC-23, and only the case where the weir crest was above the water surface was there any significant improvement in protection of the upper outer bank. Higher approach velocities were found associated with an increased rate of erosion. The point velocity measurements did not give strong evidence that the overtopping flow had substantial erosion potential. They did suggest that erosion could occur even where the local velocities were markedly below the critical velocity associated with equilibrium straight-channel flows, even where slope effects were included. Mass failure or slumping rather than direct shear erosion seems a more plausible mechanism for much of the observed bank retreat.

\section{Key Words}

Bendway weirs, bank erosion countermeasure, riprap, spur structure

\section{Distribution Statement}

No restrictions. This document is available to the public through the National Technical Information Service, Springfield, VA 22161

\section{Security Classif. (of this report) Unclassified}

\section{Security Classif. (of this page)}

Unclassified

21. No. of Pages
66

22. Price 


\section{Table of Contents}

$1 \quad$ Background and scope of work ............................................................................................

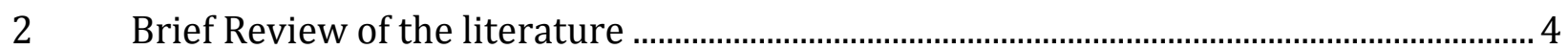

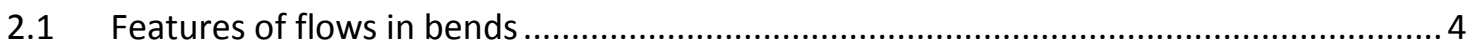

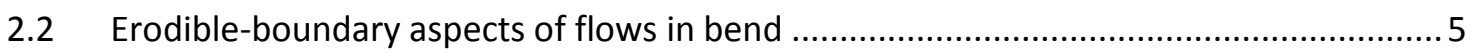

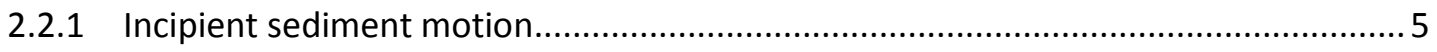

2.2.2 Bank retreat, lateral migration rates, and equilibrium channel morphology ............. 6

2.3 River training structures in bends and bendway weirs............................................... 7

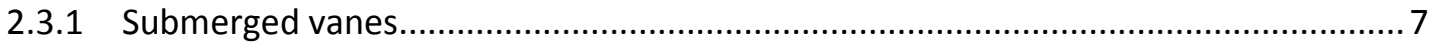

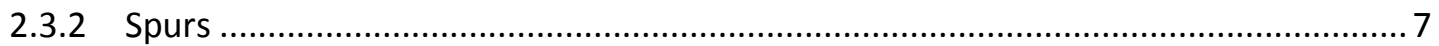

2.3.3 Bendway weirs and closely related structures ....................................................... 7

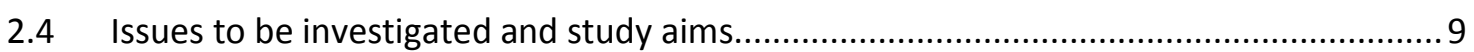

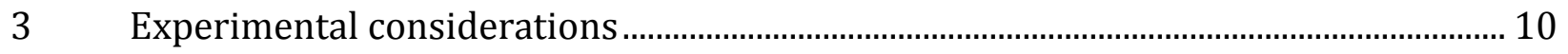

3.1 Experimental setup, materials, and instrumentation ............................................... 10

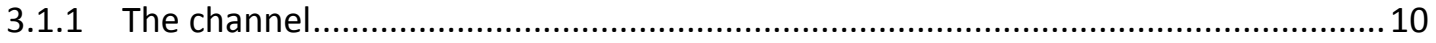

3.1.2 The sediment and initial boundary geometry ..................................................... 12

3.1.3 The traversing system and instrument positioning …............................................ 13

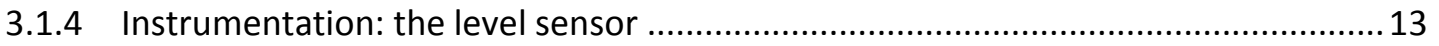

3.1.5 Instrumentation: the acoustic Doppler velocimeter ................................................ 15

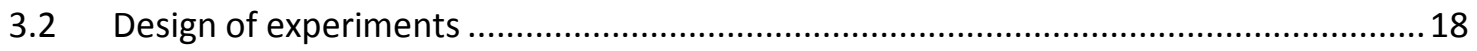

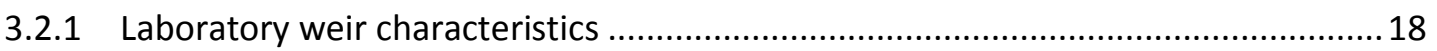

3.2.2 Other aspects studied and experimental conditions ................................................ 19

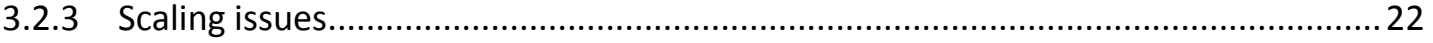

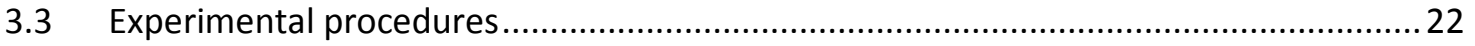

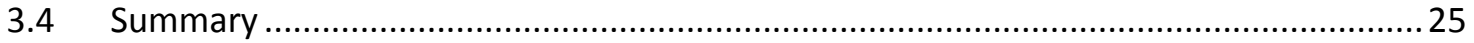

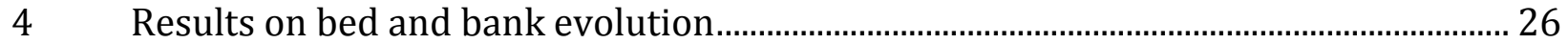

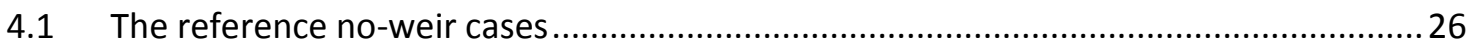

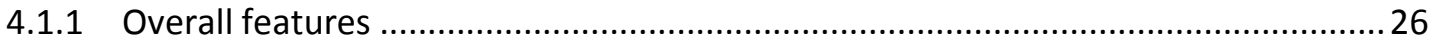

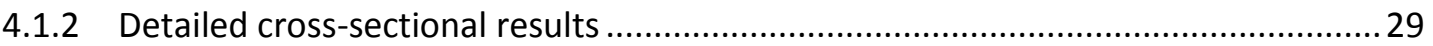

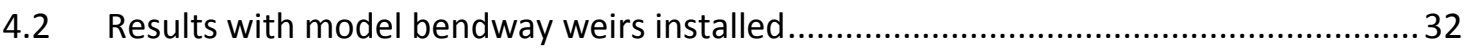

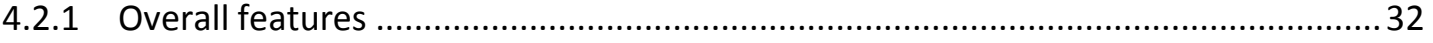

4.2.2 More detailed cross-sectional profiles in weir cases ............................................... 37 


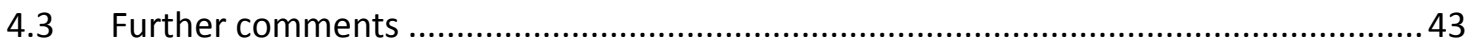

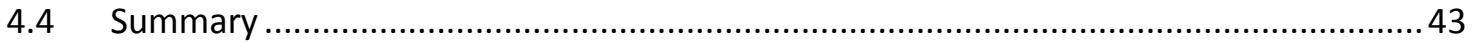

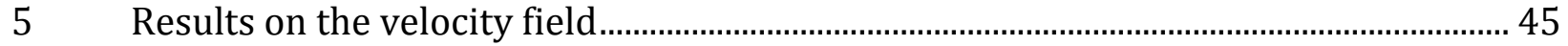

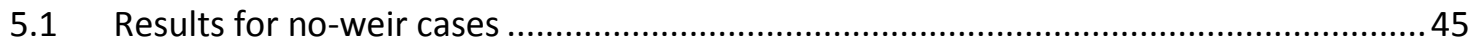

5.2 Results for cases with bendway weirs installed............................................................5

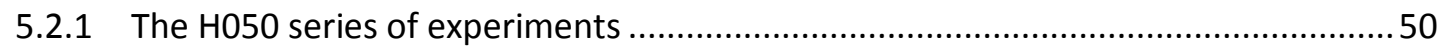

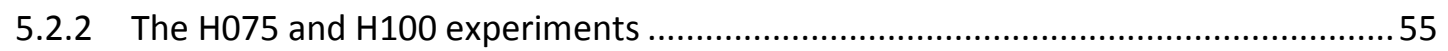

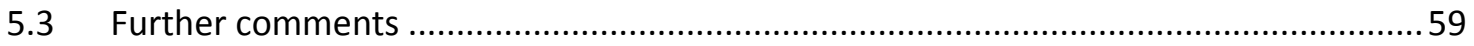

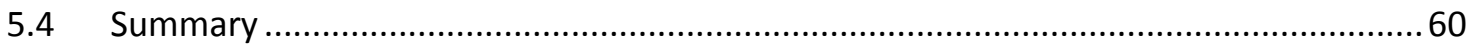

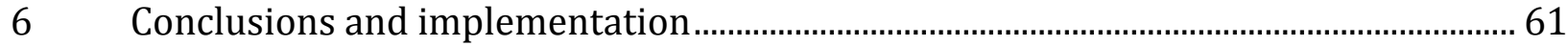

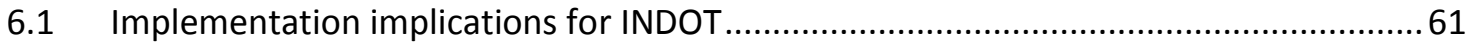

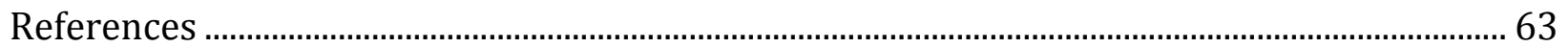




\section{Background and scope of work}

The planform instability of a stream may have severe consequences for bridges in that the geotechnical and structural design assumes a fixed channel cross-sectional and planform geometry. At bends, the situation is especially of concern due to the natural tendency for erosion at the outer bank and deposition at the inner bank (Lagasse et al., 2001, also known and referred to as HEC-20; Lagasse et al., 2009, also known and referred to as HEC-23). The traditional countermeasure to bank erosion has been riprap revetment (see example in Fig. 1.1), which is generally considered effective from the perspective of bank stability, but may be less advantageous in other respects. Riprap design is discussed at length in a number of references (Maynord, 1988; Brown and Clyde, 1989, also known and referred to as HEC-11; HEC-23). The homogeneity of the revetment is highly artificial and may adversely affect the quality of the aquatic habitat. Fischenich (2003) discusses adverse ecological impacts of riprap on the riverine environment. The present study is however restricted to the physical aspects of flow and scour around an alternative bank stability countermeasure, the bendway weir, and will not examine waterquality aspects.

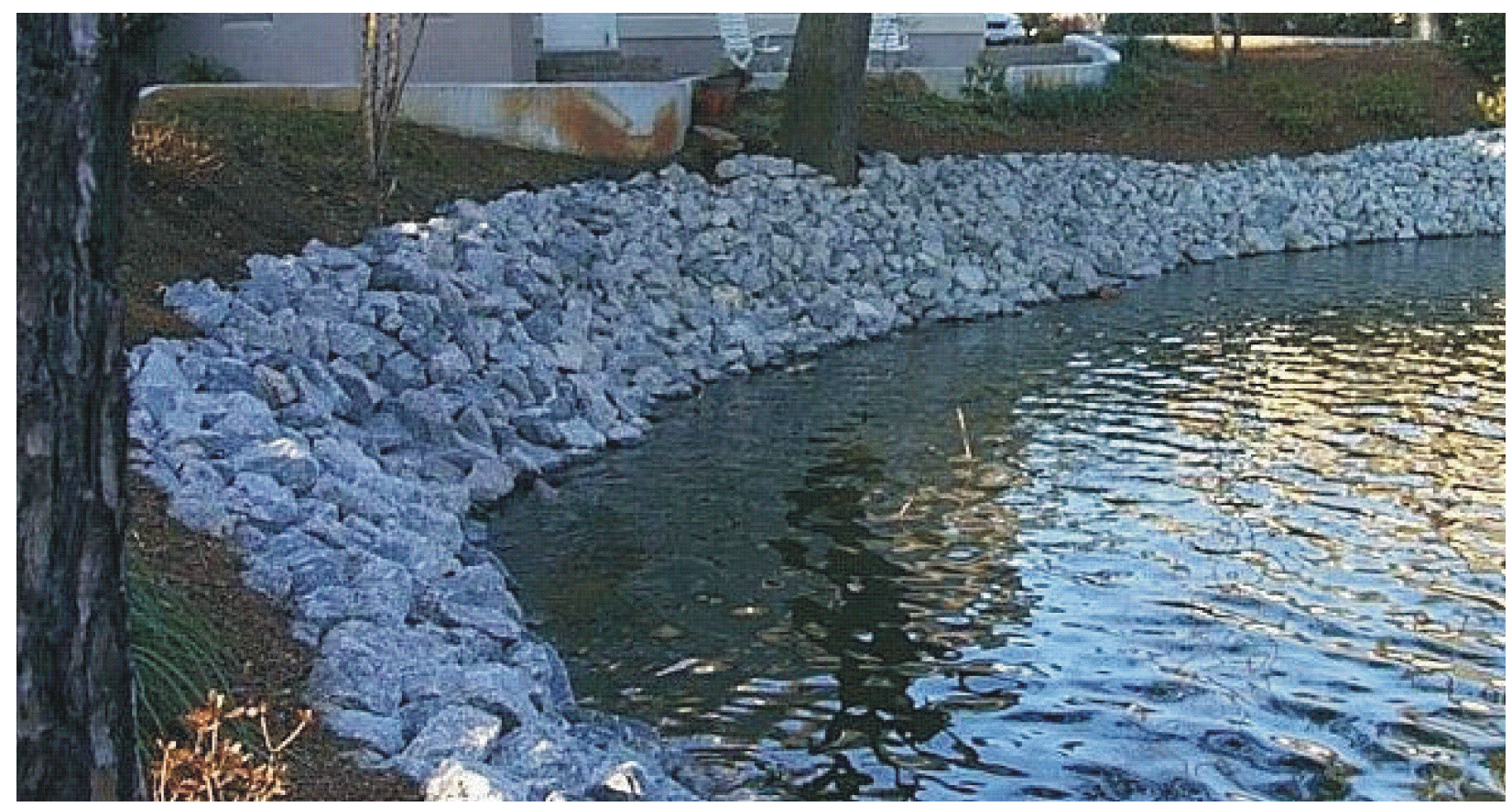

Fig. 1.1: Example of riprap revetment (adapted from http://www.norfolk.va.us/utilities/resources/riprap.jpg)

With greater emphasis on the quality of the stream as habitat, the search for a more environmentally sensitive, the search for less 'intrusive' approaches to bank stabilization at bends has stimulated interest in alternative countermeasures. In particular, the application of bendway weirs has attracted attention recently from several government agencies including the Soil Conservation Service (now the Natural Resources Conservation Service or NRCS), the U. S. Army Corps of Engineers (USACE) as well as INDOT (and more generally, the Federal Highway Administration, FHWA). Bendway weirs are similar to the more traditional groin or spur, in that they are structures, often consisting of gabions or stone-filled baskets, extending linearly from the outer bank, either perpendicular to the bank or angled slightly upstream. They differ in their main intended effect under design flow conditions, namely that, in 
contrast to a spur, they are designed to be overtopped (Fig. 1.2) by the flow. It is thought that the flow over the overtopped structure should be directed perpendicular to the lateral axis of the structure, and therefore away from the outer bank, thereby reducing streambank erosion. Under low-flow conditions when they are not overtopped, these structures would act essentially like spurs.

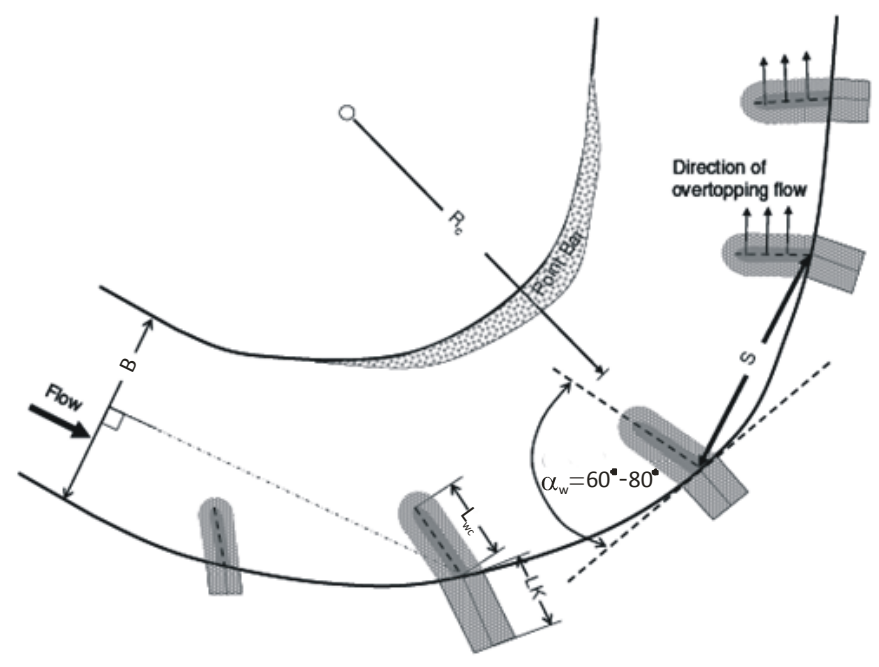

(a)

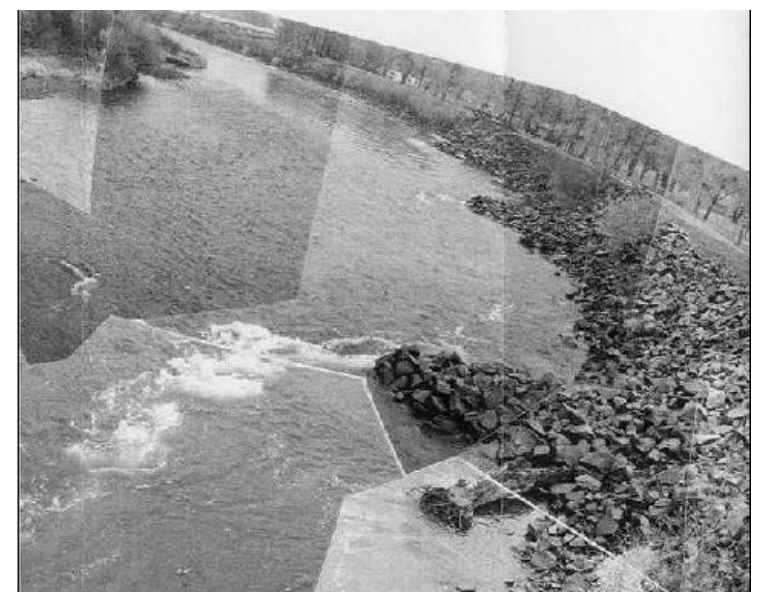

(a)

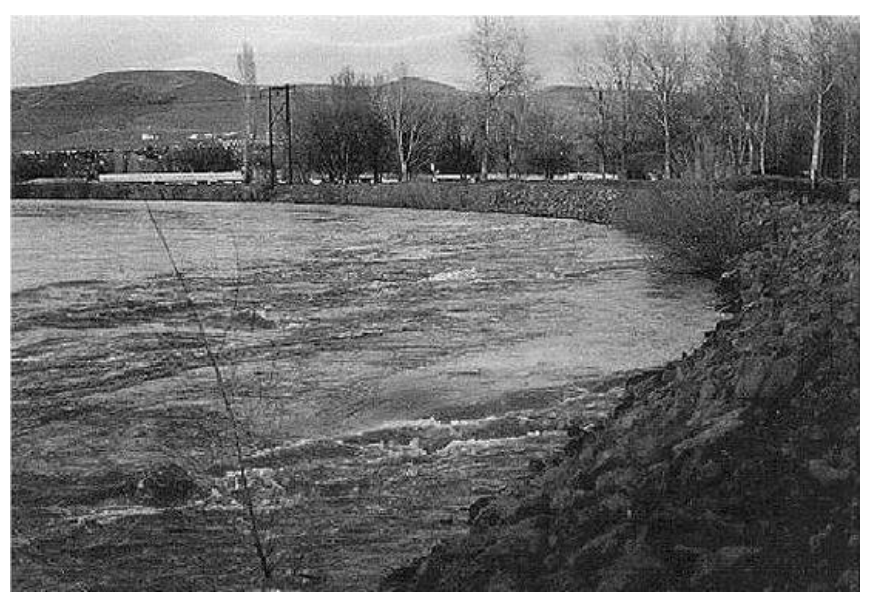

(b)

Fig. 1.2: a) Sketch of bendway weirs (adatpted from HEC-23, vol. 2), b) unsubmerged, and b) submerged bendway weirs in Yakima, Washington (both taken from HEC-23, vol. 2)

In the late 1990's, the INDOT Hydraulics group became interested in the possibility of using bendway weirs for bank stabilization, and implemented this countermeasure at one site, namely at the bend in Village Creek over which runs SR 1, near Connersville in East-Central Indiana. The aerial photograph (Fig. 1.3a) shows an approximately $90^{\circ}$ bend beginning just upstream of the bridge (flow is from right to left, with north pointing to the top of the picture). As stated in an INDOT memo, dated 9/28/1998, from Dave Finley, then in the INDOT Hydraulics group, "In the years since the SR 1 bridge was built, Village Creek has been migrating towards the north, causing a great deal of erosion on the north bank, and creating a large scour hole at the abutment. In order to correct this problem, it is proposed to use gabions to construct four structures, known as 'bendway weirs' upstream of the bridge." 
The design was largely completed before any design guidance was available (the 2001 edition of HEC-23 seemed to have been the first to provide a systematic design guidance for bendway weirs) and so departs substantially from that outlined in HEC-23.

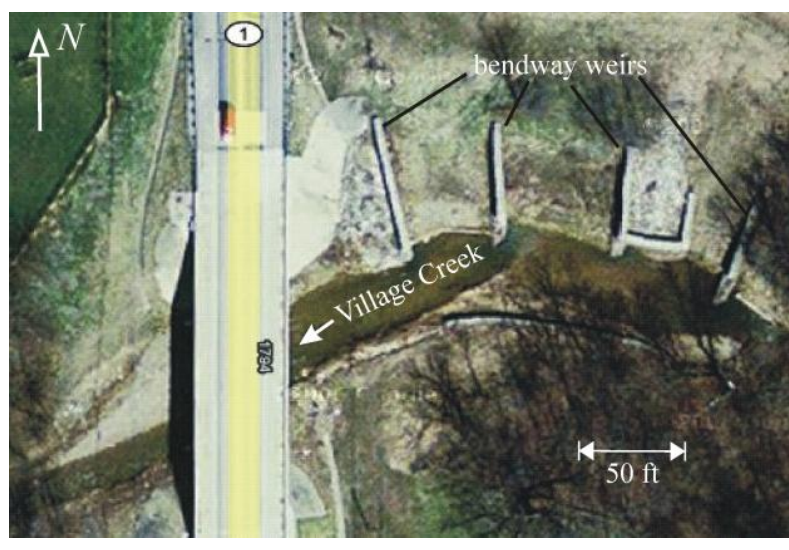

(a)

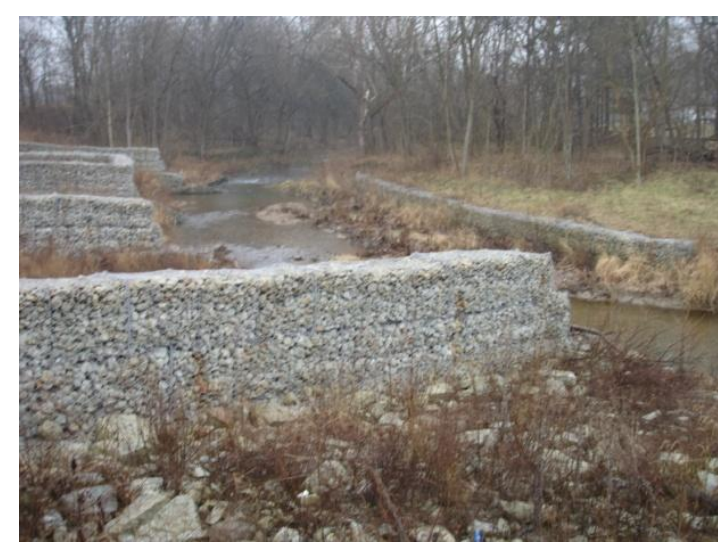

(b)

Fig. 1.3: a) Aerial photograph of INDOT site with bendway weirs at SR 1 over Village Creek near Connersville, IN (adapted from Google Maps), b) closeup photograph of bendway weirs, looking upstream

As will become evident in the review of the literature in Chap. 2, the effectiveness of bendway weirs in bank stabilization remains somewhat controversial. The current project was planned primarily as a laboratory study of bendway weirs with an erodible boundary to examine their performance in inhibiting bank erosion. The reference system is based on the design given in HEC-23, with the main variation examined being the height of the weirs. In addition to measurements of bed elevation in the presence or absence of weirs under nominally the same approach flow conditions, measurements of the velocity fields using an acoustic Doppler velocimeter (ADV) were also made in order to investigate in more detail the relationship between flow and erosion.

Although it was initially thought to complement the laboratory study with a field study at the SR 1 site, this was ultimately abandoned because the design at SR 1 departed so much from the HEC-23 guidelines. Whereas the height of the weir as recommended by HEC- 23 should be $30 \%$ to $50 \%$ of the mean annual high water level, the main part of the SR 1 weirs seems to have been designed to be overtopped significantly by probably only the 50-year event. As such, it was not clear whether the weirs would act as weirs at any time during the project period. On several site visits, at various times of the year, the water surface level was quite low, much below the crest of the weirs. Thus, while the structures since their construction seem to have been effective in stabilizing the banks, they are likely to have acted purely or primarily as spurs rather than as weirs.

The report is organized as follows. A brief review of the literature on flow and scour in bends in general and various countermeasures, with particular emphasis on bendway weirs is given in Chap. 2. Experimental methods and procedures as well as the design of experiments are then discussed in Chap. 3. Results on erosion are then presented in Chap. 4, and are followed in Chap. 5 by a presentation of the velocity field measurements. A final summary and implementation plan end the report. 


\section{Brief Review of the literature}

In this chapter, the literature on three aspects of increasing complexity is reviewed: i) the general features of flows in bends, ii) the implications of bend flows for erodible beds and banks, and iii) countermeasures for dealing with bank erosion at bends, with emphasis on river training structures such as bendway weirs.

\subsection{Features of flows in bends}

Hydraulic problems at flow bends have long been recognized, and hence standard texts on open channel flow (e.g., Chow, 1959; Henderson, 1966) as well as various FHWA Hydraulics publication, including HEC-11 and HEC-23, and USACE manuals (e.g., USACE EM 1110-2-1601) discuss flow aspects to a greater or lesser degree. A more detailed account, with a review of the literature, including specifically sediment-transport aspects, up to the late 1980's, may be found in Chang (1992).

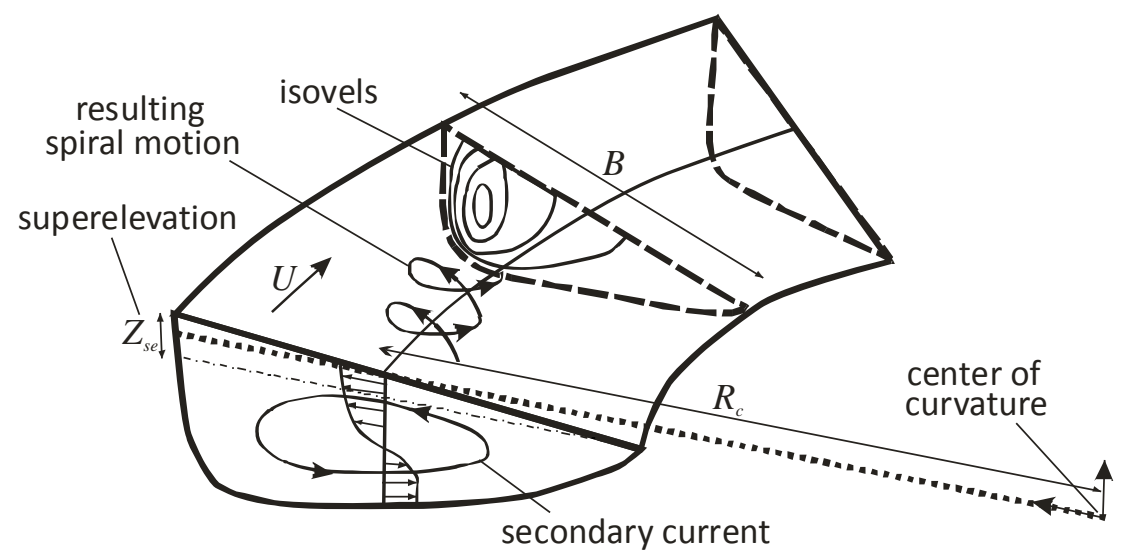

Fig. 2.1: Definition sketch of flow in a curved channel

A definition sketch of a general curved channel is shown in Fig. 2.1. The essential additional element in bend flows is the centrifugal force acting on the flow as it traverses a curvilinear path. This introduces the important length scale, the radius of curvature, $R_{c}$, which generally is a point quantity, varying at every point in the cross-section, but quite often is applied in simple one-dimensional engineering models to an entire section or even to an entire bend, usually justified only for rather gradual bends, in which case it might be the minimum radius of curvature to the stream centerline, e.g., as shown in Fig. 2.1.

The effect of superelevation, which refers to the difference in elevation of the water surface between the outer and the inner bank, provides a simple illustration of the effect of centrifugal force. An estimate of this difference, $Z_{s e}$, is usually given as

$$
\frac{Z_{s e}}{h}=\left(\frac{U^{2}}{g h}\right)\left(\frac{B}{R_{c}}\right) \sim F r^{2}\left(\frac{B}{R_{c}}\right)
$$

where $U$ is a cross-sectionally averaged velocity, $h$ is a flow depth, $B$ is the top width, and $g$ is the acceleration due to gravity. This estimate assumes that $B / R_{c}$ is small, and for low Froude numbers, $F r=U / \sqrt{g h}$, can be quite small, and in a laboratory setting difficult to measure precisely. The role of $B / R_{c}$ is clearly seen. 
In itself, the superelevation tends to be of less direct concern for bank erosion and sediment transport, but it is associated with a secondary current that is due to local imbalance between a basically hydrostatic pressure force and the centrifugal force. As shown in Fig. 2.1, the main secondary current is directed towards the outer bank near the free surface, and returns to the inner bank along the bed. For relatively sharp bends, $B / R_{c} \geq 0.2$, secondary current velocities may locally attain maximum magnitudes larger than $0.15 U$ (Hicks et al., 1990). The combination of the dominant streamwise flow with the secondary current results in a spiral streamwise motion.

Of more direct concern for bank erosion is the distribution of streamwise (tangential) velocities, $u$, which generally provide the dominant contribution to the boundary shear stress. Henderson (1966) gave a simplified theoretical argument for $u$ to decrease from the inner to the outer bank. The laboratory results of Ippen and Drinker (1962) for rather sharp $60^{\circ}$ bends in trapezoidal channels show a more complicated picture, with the maximum- $u$ region nearer the inner bank towards the beginning of the bend, but then shifting to the outer bank towards the end of the bend. Similar though less striking results can also be seen in the more gradual $270^{\circ}$ bend in a half trapezoidal channel (Hicks et al., 1990). Further the maximum- $u$ region may dip below the free surface, such that velocity gradients and hence bed shear stresses may be significantly increased. The early laboratory studies (e.g., Ippen and Drinker, 1962; Hicks et al., 1990) focused on channels with flat bottoms and sloping sides. More realistic crosssectional geometries with a bar-pool geometry (similar to that shown in Fig. 2.1) may reinforce the velocity distribution features. Laboratory measurements (Blanckaert and Graf, 2001) in a $120^{\circ}$ bend with fixed vertical sidewalls indicated a maximum velocity, $u_{\max } \approx 1.5 \mathrm{U}$. This was observed much closer to the bed than to the free surface at the $60^{\circ}$ section where the transverse bed slope was $\approx 15^{\circ}$ over a stable fine-gravel bed with no active sediment transport. In EM-1110-2-1601 (USACE, 1991), equations are given for the design velocity, $U_{d}$, taken to be the depth-averaged local velocity over the bank slope at a point $20 \%$ of the slope length from the toe of the bank slope and somewhat downstream of the curve apex and are of the form:

$$
\frac{U_{d}}{U}=A_{0}-B_{0} \log _{10} \frac{R_{c}}{B}
$$

for the range, $2 \leq R_{c} / B \leq 12$, where $A_{0}$ and $B_{0}$ are constants with values of 1.71 and 0.78 for trapezoidal channels and 1.74 and 0.52 for natural channels. Here again the role of $B / R_{c}$ is highlighted.

The hydraulic parameter of primary importance for erosion and sediment transport is the boundary shear stress, $\tau$, or tractive force, though accurate estimates of $\tau$ are often difficult to obtain in practical applications. The early laboratory measurements of Ippen and Drinker (1962) tended to show two high- $\tau$ regions, one close to the inner bank somewhat upstream of the mid-bend, and another close to the outer bank towards and even somewhat downstream of the bend outlet. In this respect, the maximum-boundary- $\tau$ regions correspond roughly with the maximum- $u$ regions. Their results suggest that the approach boundary $\tau$ could be considerably amplified, even by over $100 \%$, in these high boundary- $\tau$ regions, with maximum values increasing with $B / R_{c}$. Rather less dramatic results were found in the more recent measurements of Hicks et al. (1990).

\subsection{Erodible-boundary aspects of flows in bend}

\subsubsection{Incipient sediment motion}

Discussions of erosion are typically based on criteria for incipient sediment motion, formulated in terms of a either critical shear stress or cross-sectionally averaged velocity. For a cohesionless particle of diameter $d$ on a side slope, at an angle of $\varphi$ with respect to the horizontal, the critical shear stress, $\tau_{c}$, for incipient motion relative to that $\left(\tau_{c h}\right)$ on a horizontal bed may be expressed as (Chang, 1992) 


$$
\frac{\tau_{c}}{\tau_{c h}}=K_{1}=\left(1-\frac{\sin ^{2} \varphi}{\sin ^{2} \psi}\right)^{1 / 2}
$$

where $\psi$ is the friction angle (angle of repose) of the sediment. The effect of bank slope (or angle) can therefore be quite significant in reducing $\tau_{c}$. Thus, even if $\tau$ acting on a bank slope may be somewhat reduced relative to that on the bed (Hicks et al., 1990), the reduced $\tau$ may still be able to mobilize sediment on a sloping bank and hence to cause erosion. Various models for $\tau_{c h}$ are available, including the classical Shields curve (Chang, 1992), but practical engineering equations are often based on simpler models, e.g.,

$$
\tau_{c h}=C_{0} \gamma s-1 d
$$

where $\gamma$ is the specific weight, $s$ the specific gravity of the sediment, and $C_{0}$ is a constant with a value between 0.03 and 0.06 .

Because $\tau$ is less convenient than $U$ to apply in practice, such relations are frequently expressed in terms of $U$ by invoking a friction relationship, such as a Manning-Strickler equation, with the result that a critical average velocity, $U_{c}$, can be expressed as

$$
\frac{U_{c}}{\sqrt{g s-1 d K_{1}}}=C_{1}\left(\frac{h_{l}}{d}\right)^{m}
$$

where $h_{l}$ may be either a local or an average flow depth, and $m$ is an exponent depending on the assumed friction relationship ( $m=1 / 6$ for a Manning-Strickler relationship), and $C_{1}$ is an empirical coefficient that may include a safety or stability factor. The equation in Richardson and Davis (2001, also known as HEC-18) for $U_{c}$ chooses $C_{0}=0.039, C_{1}=1.53$, and $m=1 / 6$, and assumes $K_{1}=1$. Eq. 1.5 may be also viewed as forming the basis for the USACE (USACE EM-1110-2-1601) or FHWA (HEC-11) riprap design approaches with however different choices of the characteristic riprap size, depth parameter, exponent $m$ and coefficient $C_{1}$ and even $K_{1}$. For bends, the USACE approach relies on more detailed modeling of the velocity field such as with Eq. 2.2, while the FHWA more simply increases the stability factor (equivalent to reducing $C_{1}$ ). It should be emphasized that Eqs. 2.4 and 2.5 are based on equilibrium straight-channel flow over a bed without bedforms, and should only with caution be applied to bend flows.

\subsubsection{Bank retreat, lateral migration rates, and equilibrium channel morphology}

The preceding discussion of critical conditions for sediment motion is relevant to what is sometimes referred to as direct fluvial entrainment (HEC-20) in which the local flow field, particularly the local boundary shear stress, is directly responsible for the movement of sediment. On sloping banks, however, another mechanism may be as or even more important, namely mass or gravitational failure. This occurs when sediment is directly entrained at a lower elevation, but this leads to a gravitational instability of the bank above this elevation, as sediment above this lower elevation is also induced to move, typically in a slumping motion.

There is empirical field evidence (Hickin and Nanson, 1984) that, for meander bends with $R_{d} / B \approx$ 2-3 may be associated with the largest migration rates. It might be noted that at the SR 1 Village Creek site $R_{c} / B \approx 3-6$ depending on section, and so might be expected to be active if not necessarily having the largest migration rates.

The cross-sectional boundary profile in a bend typically has a shallow transverse slope towards the inner bank and a steeper slope towards the outer bank (Fig. 2.1). The inner bank region is generally thought to be region of deposition (point bar), whereas the outer bank region is considered a region of 
erosion. Rhoads (2003) argues that this is primarily due to the shift in the location of maximum boundary shear stress from the inner bank to the outer bank.

\subsection{River training structures in bends and bendway weirs}

Various river training structures have been proposed for bank stabilization in bends, notably spurs, but also submerged vanes and bendway weirs. Within the context of bank stabilization, these stand in contrast to direct armor approaches such as riprap application, and so have been classified as indirect techniques (Biedenharn et al., 1997) in that they aim to modify the flow field so as to achieve bank protection. A brief overview of flow changing techniques is given in Technical Supplement $14 \mathrm{H}$ of the National Resources Conservation Service handbook (NRCS, 2007, also to be referrred to as NEH-654).

\subsubsection{Submerged vanes}

In their most well known variation, the lowa vanes, these are short vertical-plate-like structures, anchored directly into the streambed rather than being keyed to the protected bank. Typically deployed in a regular multi-vane array in the vicinity of the protected bank, each induces its own secondary circulation which together acts to disrupt the larger-scale secondary current or spiral flow associated with the bend flow. Their action can be rather subtle, and successful application may require more expertise both in design and implementation than other countermeasures. Greater uncertainty and variability in field conditions may also limit their range of applicability. Odgaard (2009) reviews the theoretical basis and discusses results of laboratory and field studies.

\subsubsection{Spurs}

These are linear structures protruding into the flow from the bank, but in contrast to weir-like structures are not designed to be overtopped, though their crest is generally at or below bank level (HEC-23). They protect the bank by deflecting entirely high-velocity flow away from the bank. Because they have had a relatively long history and have been widely studied and applied, comprehensive guides to their application and design have long been available (Copeland, 1983; Brown, 1985), and experience with them has influenced the design of bendway weirs.

\subsubsection{Bendway weirs and closely related structures}

Like submerged vanes, bendway weirs are relatively new, having first attracted attention in the late 1980 's, with a number of model studies, as well as field installations, by the USACE Waterways Experiment Station (WES), e.g., Derrick et al. (1994). A cross-sectional schematic view is given in Fig. 2.2. As noted previously, these structures are intended to be inundated at normal or seasonal mean water level. They do directly deflect the near-bed flow away from the toe of the protected bank, and hence inhibit scour at the bank toe, but also aim to direct the overtopping flow away from the top of the protected bank. To what extent the latter aim is achieved is uncertain. In the extreme case of a classic sideweir, the flow exiting over the sideweir is not entirely perpendicular to the plane of the weir. The effect of downstream submergence of the weir flow is also uncertain. Whether the deflecting of the near bottom flow or the redirecting of the near free-surface flow is more important may depend on the specific conditions.

The bendway weir is distinguished by a substantially horizontal crest, though it may terminate in a short sloping section at the toe. A closely related structure, the barb (or rock vane), differs mainly in geometry in that the crest tends to be gently sloping ( $1 \mathrm{~V}: 5 \mathrm{H}$ to $1 \mathrm{~V}: 10 \mathrm{H}$, see Fig. $2.2 \mathrm{~b})$. HEC-23 makes no distinction between a bendway weir and a stream barb, and discusses them together. On the other hand, NEH-654, which gives a detailed design procedure for stream barbs, recommends a much more pronounced upstream orientation for a barb $\left(20^{\circ}\right.$ to $45^{\circ}$ with respect to the bend tangent, with smaller angles for smaller $R_{d} / B$ ) compared to the HEC-23 general recommendation of $60^{\circ}$ to $80^{\circ}$. 
Although a systematic design procedure was already given in the second edition of HEC-23, which appeared in 2001, the merits of the bendway weir for bank protection remain controversial. In a study of field sites in Illinois, Rhoads (2003) found evidence of scour in some though not all of the sites with installed bendway weirs. This does not necessarily imply that these structures are not generally effective, but rather that their design or implementation may have been inadequate. The bendway weirs at the Illinois sites were constructed during the period 1997-2002, and seemed to have followed NRCS design guidelines. Rhoads (2003) notes that weirs upstream of the bend apex are unnecessary, and installation of weirs at a given bend may not offer any protection to adjacent unprotected bends. There was also question regarding the effect of large events, as the flow depth relative to the weir crest, increases, when any effect of the weirs is expected to diminish.

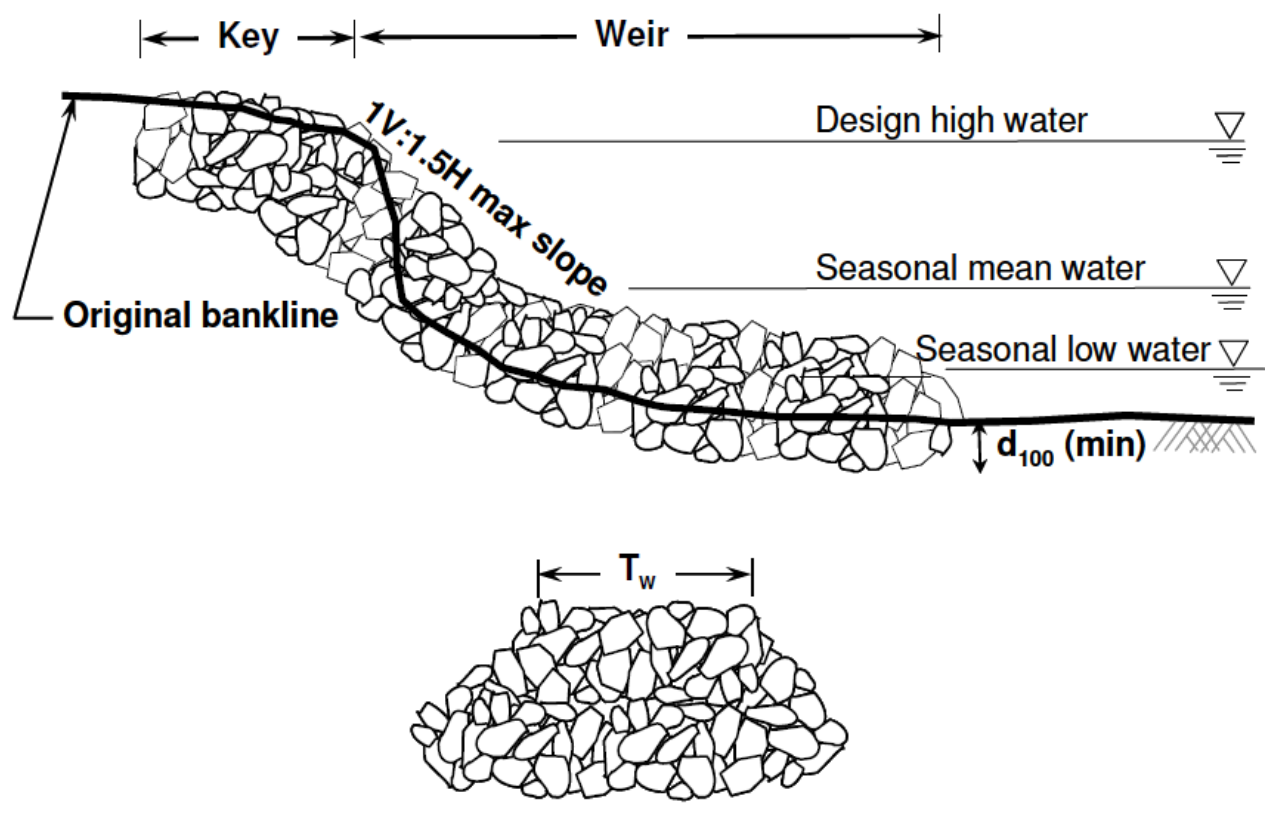

a)

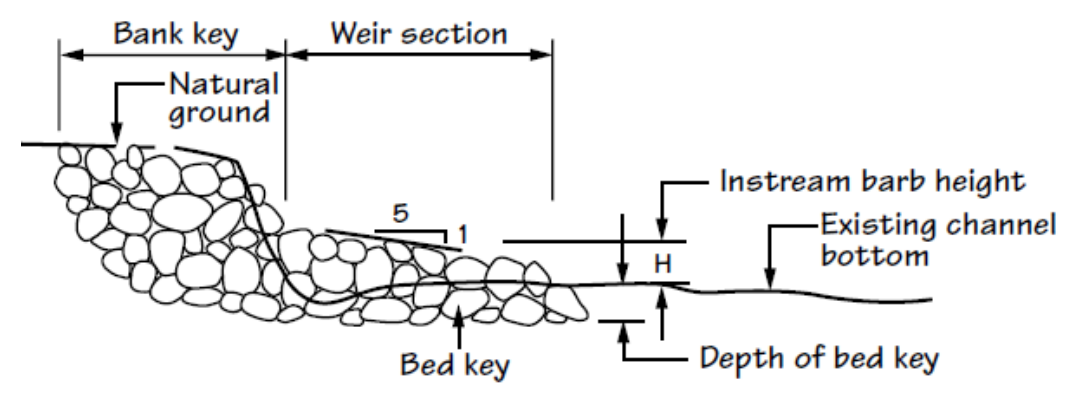

b)

Fig. 2.2: a) Cross-sectional view of a bendway weir (taken from HEC-23), b) Cross-sectional view of a stream barb (taken from NEH-654)

Although several model studies and field studies have been carried out, detailed studies of the hydraulics of bendway-weir-like structures are rather few. Studies at Colorado State University (Heintz et al., 2002; Darrow et al., 2004) were conducted on an undistorted 1/12 scale fixed-bed trapezoidalcross-section model of a reach on the Middle Rio Grande River with and without bendway weirs 
installed. Limited point velocity and bed shear stress measurements were made with acoustic Doppler velocimeter (ADV) and Preston tube respectively. Individual weir dimensions except for weir length were constant, but discharges, weir spacing, and orientation were varied. Velocities in the outer-bank region were found to be reduced to $20 \%-40 \%$ of the maximum centerline velocity measured in the reference case without weirs, and weir length was found to be the dominant influence on flow characteristics within the weir field. They also proposed to characterize the effect of the weirs in terms of certain characteristic velocity ratios. Because it was a model study, the plan form geometry was complicated in that a double bend was modeled, with variable channel width, with each bend of different $R_{c} / B(2$ and 4.4$)$ and different bend angle $\left(125^{\circ}\right.$ and $\left.73^{\circ}\right)$.

Abad et al. (2008) report on a companion study to Rhoads (2003), in which field measurements were taken on a small Illinois stream (Sugar Creek, IL), unfortunately during an event in which the weirs were not overtopped. These measurements were used to validate a three-dimensional fixed-bed numerical model, which was then applied to study cases in which the weirs were overtopped. Details of the weirs or the stream bend characteristics were not given. Nevertheless, the numerical simulations, which did not consider an erodible boundary, suggested that, when the weirs are overtopped, highvelocity and high-boundary-stress-regions can develop near the outer bank, particularly in the region above the weirs, and the effectiveness of the weirs in protecting the bank may diminish significantly when the weirs are submerged. While suggestive, the field studies and numerical simulations do not provide any direct evaluation of weir effectiveness since a pre-weir condition was neither measured nor simulated.

Laboratory studies of stream barbs have been reported by Matsuura and Townsend (200) and by Fox et al. (2005). The study of Fox et al. (2005) however examined flow in a straight channel, while the work of Matsuura and Townsend (2004) was based on a bend with fixed vertical banks and did not include any velocity measurements. In a more comprehensive study by Bhuiyan et al. (2010) of bankattached vanes in a sine-generated meander channel, an erodible bed was present, but the flow was again restricted by fixed vertical walls.

\subsection{Issues to be investigated and study aims}

The above review has shown that there seems to have been no detailed systematic laboratory study of the effectiveness of bendway weirs for bank protection. Though some detailed laboratory studies of such weirs (or closely related structures) have recently been reported, each has been limited in some respect, e.g., an erodible bed was not considered in the CSU studies of Heintz et al., 2002 and Darrow et al., 2004, the barb study of Matsuura and Townsend (2004) included neither an erodible bank (only the bed was erodible, and fixed vertical channel walls was used) nor velocity measurements, and the barb study of Fox et al. (2005) was performed in a straight channel. More specifically, no study of bendway weirs designed according to HEC-23 guidelines is available.

The present study was therefore planned as a systematic laboratory study of bendway weirs and their performance in protecting the outer bank of an erodible channel bend. The basic weir geometry will correspond to that recommended in HEC-23. Weir performance will be based on a comparison with the no-weir case as well as with the 'initial' bank. In addition, the effect on performance of varying the height of the weir crest and the inlet velocity will also be examined. 


\section{Experimental considerations}

This chapter describes the experimental setup, materials and methods, and then discusses the design of the experiments performed. The general procedure followed in performing the experiments is then outlined.Experimental setup, materials, and instrumentation

\subsubsection{The channel}

A curved channel was specially constructed for the project. There was no attempt to conduct a strict scale-model study of the SR 1 - Village Creek site, but the general features of that site influenced the choice of basic parameters in the design of the channel and for orientation it might be considered very loosely a $1 / 24$ scale model. Thus, a $90^{\circ}$ bend with a constant radius of curvature, $R_{c}$, was specified. Due to laboratory space constraints, $R_{c}=8.3 \mathrm{ft}(2.5 \mathrm{~m})$ was chosen, which allowed 5.3-ft $(1.6 \mathrm{~m})$ straight sections at both inlet and outlet, plus head- and tailboxes (Fig. 3.1). The bend section plus $0.5 \mathrm{ft}(0.15 \mathrm{~m})$ of the straight sections at the inlet and outlet were erodible (shaded in Fig. 3.1); the remainder of the straight inlet and outlet sections was non-erodible. This permitted measurements of the erodible boundary at angular positions, $\theta=0^{\circ}$ (the angular position, $\theta$, is measured positive from the bend inlet, see Fig. 3.1) and $\theta=90^{\circ}$ (bend outlet) if desired. The entire channel was constructed on a $16-\mathrm{ft}(4.9 \mathrm{~m})$ square plywood platform.

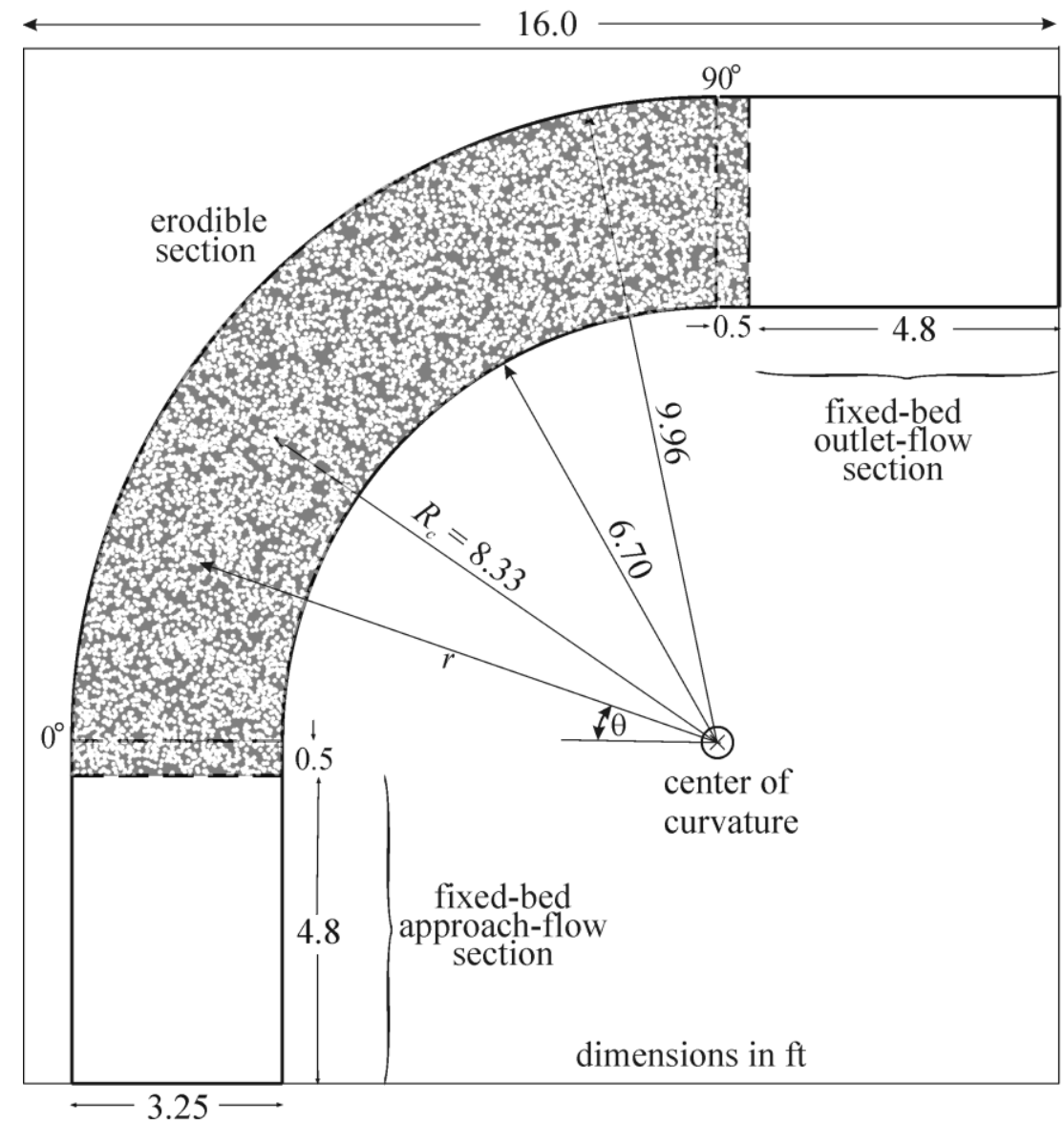

Fig. 3.1: Sketch of laboratory channel with dimensions 


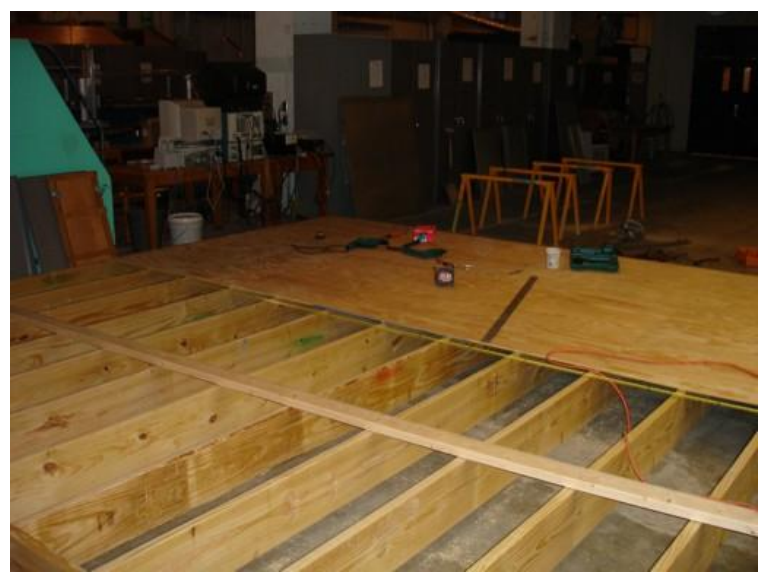

(a)

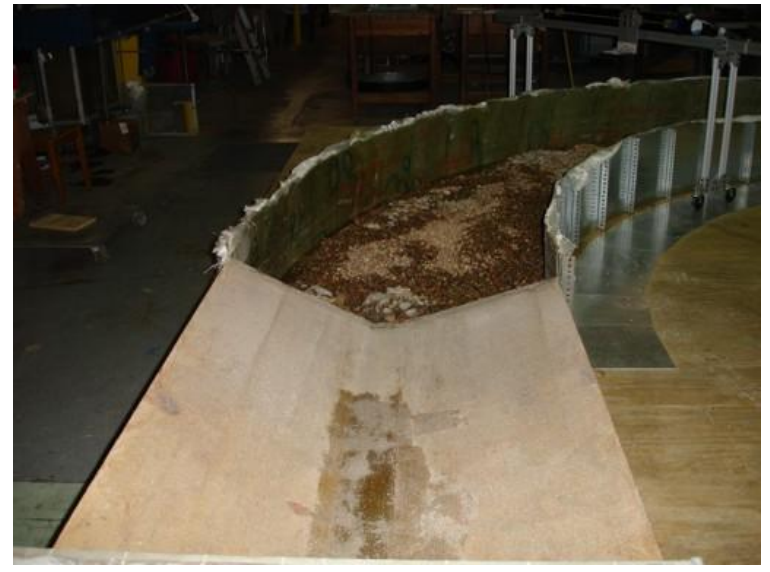

(c)

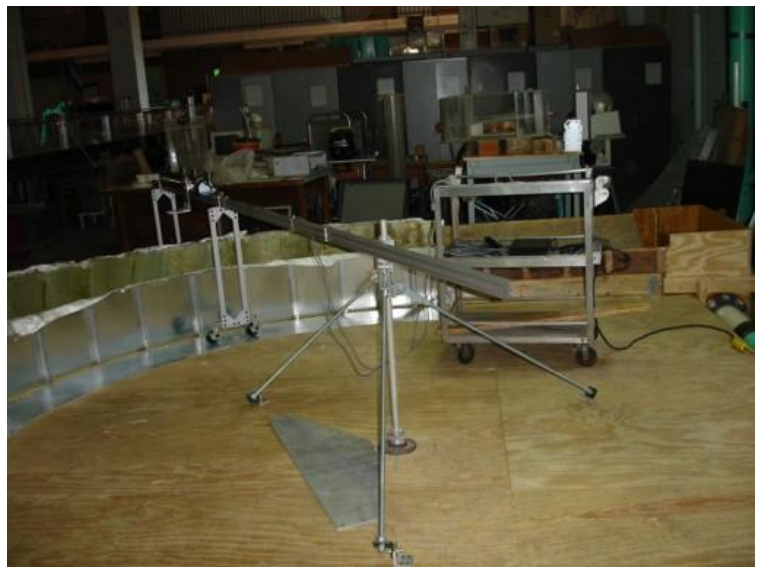

(e)

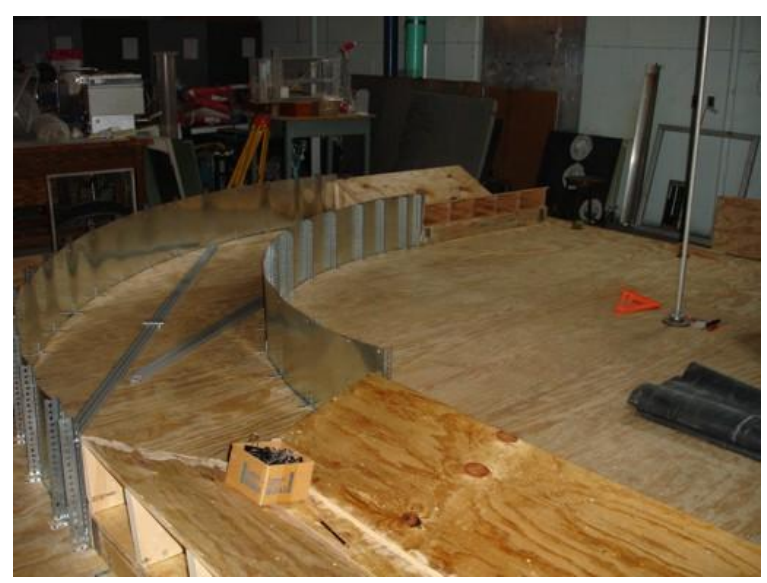

(b)

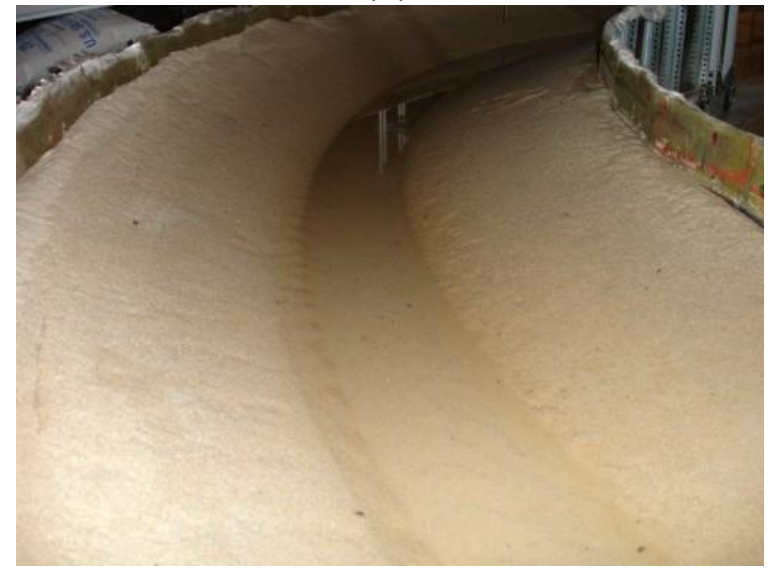

(d)

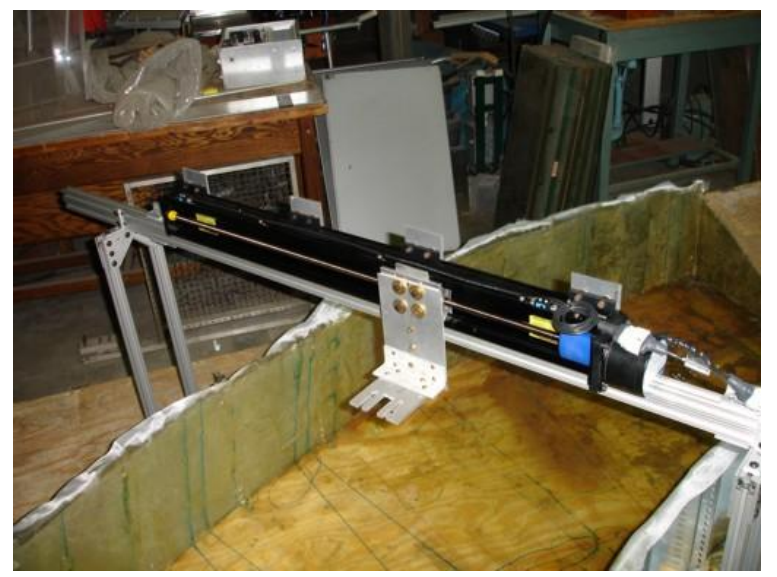

(f)

Fig. 3.2: Photographs of channel under construction, a) platform for channel, b) straight fixed-bed inlet and outlet sections with vertical sidewalls for the bend section, c) roughened inlet section, with the base layer of gravel in the bend section, d) final bend section with erodible sand layer for bed, e) radial instrument carriage on castors, and f) traversing system mounted on instrument carriage with instrument mount 
Photographs taken during construction are shown in Fig. 3.2. The platform was built with feet that could be varied in elevation, and an average slope of $\approx 0.001$ from inlet corner to outlet corner was set at the outset, but no attempt was made to adjust this for the different experiments. Aluminum flashing was used to form the basic fixed vertical sidewalls of the curved section (Fig. 3.2b). A fiberglass fabric impregnated with resin to make it watertight was used to cover the entire bend section including the sidewalls, before a gravel base layer was placed on the fabric (Fig. 3.2c). Plastic sheeting separated the gravel layer from the final sand layer (Fig. 3.2d), which constituted the entire flow boundary in the bend. Thus, both bed and bank were erodible. An instrument carriage (Fig. 3.2e) that could be rotated about the center of curvature was also fashioned. On the carriage could be mounted a motorized traversing system (Fig. 3.2f) that could be computer-controlled to move the measuring point in the radial direction. Further details of the traversing system are given below. A screed for reshaping the erodible bed for each different experimental run could also be mounted on the instrument carriage.

Water from a laboratory sump is drawn by a pump controlled by a programmable variablefrequency drive (ABB ACH 400 series) and discharged into the channel. An electromagnetic flowmeter (Omega FMG400 series) with manufacturer's specified accuracy of $\pm 0.5 \%$ of rate was installed in the supply line downstream of the pump but upstream of the channel inlet. The variable frequency drive was linked in a feedback control loop with the flow meter so as to maintain the desired steady flow rate, and the discharge could be varied by a calibrated linear rheostat control knob. The headbox contained two sets of baffles for reducing the large-scale turbulence produced at the junction of the supply line and the headbox.

The tailbox incorporates an adjustable weir that could be used to control the outlet water surface level. It also had a shelf between the transition straight fixed-bed section and the weir that aimed to trap transported sediment and thus minimize loss of sand into the sump. The water was then gravity fed back into the sump.

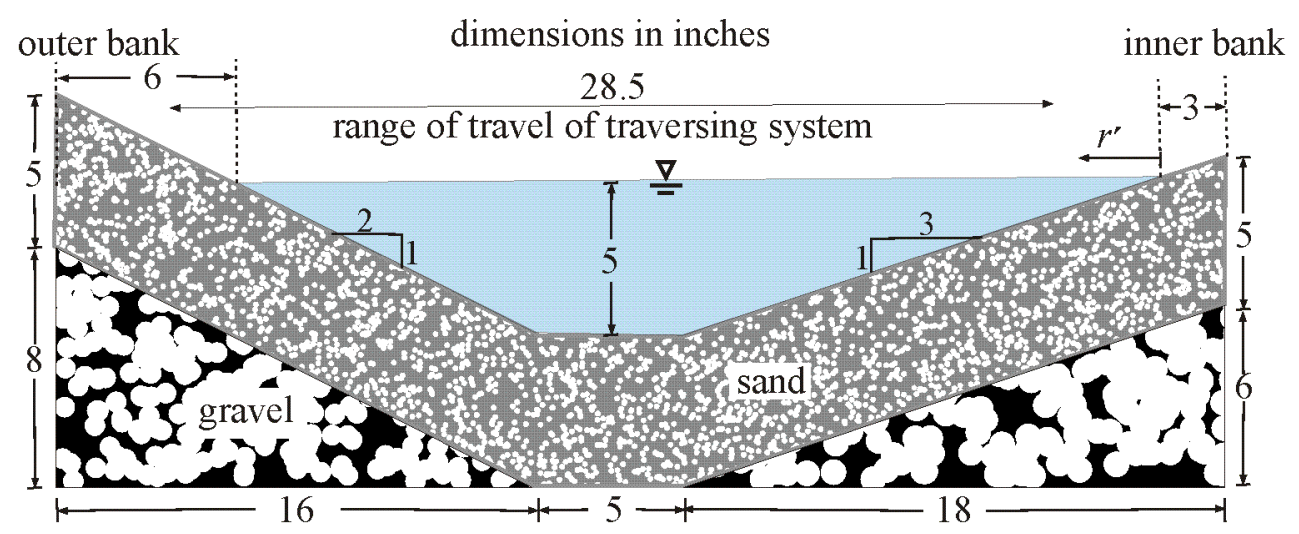

Fig. 3.3: Initial sand-bed cross-sectional geometry

\subsubsection{The sediment and initial boundary geometry}

Only a single sized sand was used in the erodible section for all experiments, namely a very uniform rounded ASTM 20/30 Ottawa quartz sand (US Silica) with a median diameter of $0.6 \mathrm{~mm}$ and an estimated geometric standard deviation of 1.1 and a specific gravity of 2.65. If the HEC-18 criterion for critical velocity (and hence assuming equilibrium uniform flow in a straight wide horizontal channel bed) is applied, $U_{c h} \approx 37 \mathrm{~cm} / \mathrm{s}$ (or $1.2 \mathrm{ft} / \mathrm{s}$ ). The initial channel bed cross-sectional geometry (Fig. 3.3) is an asymmetric trapezoid with a side slope of $1 \mathrm{~V}: 2 \mathrm{H}$ on the outer bank side and a side slope of $1 \mathrm{~V}: 3 \mathrm{H}$ on the inner bank side, with a sand layer of uniform thickness of 5 in $(12.7 \mathrm{~cm})$. The asymmetric slope was 
chosen to accelerate the approach to an expected bar-pool (Fig. 2.1) equilibrium bend geometry. Except possibly at the entrance of the bend section, the initial channel cross-sectional geometry was not expected to play a major role because the flow was expected to shape the bed through erosion and deposition, with eventually a naturally evolved cross-sectional geometry ultimately resulting. Whether an equilibrium geometry was established remains however unclear. Unlike previous laboratory studies of bendway-weir-like structures, an erodible bank was specifically desired, and the initial geometry, for the initial depth of 5 -in $(12.7-\mathrm{cm})$ permitted 6 -in $(15-\mathrm{cm})$ of lateral migration in the outward radial direction before the fixed outer vertical wall would be reached. Because less erosion was expected towards the inner bank, a smaller lateral distance $(3-$ in or $7.6-\mathrm{cm})$ to the inner vertical wall was allowed. In the presentation of profile results in Chapters 4 and 5, an offset radial coordinate, $r^{\prime}$, will be used where $r^{\prime}=$ 0 corresponds to the radial location of the inner bank limit of the initial inlet flow (Fig. 3.3). The crosssectional geometry of the straight fixed-bed sections at the inlet and the outlet was the same as that of the initial erodible bend section. Further, a thin layer of the same sand was glued onto the fixed beds to provide similar roughness.

If an angle of repose of $39^{\circ}$ is assumed for the sand, then $U_{c} \approx 30 \mathrm{~cm} / \mathrm{s}$ (or $1 \mathrm{ft} / \mathrm{s}$ ) if the initial lateral slope $(1 \mathrm{~V}: 2 \mathrm{H})$ of the outer bank is taken into account (still assuming uniform flow in a straight channel). For the inner bank, the initial slope of $1 \mathrm{~V}: 3 \mathrm{H}$, and so $U_{c} \approx 34 \mathrm{~cm} / \mathrm{s}$ (or $1.1 \mathrm{ft} / \mathrm{s}$ ). Unless otherwise specified, the following will refer to $U_{c 0} \approx 30 \mathrm{~cm} / \mathrm{s}$ (or $1 \mathrm{ft} / \mathrm{s}$ ) as the critical velocity since, as the minimum, it might be considered the controlling critical velocity, though still based on initial conditions.

\subsubsection{The traversing system and instrument positioning}

The Velmex ${ }^{\circledR}$ VMX Stepping Motor Traversing System was used to automate measurements in the radial direction, and provided a more consistent placement of measuring instruments. The system could be operated in three modes. The first manual operation was not used. A second mode, via computer control, allows for precisely pinpointing the location of the instrument at any time. In the specific case of the W1 type motor, $2.54 \mathrm{~cm}$ of travel corresponds to 4000 steps, i.e., a resolution of $\approx 6 \mu \mathrm{m}$. This second method was used in the collection of velocity data. The third mode allows programmable control, with the advantage that operation could be automated once the measurement instrument being used is located at the appropriate section. The third mode was used in the collection of crosssectional boundary profile data. The nominal length of travel of the system was 30 -in, but, with the instrument mount included, the effective length of travel was $\approx 28.5$-in. This was not sufficient to cover the entire top width of the flow, and so it was decided to position the system so as to allow profile measurements beyond the outer limit of the initial flow (see Fig. 3.3) as outer-bank scour was expected and of primary interest. Consequently, the inner limit of water surface and corresponding part of the inner bank could not be included in the measurement range.

The angular position or location of a cross-section at which a profile was taken was perhaps the coordinate with the largest uncertainty. Arc lengths along the inner fixed wall corresponding to specified angles, $\theta$, were measured from the bend inlet $\left(\theta=0^{\circ}\right)$ and the location was marked on the inner wall. The instrument on the traversing system was then aligned with the appropriate mark when a profile is taken. By using the same marks consistently, reproducible results may be obtained, but absolute position may still be uncertain. As will be seen in Chap. 4 in the the cross-sectional boundary elevation profiles in the vicinity of weirs, discrepancies suggest uncertainties in the recorded angular positions.

\subsubsection{Instrumentation: the level sensor}

The two main types of measurements made in the laboratory study were level (bed/bank eleva-

tions) and velocity measurements. Because of the large number of measurements at a point to be made, it was essential that the instrumentation be capable of measuring rapidly and to a large extent of being 
automated. This necessitated some compromise between accuracy and speed. For example, manual measurement of bed level using a point gage remains a highly accurate method which is however quite time consuming. An acoustic sensor was chosen for level measurements, while an acoustic Doppler velocimeter (ADV) was used for velocity measurement (Fig. 3.4).

A Senix Toughsonic (TS-30) ultrasonic distance sensor, which, when deployed on the traversing system on the instrument carriage, could be programmed to determine automatically the distance to the sand or water surface at specified locations on a radial line, was used to determine bed and water surface profiles. The sensor gave a linear response, outputting a voltage (0-10 VDC) that could be calibrated. According to manufacturer's specifications, its overall usable range lies between $4.4 \mathrm{~cm}$ and 107 $\mathrm{cm}$, but it was only calibrated over the expected operating range of $5.08 \mathrm{~cm}$ (2-in) to $25.4 \mathrm{~cm}$ (10-in). Readings were recorded at the default frequency of $40 \mathrm{~Hz}$ for a sampling duration of 5 seconds at each measurement point, from which an average could be determined.

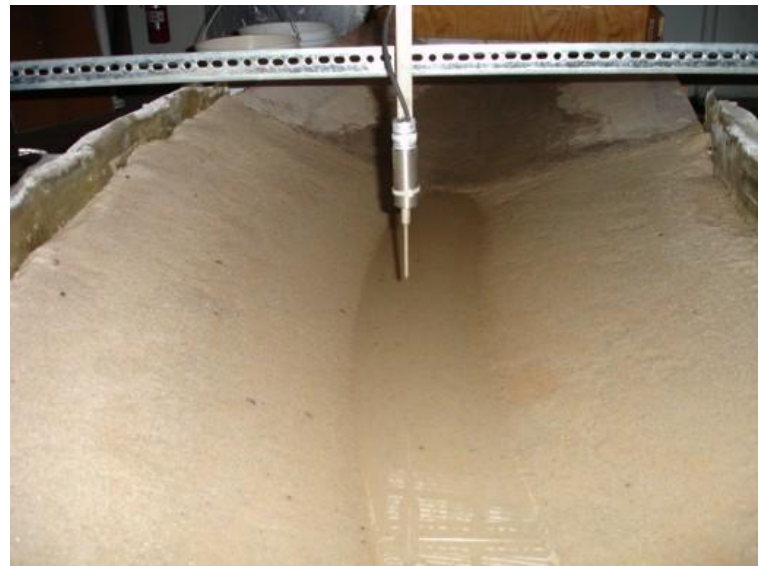

(a)

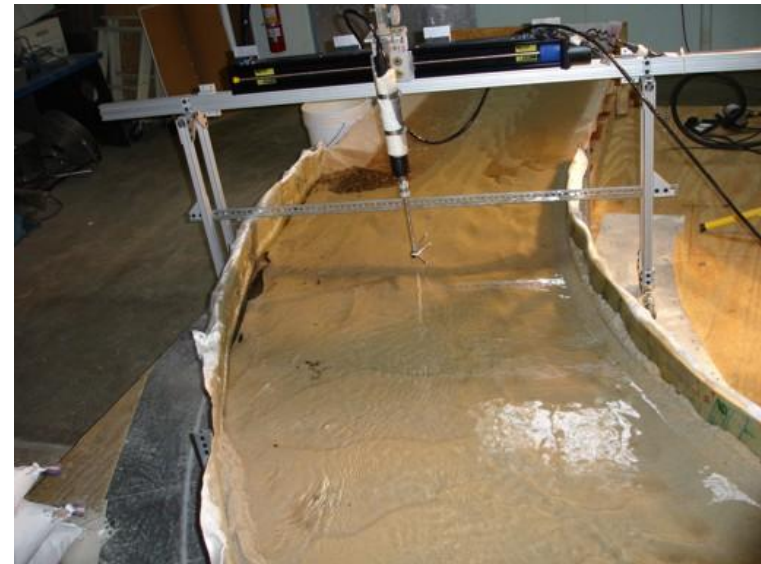

(b)

Flg. 3.4: a) Senix level sensor (note point gage directly behind it), b) Sontek ADV in a sidelooking probe configuration (probes directed towards the center of curvature)

There were small but consistent local variations in the level measurements because the traversing system was not sufficiently horizontal. These were compensated for by applying an adjustment factor, evaluated by placing a channel of still water atop the fixed channel walls and taking measurements of the level still water surface as a horizontal reference. Fig. 3.5a shows an example of the unadjusted and the adjusted data for a still-water measurement. The scatter of the compensated data about the horizontal line also provides an indication of attainable uncertainty, i.e., $\approx 0.01$-in $(0.25-\mathrm{mm})$. When measuring a flowing water surface or a rough bed surface, uncertainties would be larger. Sand surface elevations were also compensated in the same manner, but the scatter in these elevations was usually substantially larger, and so the adjustment was negligible. Fig. 3.5b shows measurements of the initial erodible bed geometry, with two measurements at a point, the first with the traversing system moving in the forward direction, the second with it moving in the reverse direction. The statistics of the differences from the reference profile are given in Table 3.1, with results distinguished depending on whether the point being measured is located in the inner bank, the flat section, or the outer bank region. An overall average difference of -0.08 -in $(-2-\mathrm{mm})$ for the averaged profile was found with a standard deviation of 0.3 -in $(7.6 \mathrm{~mm})$, with the least difference being found in the flat section, then the inner bank, and then the outer bank region. Fig. 3.5b suggests also that the results for the reverse direction suffer from a greater bias, being shifted somewhat in the radial direction. This indicates some degree of uncertainty, as much as 1-in, in the radial position of a measurement. 

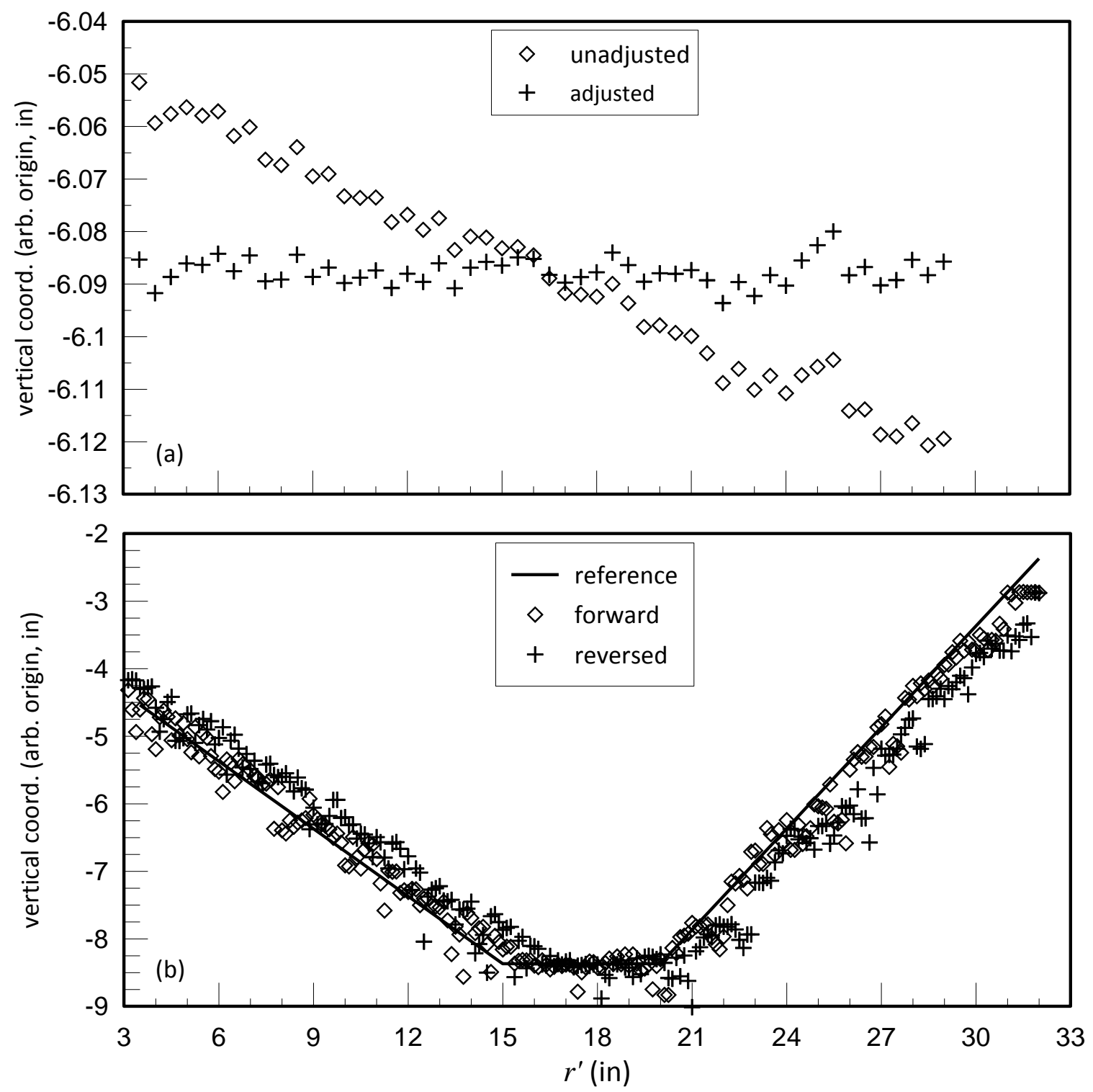

Fig. 3.5: a) Radial water surface profile for still water, with and without adjustment, b) radial erodible bed profile measured in the forward and the reverse direction, compared with the reference profile

\subsubsection{Instrumentation: the acoustic Doppler velocimeter}

Velocity measurements were made with an acoustic Doppler velocimeter (Sontek, $10 \mathrm{MHz} A D V$ ) with a 2D/3D probe, operated in a side-looking mode due to shallow depths ( $\approx 5$ in or $12.7 \mathrm{~cm}$ ). Since its development in the early 1990's (Kraus et al., 1994), the ADV has been widely used in both the laboratory and the field as a relatively inexpensive and versatile high-resolution multicomponent velocimeter. The probe consists of a central acoustic transmitter, with three receivers arranged around it, so as to be able to distinguish three velocity components. Transmitter and receivers must be submerged for proper operation. According to manufacturer's specifications, the accuracy is $\pm 1 \%$ of measured velocity. Because of the small depths in the laboratory channel, the ADV was operated in a side-looking 
mode (see Fig. 3. 4 and Fig. 3.6), in which only two velocity components, the tangential (i.e., streamwise) and the radial (i.e., lateral), were measured, and therefore requiring that only two of the three receivers

Table 3.1: Statistics of differences between measurements and reference erodible bed boundary

\begin{tabular}{|c|c|c|c|c|}
\hline \multirow{2}{*}{ region } & \multirow{2}{*}{ statistic } & \multicolumn{2}{|c|}{ direction of travel } & \multirow{2}{*}{ average } \\
\hline & & forward & reverse & \\
\hline \multirow{2}{*}{$\begin{array}{l}\text { Inner bank } \\
\text { region }\end{array}$} & Average difference (in) & $0.03(0.8)$ & $0.35(8.7)$ & $0.19(4.8)$ \\
\hline & Std. dev. (in) & $0.23(5.8)$ & $0.22(5.5)$ & $0.15(3.8)$ \\
\hline \multirow{2}{*}{$\begin{array}{l}\text { Flat section } \\
\text { region }\end{array}$} & Average difference (in) & 0.00 & $0.05(1.3)$ & $0.03(0.75)$ \\
\hline & Std. dev. (in) & $0.12(3)$ & $0.21(5.3)$ & $0 . ` 14(3.5)$ \\
\hline \multirow{2}{*}{$\begin{array}{l}\text { Outer bank } \\
\text { region }\end{array}$} & Average difference (in) & $-0.16(4)$ & $-0.59(14.8)$ & $-0.38(9.5)$ \\
\hline & Std. dev. (in) & $0.28(7)$ & $0.27(6.8)$ & $0.18(4.5)$ \\
\hline \multirow[t]{2}{*}{ Overall } & Average difference (in) & $\begin{array}{l}-0.06 \\
(1.5)\end{array}$ & $0.09(2.3)$ & $-0.08(2)$ \\
\hline & Std. dev. (in) & $0.25(6.3)$ & $0.49(12.3)$ & $0.31(7.8)$ \\
\hline
\end{tabular}

numbers in parentheses are $\mathrm{mm}$.

(plus the transmitter) be submerged. The sampling volume is specified to be $\approx 4$-in $(10-\mathrm{cm})$ from the transmitters/receivers, and its dimensions are 0.35 -in $(9 \mathrm{~mm})$ in the radial direction and 0.24-in (6 $\mathrm{mm}$ ) in the tangential direction. The irregular erodible boundary, combined with the sidelooking orientation of the ADV probe and the 4-in blanking or stand-off distance of the probe from the measurement volume also constrained the range of measurements. All velocity results were obtained with the \pm 30 $\mathrm{cm} / \mathrm{s}$ range setting, and were evaluated using the provided WinADV software, with only the phase-space despiking and filtering out communication errors being selected.

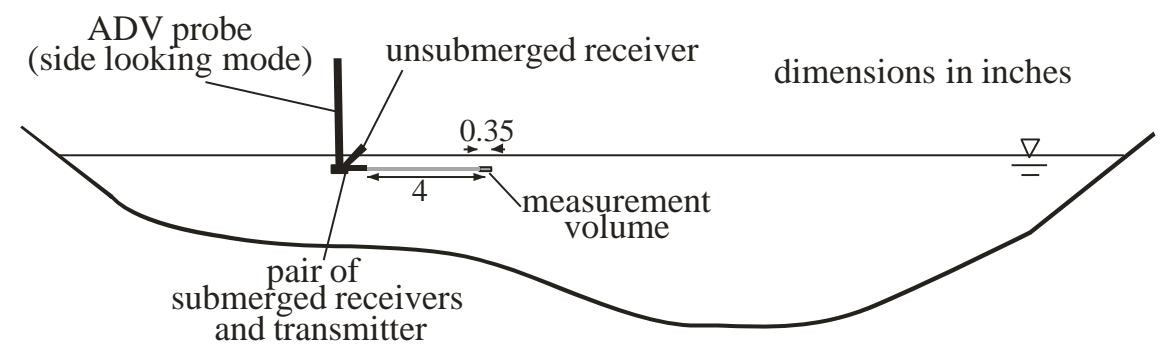

Fig. 3.6: Sketch of ADV unit in flow

A check on the accuracy of the ADV was made by comparing the mean streamwise velocity measurements in a straight-channel flow with those obtained with a laser Doppler velocimeter (LDV) for different choices of ADV settings (Table 3.2). Two ADV estimates are shown, one based on all data (unfiltered), and another based only on data which have passed the phase-space despiking procedure (filtered) available in the WinADV software. Two sampling frequencies were tested, $25 \mathrm{~Hz}$ and $0.33 \mathrm{~Hz}$, with varying total number of samples. The results indicate that the ADV measurements are remarkably robust, with close agreement with the LDV results, even with the unfiltered data, and even when the signal quality measures, such as signal-to-noise ratio (SNR) and the signal correlation are quite low ( $<10$ $\mathrm{dB}$ in the case of SNR, and $<60 \%$ in the case of the correlation). The average difference between the reference LDV data and the filtered ADV data is $-0.14 \mathrm{~cm} / \mathrm{s}(\approx-1 \%$ of the measured velocity) with a 
standard deviation of $0.42 \mathrm{~cm} / \mathrm{s}(\approx 3 \%$ of measured velocity). Except for two measurements, the filtered and unfiltered ADV results also agree.

The values of the signal quality measures reported by WinADV are averaged over the three signals (for the different velocity components). One reason for the apparently low values of SNR and correlation is that frequently only one (the vertical component) of the three signals was very noisy, e.g., because unsubmerged, so that while the signal quality for the other two components was acceptably high, the average value for all three components was misleadingly low. This is of particular significance for the present work in which only the streamwise velocity will be of concern. Further, as noted in Sontek (2001), if only mean velocities are of interest, then acceptable values of SNR and correlation, and even \% good data may be considerably relaxed, and so SNR as low as $5 \mathrm{~dB}$ or correlation as low as $30 \%$ may still provide useful results.

In the examination of the results for the bend flow, it became evident however that some of the ADV results for the mean streamwise velocity were unrealistic, and these seemed to be associated with low values of correlation. It was decided then to retain the filtered measurements as valid, to be termed 'validated', only if the signal correlation exceeded $50 \%$ and the \%good data exceeded $50 \%$. At some cross-sections, these additional validation criteria resulted in less than $10 \%$ of measurements being discarded, while at others almost $40 \%$ were discarded. The discarded measurements were typically those at the edges of the measurement region, which unfortunately were often those close to the banks and close to the bed. Some of the discarded measurements were probably reliable, but were discarded in order to adhere to a consistent and relatively simple validation criterion. For the retained measurements, values of SNR, correlation, and \%good exceeded $25 \mathrm{~dB}, 60 \%$, and $85 \%$ respectively. Although the radial component of velocity was also measured, preliminary analysis indicated that the uncertainties associated with measurements of this component were probably too large to be meaningful. Hence, these will not be presented.

Table 3.2: Comparison of ADV results with LDV results for different ADV settings

\begin{tabular}{|c|c|c|c|c|c|c|c|}
\hline \multirow{2}{*}{$\begin{array}{l}\text { LDV } \\
(\mathrm{cm} / \mathrm{s})\end{array}$} & \multicolumn{2}{|c|}{$\operatorname{ADV}(\mathrm{cm} / \mathrm{s})$} & \multirow{2}{*}{$\begin{array}{c}\text { No. of } \\
\text { samples }\end{array}$} & \multirow{2}{*}{$\begin{array}{c}\text { Sampling } \\
\text { frequency }(\mathrm{Hz})\end{array}$} & \multirow{2}{*}{$\begin{array}{l}\text { SNR } \\
(\mathrm{dB})\end{array}$} & \multirow{2}{*}{$\begin{array}{c}\text { Correlation } \\
(\%)\end{array}$} & \multirow{2}{*}{$\begin{array}{c}\% \\
\text { good }\end{array}$} \\
\hline & filtered & unfiltered & & & & & \\
\hline 13.25 & 13.19 & 13.58 & 101 & 0.33 & 15.4 & 53 & 30 \\
\hline 13.07 & 13.75 & 13.64 & 101 & 0.33 & 15.1 & 54 & 74 \\
\hline 14.58 & 13.96 & 13.80 & 93 & 0.33 & 9.6 & 52 & 80 \\
\hline 14.79 & 14.21 & 14.09 & 73 & 0.33 & 9.5 & 50 & 77 \\
\hline 14.94 & 15.40 & 15.41 & $\mathrm{n} / \mathrm{a}$ & $\mathrm{n} / \mathrm{a}$ & $\mathrm{n} / \mathrm{a}$ & $\mathrm{n} / \mathrm{a}$ & $\mathrm{n} / \mathrm{a}$ \\
\hline 15.03 & 15.49 & 15.48 & $\mathrm{n} / \mathrm{a}$ & $\mathrm{n} / \mathrm{a}$ & $\mathrm{n} / \mathrm{a}$ & $\mathrm{n} / \mathrm{a}$ & $\mathrm{n} / \mathrm{a}$ \\
\hline 15.41 & 15.52 & 15.49 & 38 & 0.33 & 8.4 & 72 & 61 \\
\hline 15.55 & 15.59 & 15.59 & 59 & 0.33 & 8.5 & 72 & 71 \\
\hline 16.32 & 16.35 & 11.13 & 36 & 0.33 & 5.5 & 60 & 33 \\
\hline 16.24 & 16.33 & 11.20 & 28 & 0.33 & 5.2 & 61 & 25 \\
\hline 16.37 & 16.82 & 16.75 & 1731 & 25 & 5.2 & 64 & 96 \\
\hline 16.27 & 16.88 & 16.74 & 2419 & 25 & 5.2 & 64 & 96 \\
\hline
\end{tabular}




\subsection{Design of experiments}

A main aim of the current work was the laboratory testing of a field of bendway weirs constructed following FHWA design guidelines. Because of the multitude of design parameters, some simplification and abstraction of the basic problem were necessary. The design of experiments was also constrained by the available laboratory facilities, and the choice of experimental parameters influenced by materials and instrumentation that was already available or easily obtainable.

\subsubsection{Laboratory weir characteristics}

Erodible bed/banks were considered essential as the main motivation of these structures is bank protection. A clear-water inlet condition was desirable because it would not involve the complication of sediment feed or recirculation. Considerations of the possible dimensions of the laboratory channel, the capacity of the available pump, and the desire to minimize potential scale issues led to the decision to restrict the study to essentially a single sediment size (median diameter, $d_{50}=0.6 \mathrm{~mm}$ ), and nominally a single depth (initial inlet depth, $h_{0} \approx 5$-in or $12.7 \mathrm{~cm}$ at the inlet). In the following, the initial parameters will be used to characterize the experimental conditions, and these will be denoted with a zero subscript. For the initial cross-sectional geometry, this implied an initial top width, $B_{0} \approx 2.5-\mathrm{ft}(0.76-\mathrm{m})$, and hence $R_{C} / B_{0}=3.3$, which lies in the range considered to be associated with particularly high migration rates. With $d_{50}=0.6 \mathrm{~mm}$ and $h_{0} \approx 12.7 \mathrm{~cm}$, the clear-water inlet-flow condition restricts the inlet velocity, $U_{0}$, to less than $\approx 30 \mathrm{~cm} / \mathrm{s}$.

While the HEC-23 design guidelines for bendway weirs/barbs are quite detailed, there is still substantial latitude in the choice of the values of the weir parameters based on judgment. The angle, $\alpha_{w}$, between the weir axis and the bankline tangent is given typically as $60^{\circ}<\alpha_{w}<80^{\circ}$. For simplicity, the present study chose a single value, $\alpha_{\mathrm{w}}=75^{\circ}$ for all experiments. There is also some ambiguity in the definition of the length, $L_{w}$, of the weir, depending on whether the sloping tip of the weir is included or excluded. In this study, $L_{w}$ is taken to be the former (Fig. 3.6), since this is the total length that protrudes (initially) into the flow. According to HEC-23 guidelines, $L_{w}$ should not exceed $B_{0} / 3$, but for bank protection, $L_{w}$ need not exceed $B_{0} / 4$, with typical values, $B_{0} / 10<L_{w}<B_{0} / 4$. In this study, it was decided to focus on the effect of the flow over the weir, because the available empirical evidence would suggest that these structures do tend to protect the base of the outer bank. Hence, $L_{w}$ was not varied, but rather was kept constant at $\approx 7.5$-in $(17.6 \mathrm{~cm})$ such that $L_{w}=B_{0} / 4$. Three weir crest heights, $H_{w}$, were studied: 2.5 -in $(6.3 \mathrm{~cm}), 3.75$-in $(9.5 \mathrm{~cm})$, and 5 -in $(13.3 \mathrm{~cm})$, or $50 \%, 75 \%$, and $100 \%$ of the initial inlet flow depth, $h_{0}$. The three different weir geometries will be referred to as H050, H075, and H10O respectively. Because the side slope of the tip of the weir was also kept constant at $0.7 \mathrm{H}: 1 \mathrm{~V}$, the length, $L_{w c}$, of the horizontal weir crest varied. HEC-23 suggests that a shorter weir can be installed at the most

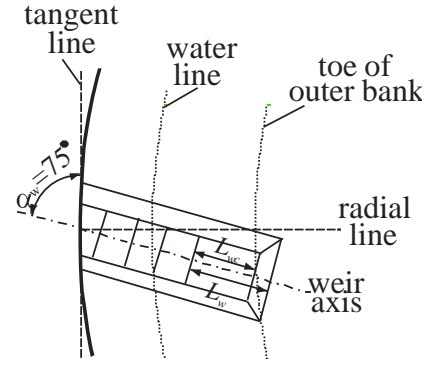

(a)

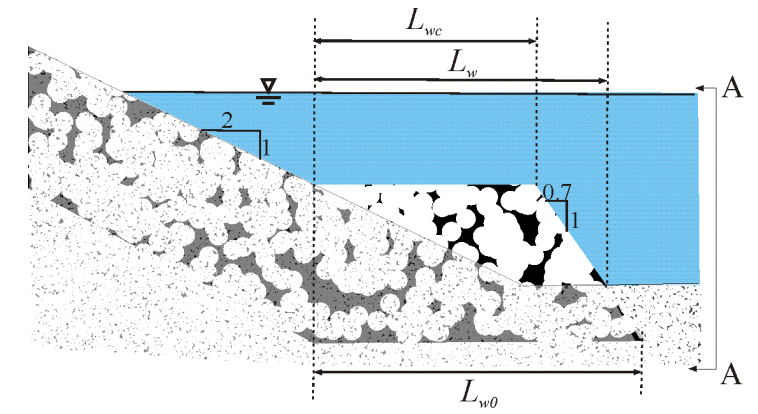

(b)

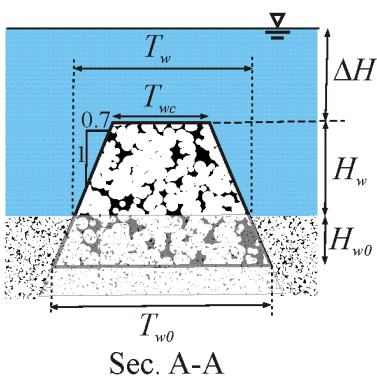

Sec. A-A 


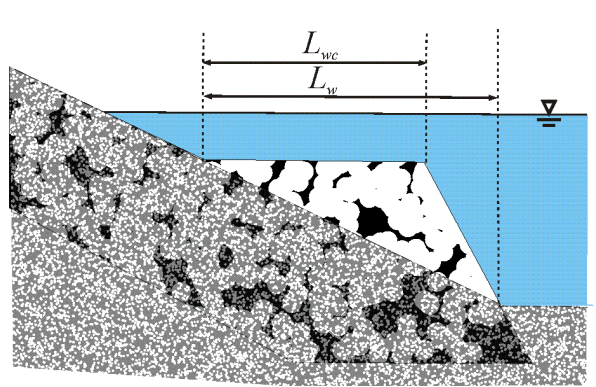

(c)

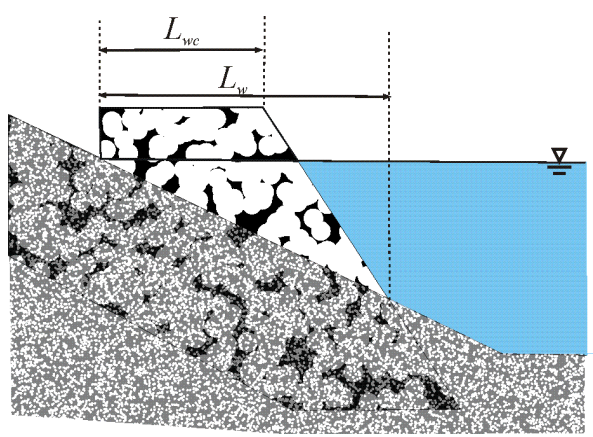

(d)

Fig. 3.6: Definition sketch of bendway weir used in laboratory study, a) plan view of placement of weir (approximately $\mathrm{H} 050$ ), b) profile of weir $\mathrm{H050}, \mathrm{c}$ ) profile of weir $\mathrm{H} 075$, and d) profile of weir $\mathrm{H} 100$

Table 3.3: Characteristic dimensions of laboratory bendway weirs

\begin{tabular}{|l|l|l|l|l|l|c|}
\hline Weir & $L_{w c}$ (in, cm) & $H_{w}$ (in, cm) & $T_{w c}$ (in, cm) & $T_{w}$ (in, cm) & $T_{w 0}$ (in, cm) & Flow blockage (\%) \\
\hline H050 & $5.8(14.7)$ & $2.5(6.4)$ & $4.5(12.6)$ & $8.0(20.3)$ & $10.1(25.7)$ & 11.9 \\
\hline H075 & $4.9(12.4)$ & $3.8(9.7)$ & $4.5(12.6)$ & $9.8(24.9)$ & $11.9(30.2)$ & 10.5 \\
\hline H100 & $4.0(10.1)$ & $5.3(13.5)$ & $2.4(6.1)$ & $9.8(24.9)$ & $11.9(30.2)$ & 10.5 \\
\hline
\end{tabular}

Notes: i) $L_{w}=7.5$ in $(19.1 \mathrm{~cm}), L_{w 0}=8.6$ in $(21.7 \mathrm{~cm})$, and $H_{w 0}=1.5 \mathrm{in}(3.8 \mathrm{~cm})$ for all weirs.

ii) flow blockage based on initial inlet flow area $\left(87.5-\mathrm{in}^{2}\right)$, and initial exposed weir area

upstream station, but for simplicity, all weirs were nominally identical in dimensions. All specified dimensions were based on the initial inlet flow, and do not take into account any changes in channel geometry due to erosion and deposition. Also, the dimensions given are nominal, given that the construction of the weirs was not highly precise. Fig. 3.6 shows the geometry of the weirs, and provides the detailed dimensions.

According to HEC-23, a reference maximum spacing between weir is given as

$$
S_{\max }=R_{c}\left[1-\left(1-\frac{L_{w}}{R_{c}}\right)^{2}\right]^{1 / 2}
$$

with a recommended range of

$$
1.5 L_{w}\left(\frac{R_{c}}{B_{0}}\right)^{0.8}\left(\frac{L_{w}}{B_{0}}\right)^{1 / 2}<S<4 \text { to } 5 L_{w} .
$$

For the laboratory case, with $L_{w}=7.5$ in and $R_{c}=8.3 \mathrm{ft}$, the value of $S_{\max }=3.2 \mathrm{ft}$, with a recommended range of $1.6 \mathrm{ft}<S<3.1 \mathrm{ft}$, and a value of $S=2.3 \mathrm{ft}$ was finally chosen, so that $S / L_{w} \approx 3.7$. In general, the present weir configuration was comparable to those in the CSU studies of Heintz et al. (2002) and Darrow et al. (2004). Five weirs were installed as shown in Fig. 3.7a, with the angular position of their centerline axis indicated. Weirs are also numbered from 1 to 5 , with W1 referring to the most upstream weir.

\subsubsection{Other aspects studied and experimental conditions}

In addition to the effects of varying the weir crest height relative to the initial inlet water depth, two other aspects were studied in a more limited manner. The HEC-23 design guidelines are based solely on mean annual depth, $R_{c}$ and $B_{0}$, and do not involve any characteristic velocity. Due to the close 


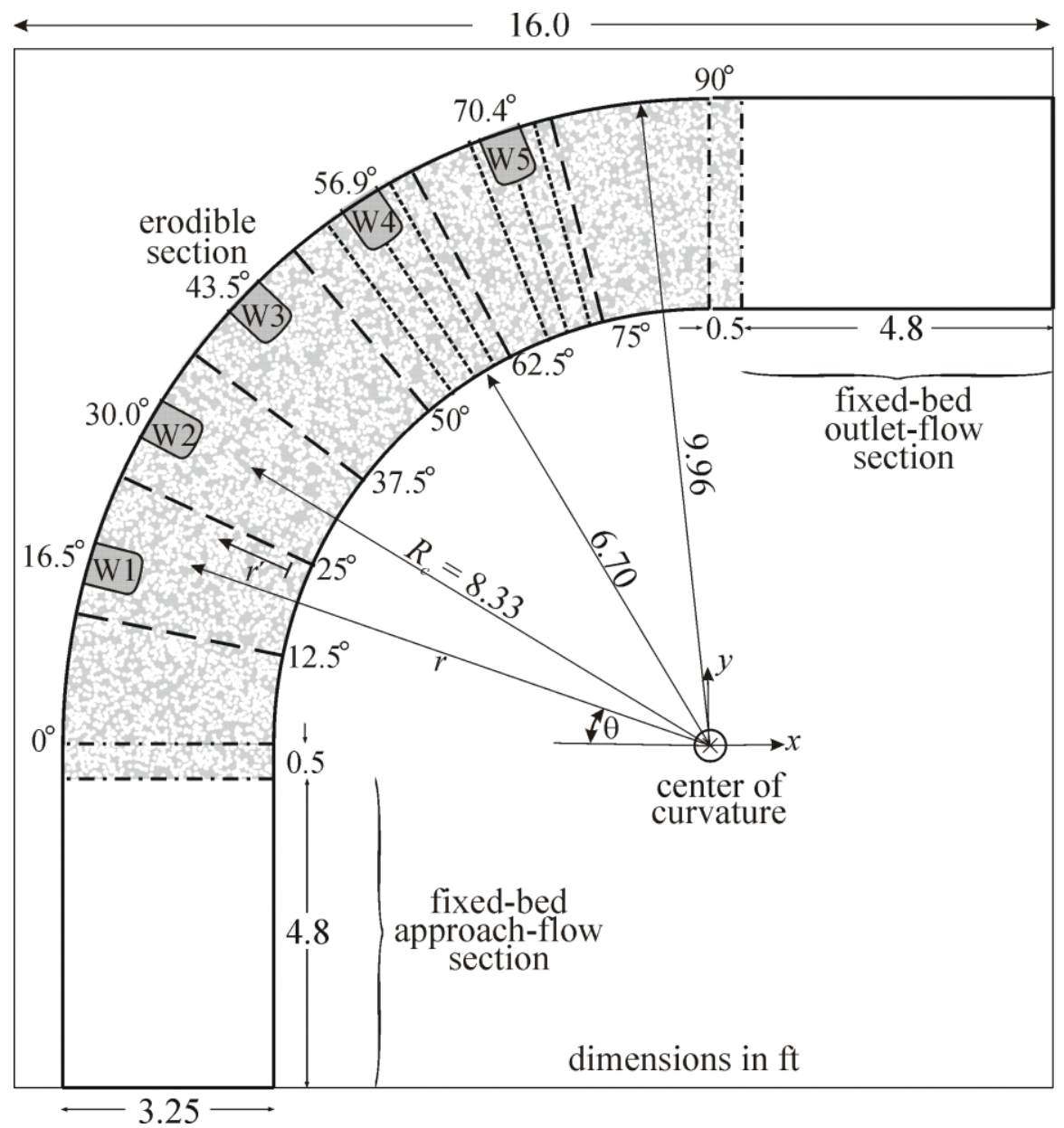

(a)

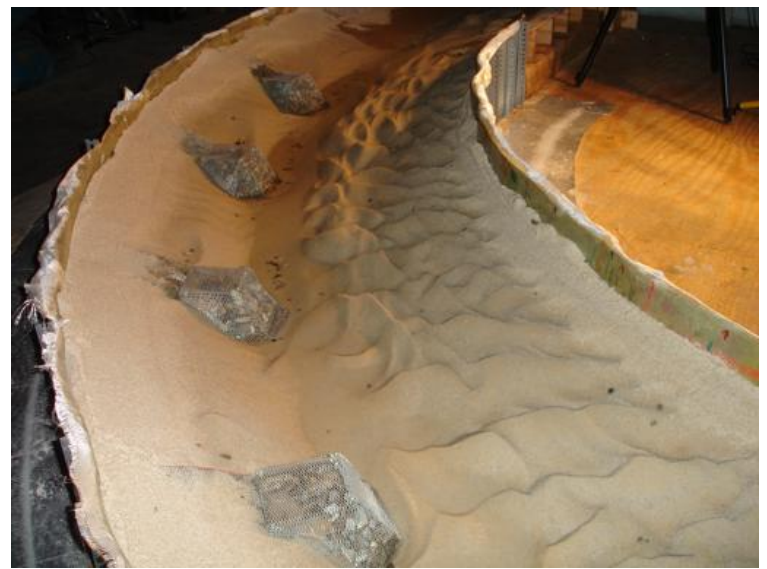

(b)

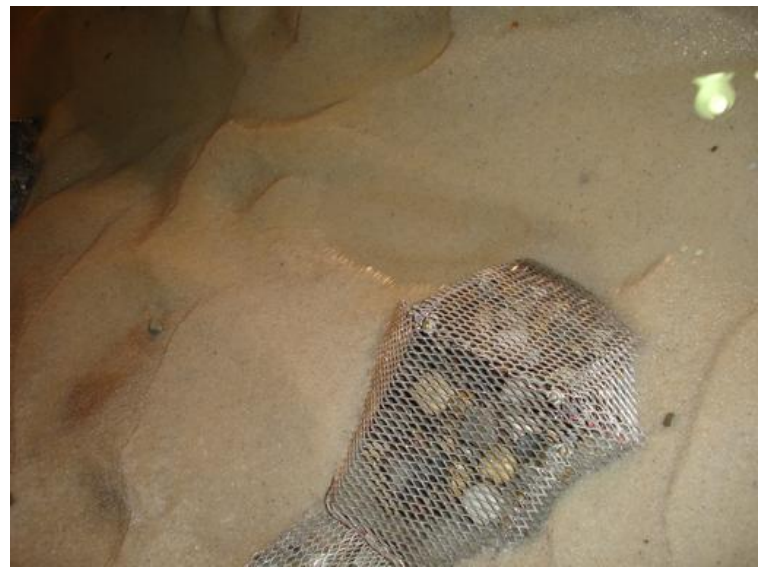

(c)

Fig. 3.7: a) Sketch of weir placement, with weirs (not necessarily to scale) labelled from W1 to W5; dashed lines indicate sections where cross-sectional profiles were taken for the no-weir case, and dotted lines indicate additional sections where crosssectional profiles were taken for the $\mathrm{H} 050$ weir, b) photograph of weirs after a 24-hr run for the H075 weir, and c) close-up of a weir after a 24-hr run for the H050 weir (note that the upper part of the weir has become exposed due to erosion) 
relationship between local boundary shear stress and local velocity, some effect of velocity on the performance of the weirs might be expected. In a study on the performance of spurs, Copeland (1983) noted an effect of approach velocity. Most of the experiments were conducted with an initial inlet cross-sectionally averaged velocity, $U_{0}=22 \mathrm{~cm} / \mathrm{s}$, which being less than $U_{c 0}=30 \mathrm{~cm} / \mathrm{s}$, should satisfy the clear-water inlet condition. Several experiments were conducted with $U_{0}=25 \mathrm{~cm} / \mathrm{s}$ to examine possible velocity effects. Another preliminary low-velocity experiment with $U_{0}=15 \mathrm{~cm} / \mathrm{s}$ was also conducted in a case with no weir, primarily to determine an appropriate velocity for most of the experiments.

The other aspect that received attention was the duration of the experimental run. The long time scales in scour phenomena have recently become better appreciated. Durations of 24-hr or more are now common in laboratory studies of scour, particularly under clear-water conditions with medium sand. Thus, experiments were carried out for durations of 12-hr, 24-hr, and 48-hr (a preliminary lowvelocity experiment with $U_{0}=15 \mathrm{~cm} / \mathrm{s}$ was terminated after 8-hr). Even after $48 \mathrm{hr}$, an equilibrium was not necessarily achieved in all experiments; nevertheless, the 48-hr duration should allow a reasonable assessment of the effectiveness of the structures for bank protection. The different conditions for the experiments performed are summarized in Table 3.4. For ease of reference, each different experiment is given a label indicating its main characteristics, of the form, HXXX-VXX-TXX-X, where HXXX refers to the height of the weir crest relative to the initial inlet depth, VXX to the average initial inlet velocity, TXX to the experiment duration. The last letter is used if an experiment is replicated. For example, the label H050-V22-T24A refers to the first replicate of an experiment with the weir crest at $50 \%$ of the initial inlet depth, an average inlet velocity of $22 \mathrm{~cm} / \mathrm{s}$, and a duration of $24 \mathrm{hrs}$. Also provided is the number of sections at which measurements of boundary (B) elevations or velocities (V) were made.

Table 3.4: Summary of experimental conditions investigated

\begin{tabular}{|l|c|c|c|c|c|c|}
\hline \multicolumn{1}{|c|}{ label } & $\begin{array}{c}H_{w} / h_{0} \\
(\%)\end{array}$ & $\begin{array}{c}Q \\
\text { (cfs) }\end{array}$ & $\begin{array}{c}U_{0} \\
(\mathrm{~cm} / \mathrm{s})\end{array}$ & $U_{0} / U_{c 0^{\dagger}}$ & $T(\mathrm{hr})$ & $\begin{array}{c}\text { No. of sections } \\
\text { measured }^{\dagger \dagger}\end{array}$ \\
\hline H000-V15-T08A,B & 0 & 0.30 & 15 & 0.5 & 8 & $0 \mathrm{~B} / 4 \mathrm{~V}$ \\
\hline H000-V22-T24A,B & 0 & 0.44 & 22 & 0.73 & 24 & $7 \mathrm{~B} / 4 \mathrm{~V}$ \\
\hline H000-V22-T48 & 0 & 0.44 & 22 & 0.73 & 48 & $7 \mathrm{~B} / 4 \mathrm{~V}$ \\
\hline H000-V25-T12 & 0 & 0.50 & 25 & 0.83 & 12 & $7 \mathrm{~B} / 4 \mathrm{~V}$ \\
\hline H000-V25-T24 & 0 & 0.50 & 25 & 0.83 & 24 & $7 \mathrm{~B} / 2 \mathrm{~V}$ \\
\hline H050-V22-T24A,B & 50 & 0.44 & 22 & 0.73 & 24 & $11 \mathrm{~B} / 6 \mathrm{~V}$ \\
\hline H050-V22-T48 & 50 & 0.44 & 22 & 0.73 & 48 & $11 \mathrm{~B} / 6 \mathrm{~V}$ \\
\hline H050-V25-T12A,B & 50 & 0.50 & 25 & 0.83 & 12 & $11 \mathrm{~B} / 6 \mathrm{~V}$ \\
\hline H075-V22-T24A,B & 75 & 0.44 & 22 & 0.73 & 24 & $12 \mathrm{~B} / 6 \mathrm{~V}$ \\
\hline H075-V22-T48 & 75 & 0.44 & 22 & 0.73 & 48 & $29 \mathrm{~B} / 12 \mathrm{~V}$ \\
\hline H100-V22-T48 & 100 & 0.44 & 22 & 0.73 & 48 & $29 \mathrm{~B} / 12 \mathrm{~V}$ \\
\hline
\end{tabular}

Notes: ${ }^{\dagger} U_{c 0}$ is evaluated using Eq. 2.2 with $d_{50}=0.6 \mathrm{~mm}$, and $h_{0}=12.7 \mathrm{~cm}$ (for zero slope)

$\pitchfork$ The number of sections measured indicates firstly the number of sections for which erodible boundary (B) and secondly for which point velocities (V) were measured.

As indicated in Table 3.4, experiments were also performed for no-weir conditions, i.e., in the absence of weirs (the $\mathrm{HOOO}$ series), under nominally the same initial inlet conditions as those with weirs. This permitted a more precise comparison of results with weirs presence and hence a more direct evaluation of weir effectiveness. It also allowed comparison with the more abundant literature on bend 
flows without structures, and possible identification of any anomalous results. Replicates of experiments were also performed. Velocity measurements were quite time consuming, and could not be completed within the time (typically $4 \mathrm{hr}$ ) that was considered sufficiently short that conditions could be considered quasi-steady. Replicates allowed more time for velocity measurements at additional crosssections. Moreover, replicates, which involved remolding the erodible bend boundary and hence starting from the same initial conditions, at different times separated typically by periods exceeding a week, also permitted an assessment of the variability and reproducibility of the measurements.

The dashed lines in Fig. $3.7 \mathrm{a}$ (at $12.5^{\circ}, 25^{\circ}, 37.5^{\circ}, 50^{\circ}, 62.5^{\circ}$, and $75^{\circ}$ ) indicate the cross-sections where measurements of boundary elevations were made for the reference experiments. For the H050 experiments, additional cross-sections just upstream, along the weir centerline, and just downstream of W4 and W5 were added (the dotted lines in Fig. 3.7a). For subsequent experiments, however, it was thought desirable to obtain boundary elevation measurements on a denser grid to examine features at a smaller scale, and so more cross-sections were added, particularly in the downstream region (e.g., in the H075-V22-T48 and H100-V22-T48 experiments, cross-sectional boundary profiles were taken at $2^{\circ}$ intervals for $\theta \geq 50^{\circ}$ ).

\subsubsection{Scaling issues}

As with any laboratory study, a discussion of scaling issues is appropriate. Because the work was not intended as a strict model study of a specific site for specific conditions, the present work is less constrained, but if the results are to be meaningful for the field scale, attention to scaling issues needs to be paid to the relevant dimensionless parameters. Traditionally, open channel flow models have emphasized the Froude number, $F r_{0}=U_{0} / \sqrt{g H_{d 0}}$, where the velocity scale has been taken as the initial inlet velocity, and $H_{d 0}=A_{0} / T_{0}$, is the hydraulic diameter, based here again on the initial inlet flow area, $A_{0}$, and the initial inlet top width, $T_{0}$. The values of $F r_{0}$ in the present study range from 0.26 to 0.29 , and so characterize subcritical flow, which is common in most applications, except for steep mountain channels. Turbulent flow is required and is achieved with a Reynolds number, $R e_{0}=U_{0} 4 R_{h 0} / v>2000$, here based on $U_{0}$ and the initial inlet hydraulic radius, $R_{h 0}=A_{0} / P_{w 0}$, where $A_{0}$ and $P_{w 0}$ are the initial inlet flow area and wetted perimeter. Values of $R e_{0}$ exceed $6 \times 10^{4}$, guaranteeing turbulent flow.

Besides $F r_{0}$ and $R e_{0}$, other dimensionless parameters may be relevant. The importance of the curvature parameter, $R_{d} / B_{0}$, for bend flows has already been discussed. Models of sediment transporting flows or scour frequently make use of some version of a Shields parameter or a (velocity) intensity parameter, here taken to be $U_{0} / U_{c 0}$, here with values ranging from 0.6 to 0.8 , depending on whether the effect of bank slope is taken into account. The chosen values allowed a clear-water inlet condition, but also definite bank scour. Another parameter that might be relevant in certain ranges is a particle-size parameter, e.g., $h_{0} / d_{50}$, but if this is sufficiently large, then its importance is considered negligible. A value of $h_{0} / d_{50} \approx 210$ is thought to be sufficient for this to be assumed. A comparison of the range of flow conditions in the present study with that at the SR 1 Village Creek site as well as selected laboratory studies in the literature is given in Table 3.5.

\subsection{Experimental procedures}

Prior to the start of an experimental run, the desired weir was installed if necessary. The weir was actually constructed in two pieces, with one part (the sloping part) always in place, and so only the other part with the variable crest height needed to be installed. For each experiment, the channel 
Table 3.5: Parameter ranges and characteristics of previous laboratory studies compared to the present study and the SR 1 Village Creek site

\begin{tabular}{|c|c|c|c|c|c|c|c|c|}
\hline Study/site & $F r_{0}$ & $\begin{array}{c}\operatorname{Re}_{0} \\
\left(\times 10^{4}\right)\end{array}$ & $B_{0} / R_{c}$ & $h / d_{50}$ & $\begin{array}{l}\text { Bend } \\
\text { angle }\end{array}$ & $\begin{array}{c}\text { structure } \\
\text { type }\end{array}$ & $\begin{array}{l}\text { erodible bed } \\
\text { /boundary }\end{array}$ & $\begin{array}{c}\text { measure- } \\
\text { ments }^{\dagger}\end{array}$ \\
\hline $\begin{array}{l}\text { Ippen \& } \\
\text { Drinker (1962) }\end{array}$ & $\begin{array}{r}0.38 \\
0.55\end{array}$ & $4.4-30$ & $0.29-0.8$ & $\mathrm{n} / \mathrm{a}$ & $60^{\circ}$ & none & fixed bed & V \\
\hline $\begin{array}{l}\text { Hicks et al. } \\
(1990)\end{array}$ & $\begin{array}{r}0.42- \\
0.55\end{array}$ & 6.4-16 & $0.24-0.27$ & $n / a$ & $270^{\circ}$ & none & fixed bed & V \\
\hline $\begin{array}{l}\text { Heintz et al. } \\
(2002)\end{array}$ & & & & $\mathrm{n} / \mathrm{a}$ & $\begin{array}{r}73^{\circ} \\
125^{\circ}\end{array}$ & $\begin{array}{c}\text { bendway } \\
\text { weirs }\end{array}$ & fixed bed & V \\
\hline $\begin{array}{l}\text { Matsuura \& } \\
\text { Townsend } \\
(2004)\end{array}$ & 0.29 & 8 & 0.51 & 128 & $\begin{array}{l}90^{\circ} \\
135^{\circ}\end{array}$ & barb & $\begin{array}{c}\text { erodible bed, fixed } \\
\text { vertical wall }\end{array}$ & B \\
\hline $\begin{array}{l}\text { Fox et al. } \\
(2005)\end{array}$ & 0.7 & 4.2 & $\begin{array}{r}0 \\
\text { (straight) }\end{array}$ & 29 & $0^{\circ}$ & barb & $\begin{array}{c}\text { erodible bed, fixed } \\
\text { vertical walls }\end{array}$ & $B, V$ \\
\hline $\begin{array}{l}\text { Bhuiyan et al. } \\
\text { (2010) }\end{array}$ & & & $\begin{array}{r}\text { sine- } \\
\text { generate } \\
d \\
\text { meander }\end{array}$ & & & $\begin{array}{l}\text { bank- } \\
\text { attached } \\
\text { vanes }\end{array}$ & $\begin{array}{l}\text { erodible bed, fixed } \\
\text { vertical walls }\end{array}$ & $B, V$ \\
\hline present study & $\begin{array}{r}0.26- \\
0.3 \\
\end{array}$ & $5.9-6.8$ & 0.3 & 212 & $90^{\circ}$ & $\begin{array}{c}\text { bendway } \\
\text { weirs }\end{array}$ & $\begin{array}{l}\text { erodible bed, } \\
\text { erodible banks }\end{array}$ & $B, V$ \\
\hline $\begin{array}{l}\text { SR 1, Village } \\
\text { Creek }\end{array}$ & $\begin{array}{r}0.21- \\
0.47\end{array}$ & $200-400$ & $0.2-0.3$ & & $\approx 90^{\circ}$ & & & \\
\hline
\end{tabular}

Note: "In the measurements column, B indicates that erodible boundary/bed elevations were measured, while $\mathrm{V}$ indicates that point velocities were also measured.

${ }^{\top}$ The SR 1 parameters are based on the 10-yr event.

erodible boundary was remolded using a screed attached to the instrument carriage on a cross-brace (Fig. 3.8). The screed was an aluminum plate cut to the desired initial geometry of the channel. Two different plates were needed, one for the entire cross-section, the other identical except that it would pass around the weirs. The carriage with the appropriate screed was passed along the length of the channel until the desired initial cross-sectional geometry all along the channel was obtained. Some local manual forming with a putty knife in the immediate vicinity of the weirs was usually required. These localized areas were spot checked with the point gage on the carriage to insure a consistent geometry. It was also noted that the channel behaved differently on the initial run with each new weir installation. This was attributed to the larger porosity of the new weirs that consisted of only gravel encased in a mesh wire, such that, after the initial run, the pores would fill with sand. To eliminate the influence of the weir installation, the channel with a new weir was run for 24 hours, and subsequently remolded prior to any experimental runs being conducted.

With the desired initial channel geometry, the channel was slowly filled by an appropriate choice of pump speed in order to prevent deforming the channel geometry from the initial wave of water through the erodible bend section. The pump speed was then very gradually increased until the desired flow rate was reached. This gradual increase was deliberate because the variable frequency drive would overcompensate for adjustments made too quickly. The inlet water surface elevation was then checked by moving the instrument carriage to the start of the bend section. The initial inlet flow depth was then adjusted to 5 -in $(12.7 \mathrm{~cm})$ by setting the crest of the outlet weir. After the flow became 


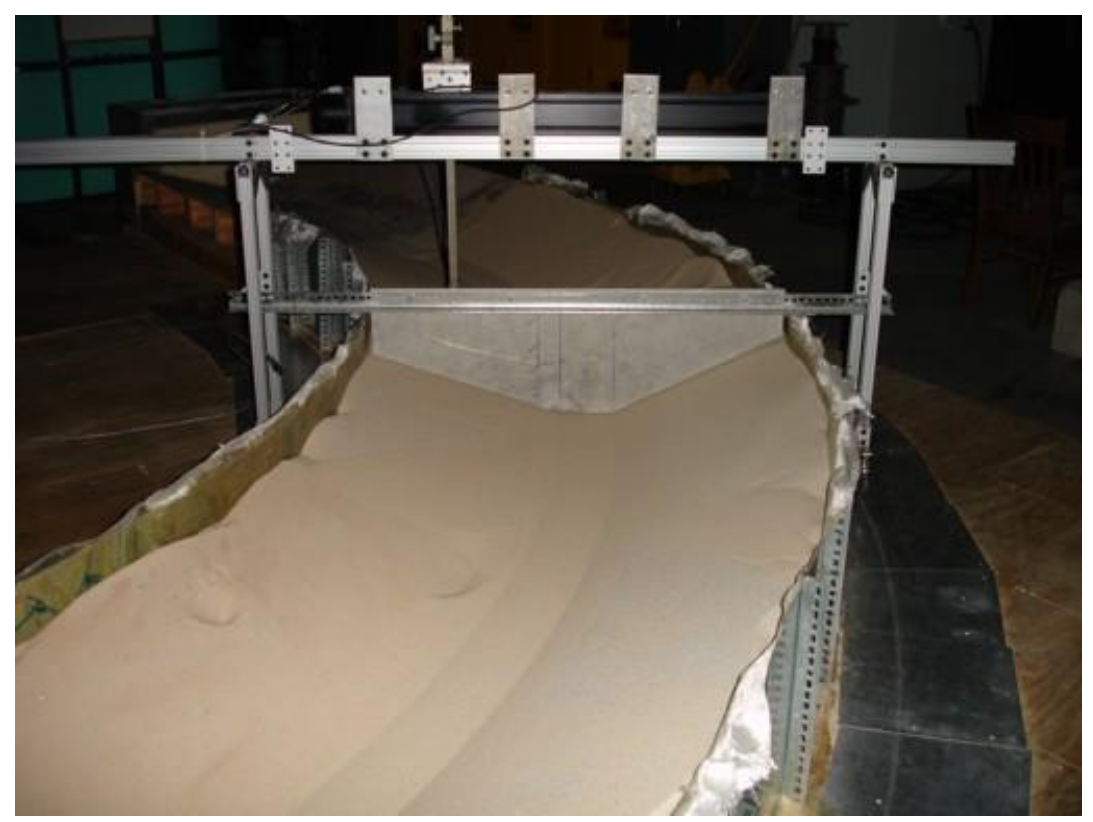

Fig. 3.8: Aluminium plate used as screed to mold initial boundary in erodible bend section

stable, the water surface at that location was again checked to ascertain the desired flow depth, and the weir adjusted if necessary.

Once the initial inlet water surface level was set to the desired elevation, the experimental run was considered to have begun. The adjustment factors (see the discussion in Sec. 3.1.4) to account for differences in elevation between the carriage and the channel at various locations were then determined. Cross-stream water surface profiles at various sections were then taken with the level sensor. Because these were taken towards the beginning of each experiment, they may not precisely correspond to the water surface elevations at the end of the experiment. Although water surface elevations were measured, they do not give much insight into the pattern of scour and deposition in the channel bend, and so will not be presented in the results.

Point velocity measurements with the ADV were taken only in the last four hours of an experimental run regardless of the run duration and were always collected from upstream to downstream. Because the time necessary for velocity measurements was quite long (mainly because positioning could not be entirely automated; vertical positioning had to be done manually), each experimental run was actually run at least twice to acquire a complete velocity data set. The first run collected data in the upstream portion of the channel and the second run in the downstream portion. Also, because the ADV was operated in the sidelooking configuration (see Figs. 3.4 and 3.6, and the discussion of Section 3.1.6), in order to access a wider range of locations at a given cross-section, measurements were taken with the instrument facing inward (towards the center of curvature) and others were taken with instrument facing outward. Locations that were measured with the ADV facing inward were measured inward with every experimental run and likewise with locations with the ADV facing outward. Also, at points of change between outward and inward measurement, a velocity measurement was made facing each direction to check consistency. All points of velocity measurement were made with a sampling duration of 30 seconds, considered sufficient for a reliable time-averaged mean velocity. The measurement grid in the both radial and vertical directions was uniform, with a grid spacing of 0.5 -in $(1.27 \mathrm{~cm})$. 
It would have been useful to have velocity data at the beginning of and indeed throughout a run, especially since much of the boundary elevation changes occurred early in the experiments. Because of the time necessary to complete velocity measurements, the more rapid changes in the boundary conditions at early times would have made data interpretation more difficult. Further, at early times, the boundary was thought highly artificial. At later times, especially for the longest-duration runs, changes in boundary conditions are much more gradual, and the boundary was considered more 'natural'. It should also be emphasized that, even for the longest-duration runs, boundary equilbirium is not thought to have been achieved. Thus, velocity measurements at later times should still reflect flow conditions under which active though slow boundary changes occurred.

After velocity measurements were completed, the channel was allowed to continue running until the desired run duration was reached, at which time the pump speed was gradually decreased to zero. The channel was typically allowed to drain until the natural draining no longer removed water from the channel. During this time, adjustment factors for the ultrasonic level sensor measurements were determined along the channel as well in preparation for the bed/bank elevation measurements. Because natural draining did not remove all the water from depressions, it was still necessary to remove additional water from the channel. This was accomplished by removing sand in a location where the sand profile was not desired, typically near the upstream transition from fixed bed to live bed, whereupon the remaining water would pool at this location, and could be pumped out. At some isolated points, some of the deeper pools were observed to remain, and these are reflected in some measurements in flat spots in the deepest scour holes.

The determination of cross-sectional profiles of the erodible boundary at any given section was automated, so that once the instrument carriage was situated at the section, an entire profile could be obtained through computer control without operator intervention. The radial measurement grid spacing was 0.5 -in $(1.27-\mathrm{cm})$. At each section, three ' $r a w$ ' profiles were obtained, with the second and third profile offset from the first by 0.125 -in $(3.175-\mathrm{mm})$ to each side, with the final profile being the average of the three 'raw' profiles. This spatial averaging was applied to remove spikes in the level sensor signal. This procedure was repeated beginning at the upstream and working downstream at each desired cross-section.

\subsection{Summary}

Details of the experimental channel and instrumentation, including the channel, the instrument carriage and traversing system, and the main instrumentation (acoustic level sensor and acoustic Doppler velocimeter) were given. The design of the experiments conducted, including the choice of conditions, the weir geometry and placement, and the associated scaling issues, was discussed. Finally, the experimental procedures followed in obtaining the measurements were described. 


\section{Results on bed and bank evolution}

This chapter focuses on the development of the erodible boundary for the various experimental conditions, with and without the weirs installed. From the point of view of application, these results are of the most direct concern. The reference cases (the $\mathrm{HOOO}$ series), i.e., without any weirs, are first presented, followed by the cases with increasing weir height (the H050, H075, and finally the H10O series), with the effects of velocity and duration examined where appropriate.

\subsection{The reference no-weir cases}

\subsubsection{Overall features}

An overall view of the reference cases is obtained from photographs of the erodible boundary at the end of the experiments of the longest duration for each velocity (Fig. 4.1). For the lowest velocity (H000-V15-T08), for which $U_{0} / U_{\mathrm{c} 0} \approx 0.5$, very little if any boundary change is observed (Fig. 4.1a) after 8 hrs when the experiment was terminated. In contrast, for the other two velocities (H000-V22-T48 and H000-V25-T24), for which $U_{0} / U_{\mathrm{c} 0} \approx 0.73$ and 0.83 , quite regular bed features are quite evident. Thus, even though $U_{0} / U_{\mathrm{c} 0}<1$, these bed features will form, even in straight channels, so they are not strictly

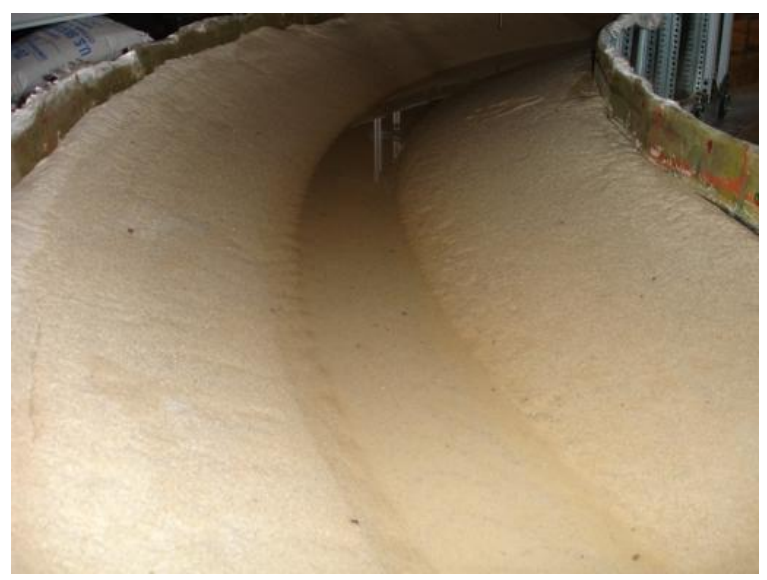

(a)

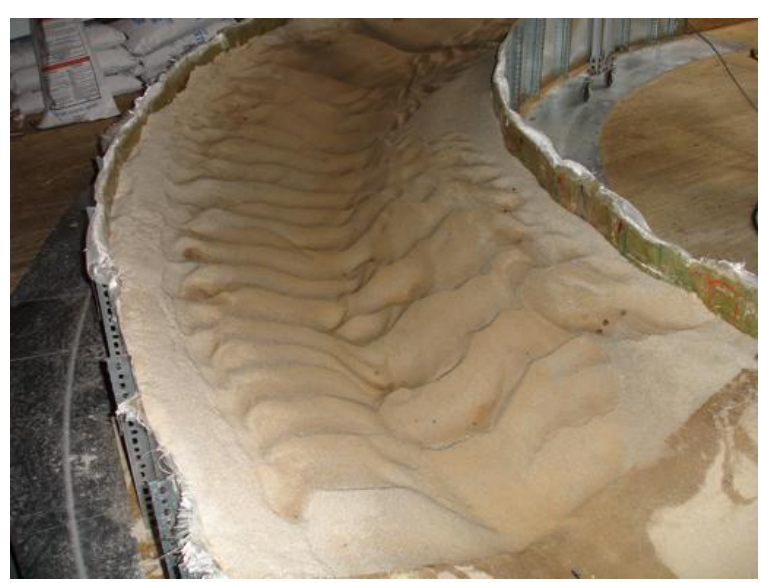

(b)

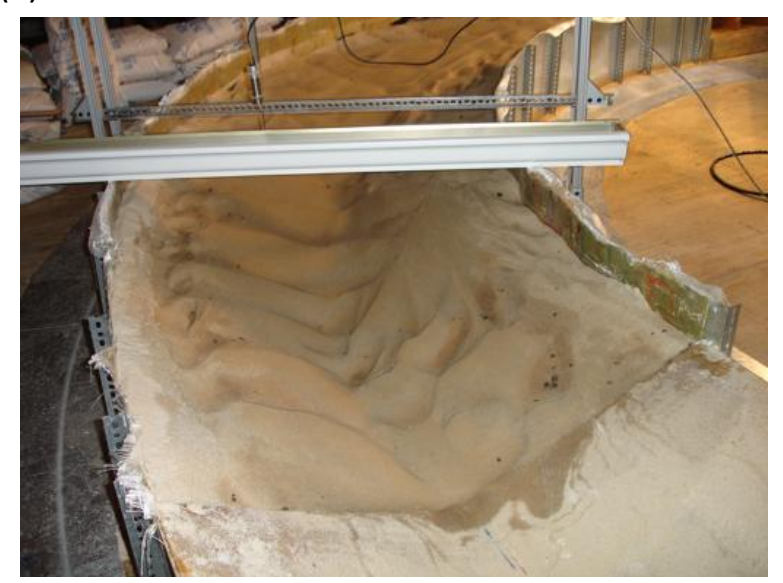

(c)

Flg. 4.1: Photographs of erodible bend section at the end of the experimental runs, view looking downstream, a) H000-V15-T08, b) H000-V22-T48, and c) H000-V25-T24 
a bend-flow phenomena. These individual bed form features, though visually prominent, will generally not be resolved in the profile measurements to be presented because their wavelengths were too short.

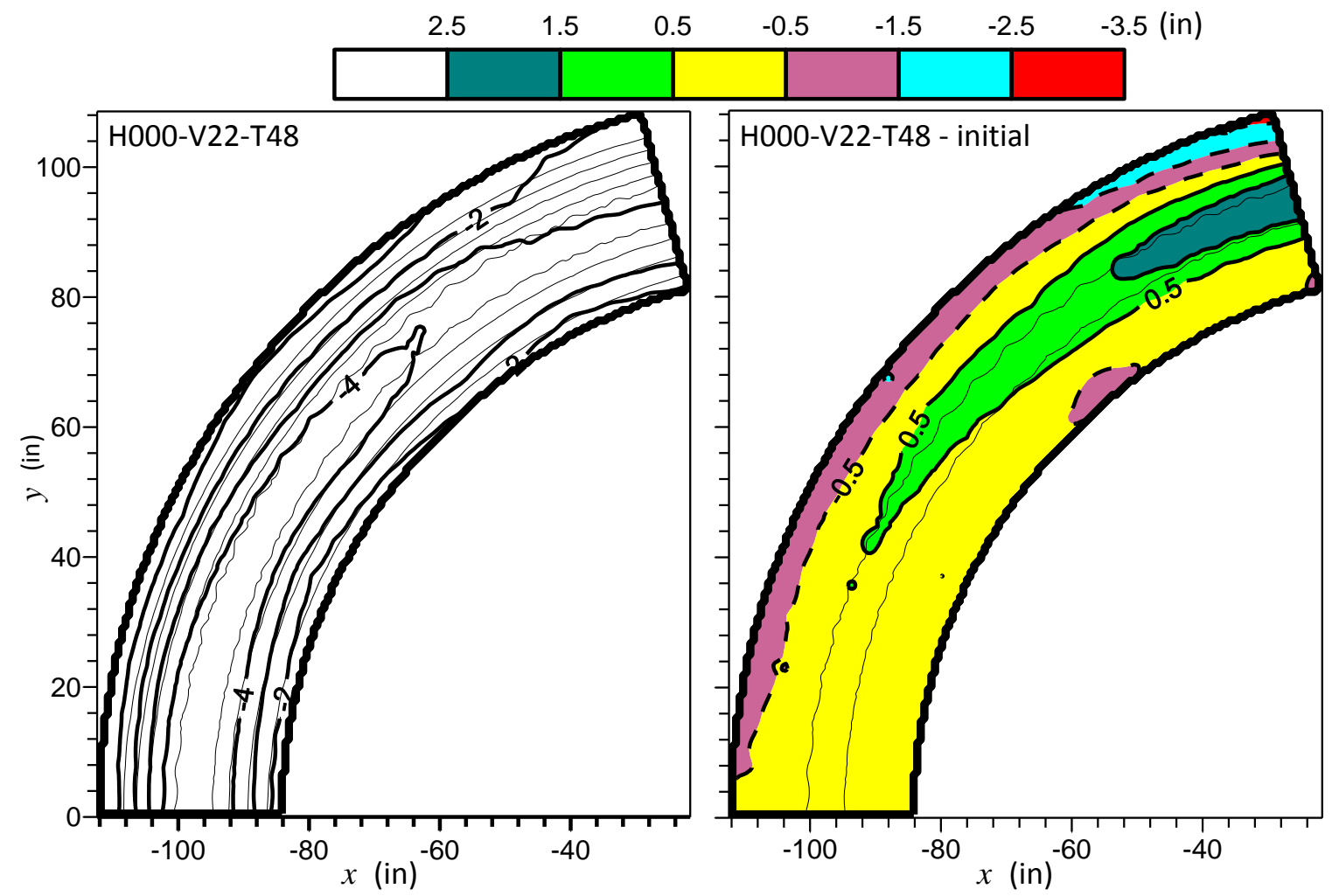

(a)
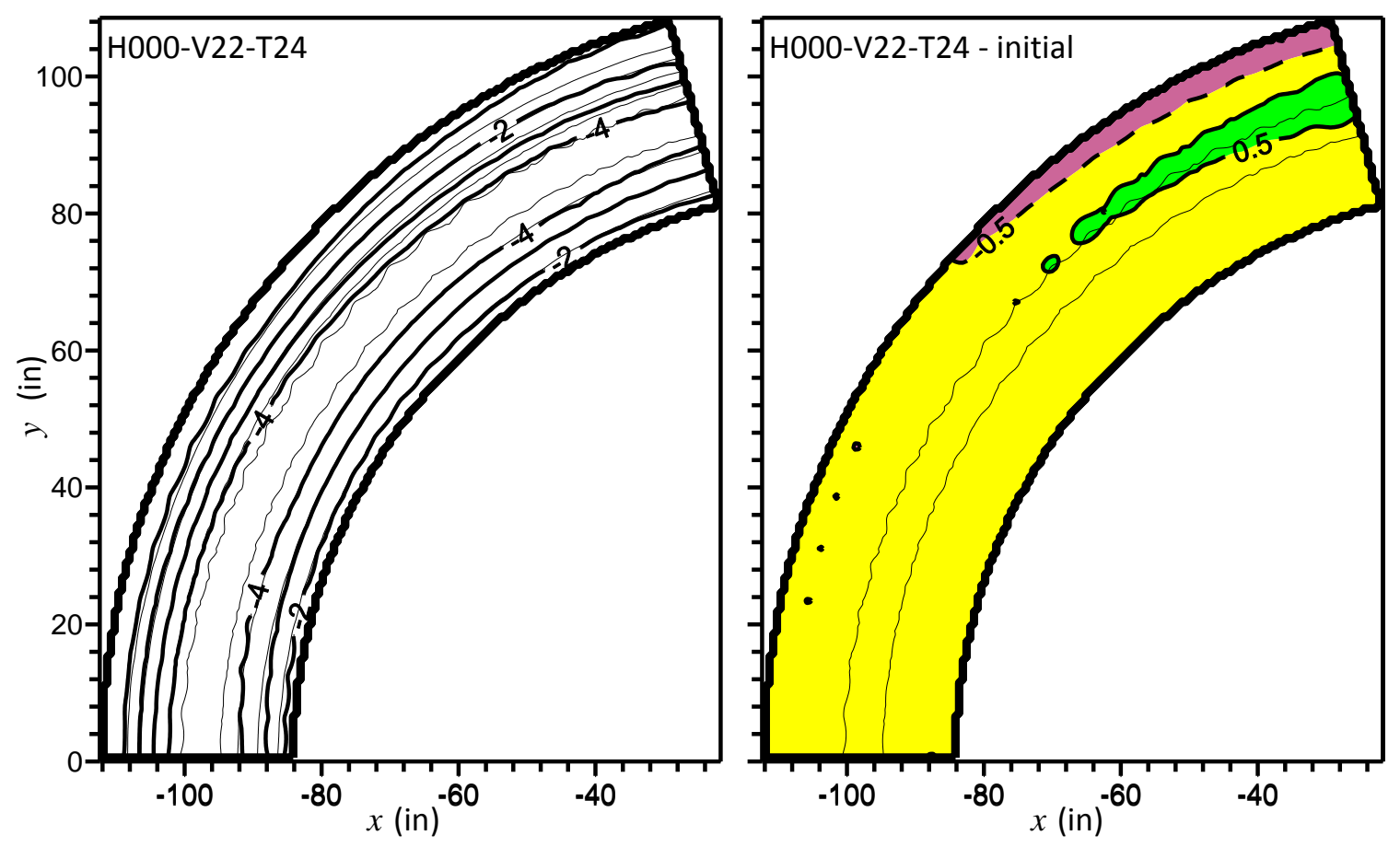

(b) 

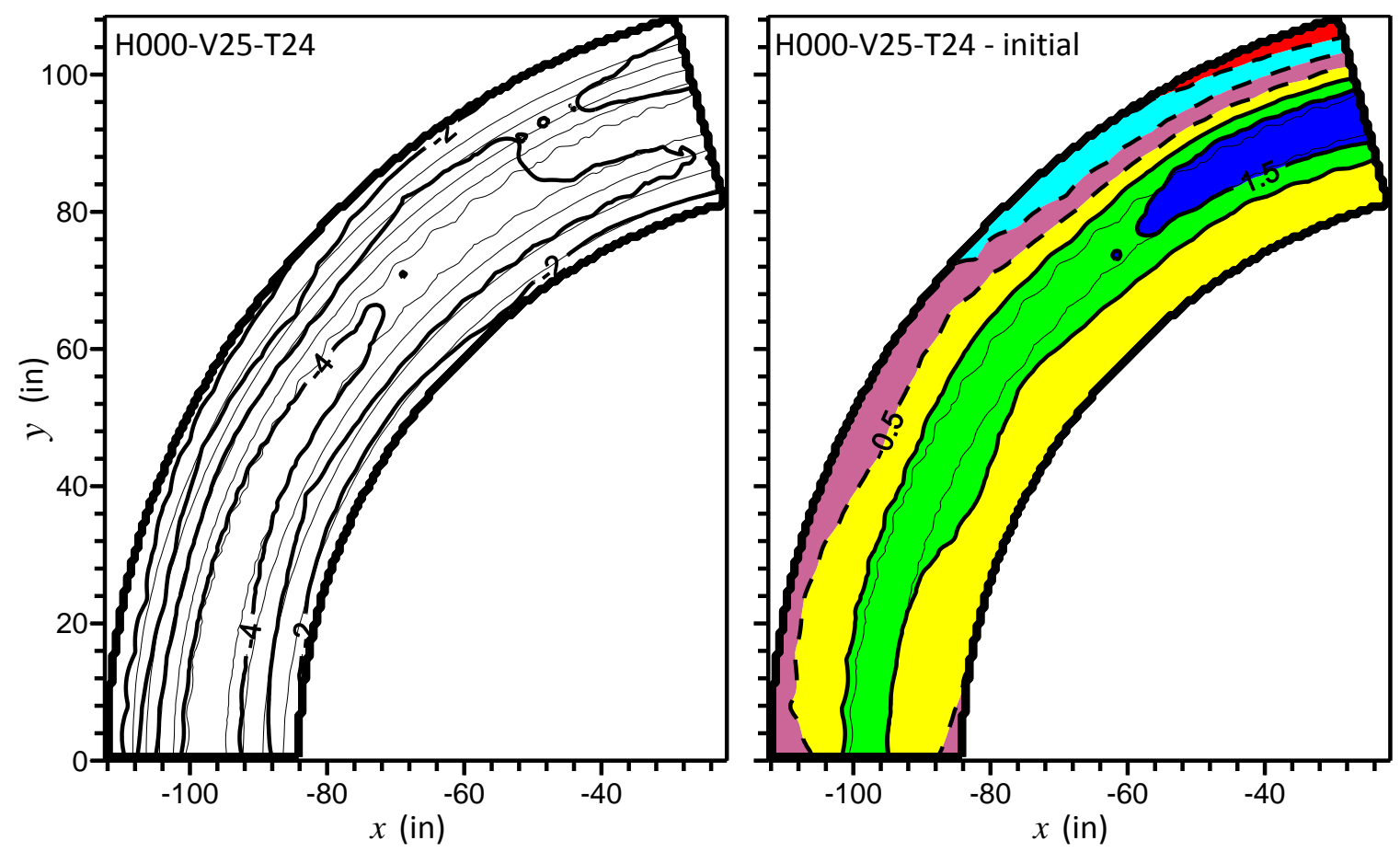

(c)

Fig. 4.2: Contours of bed elevations (on the left, relative to a zero level, on the right, relative to the 'initial' bed elevation), a) H000-V22-T48, b) $\mathrm{H} 000$ V22-T24, and c) H000-V25-T24

More quantitative results may be viewed in the contours of the elevation of the erodible boundary (Fig. 4.2). These were generated from the cross-sectional profiles ( 7 equally spaced from $0^{\circ}$ to $75^{\circ}$ for the HOOO series) using contouring software (Surfer v.8), where a low level of smoothing and kriging interpolation have been applied. Each case is presented in two forms: i) on the left, the contours in thick lines are elevations in inches relative to a zero level, corresponding to the 'initial' water surface elevation, and ii) on the right, the contours are differences (again in inches) from the 'initial' bed surface elevations. On the left, the thin lines are the initial boundary elevations, essentially concentric arcs; thus, any significant deviations of the heavy lines from concentric arcs indicate significant changes in the erodible boundary. On the right, scour is indicated by thick dashed-line contours, with deposition indicated by thick solid-line contours; the thin solid lines indicate approximately the toe of the 'initial' banks. Further, on the right, color fill is also used to make clear the different regions, and so this document should optimally be viewed in color.

As seen in Fig. 4.2a for H000-V22-T48, scour is observed as expected on the outer bank, even fairly close to the inlet, and increasing in the streamwise direction. Deposition occurs in the region between the 'initial' banks, though not necessarily towards the 'initial' inner bank. The latter may however reflect the choice of the 'initial' asymmetric cross-section, in which the initial sideslope of the inner bank was chosen shallower than that on the outer bank as being more 'natural'. The effect of experiment duration is clearly seen by comparing Figs. $4.2 \mathrm{a}$ and $4.2 \mathrm{~b}$. After $24 \mathrm{hrs}$, relatively small changes are noted over much of the bend, and scour and deposition are restricted to quite limited regions. During the period between $24 \mathrm{hrs}$ and $48 \mathrm{hrs}$, however, the amount and extent of scour and deposition are considerably increased. Indeed, it is not clear that any equilibrium has been established after 48 hrs, 
and, as will be argued below, there is some basis for thinking that the process of outer-bank scour and inner-bank deposition could well continue beyond the experiment duration.

That velocity can play a substantial role can be inferred from a comparison of H000-V22-T24 and H000-V25-T24 (Figs. 4.2b and 4.2c). Whereas the lower-velocity case exhibits only small changes over most of the bend section after 24 hrs, the larger velocity, after the same duration, results in scour and deposition that are even greater in magnitude and extent than those seen in the lower-velocity case after $48 \mathrm{hrs}$. By itself, this does not imply that velocity effects will be important in the presence of weirs, but certainly it suggests that such effects merit further study.

\subsubsection{Detailed cross-sectional results}

The preceding contour plots provide a view of the overall time evolution in the erodible boundary in the bend section, yet do involve interpolation and smoothing. The actual cross-sectional profiles give additional details that better reveal other aspects.
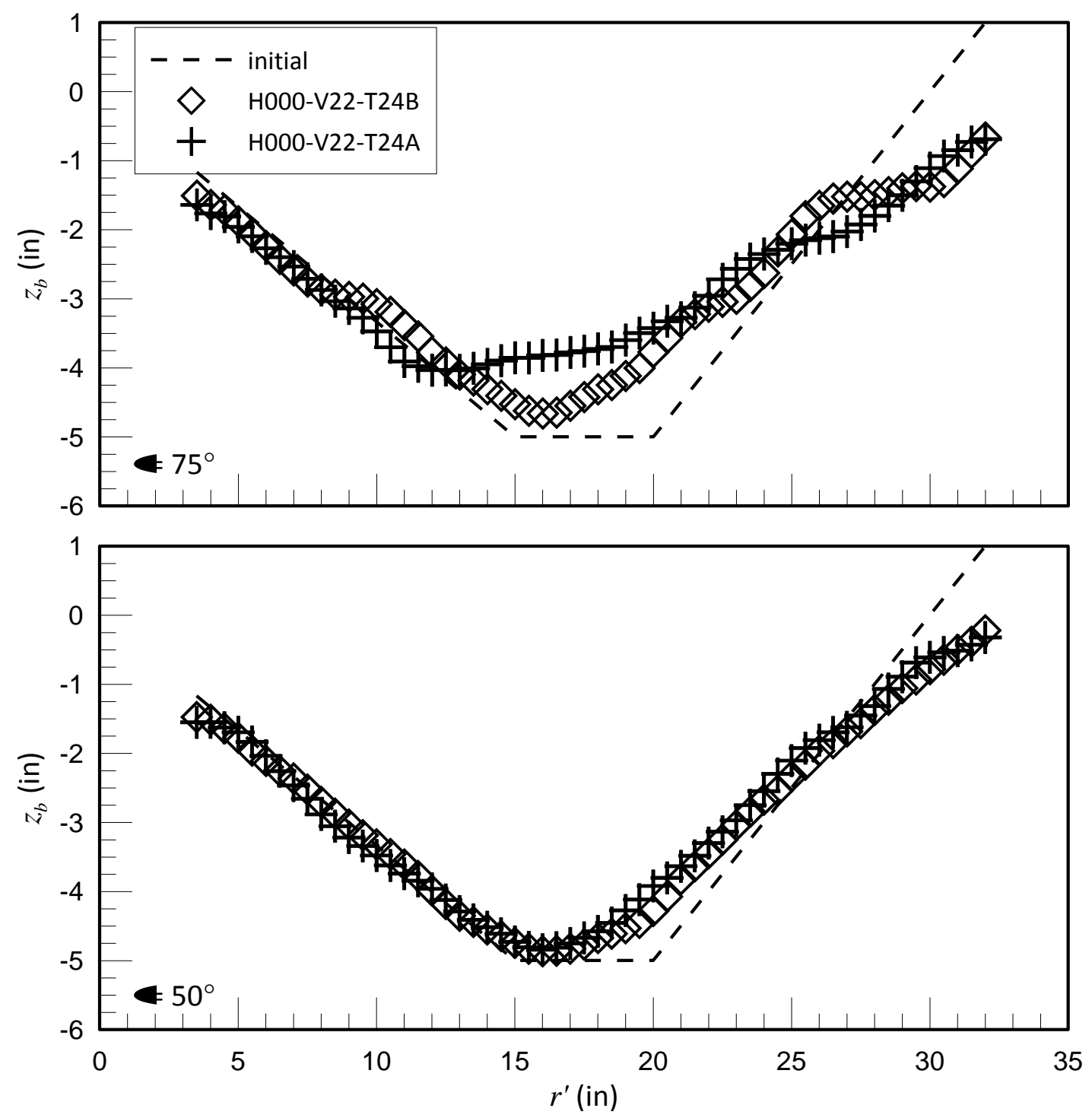

Fig. 4.3: Comparison of cross-sectional profiles of erodible-surface elevation $\left(z_{b}\right)$ measurements from two replicates for H000-V22-T24 conditions at two sections (angles, $\theta=75^{\circ}$ and $\theta=50^{\circ}$ ) 
Determining the effects of the various imposed changes as was done in the preceding discussion implicitly assumes that the scatter in measurements is sufficiently small, or equivalently that the reproducibility of quantitative results is high. This is investigated in Figs. 4.3 and 4.4, where measurements at two downstream cross-sections $\left(\theta=50^{\circ}\right.$ and $\left.\theta=75^{\circ}\right)$ for two different experimental conditions that were replicated, i.e., experiments were performed with nominally identical conditions, are presented. As noted in Chap. 3, $r^{\prime}$ denotes a coordinate in the radial direction, with however an offset origin, with $r^{\prime}$ $=0$ being taken at the initial inner-bank limit of the water surface. For orientation, it is also recalled that the water surface would be approximately at the zero level. Under both conditions, the results indicate quite a high degree of reproducibility, better as expected in the less active upstream cross-sections where changes are smaller, but still quite acceptable in the active downstream cross-sections, where changes from the initial bed profile are notable. Larger differences are observed in localized regions, typically in the central channel region, e.g., $r^{\prime} \approx 16$-in in the H000-V22-T24 replicates, but these may at
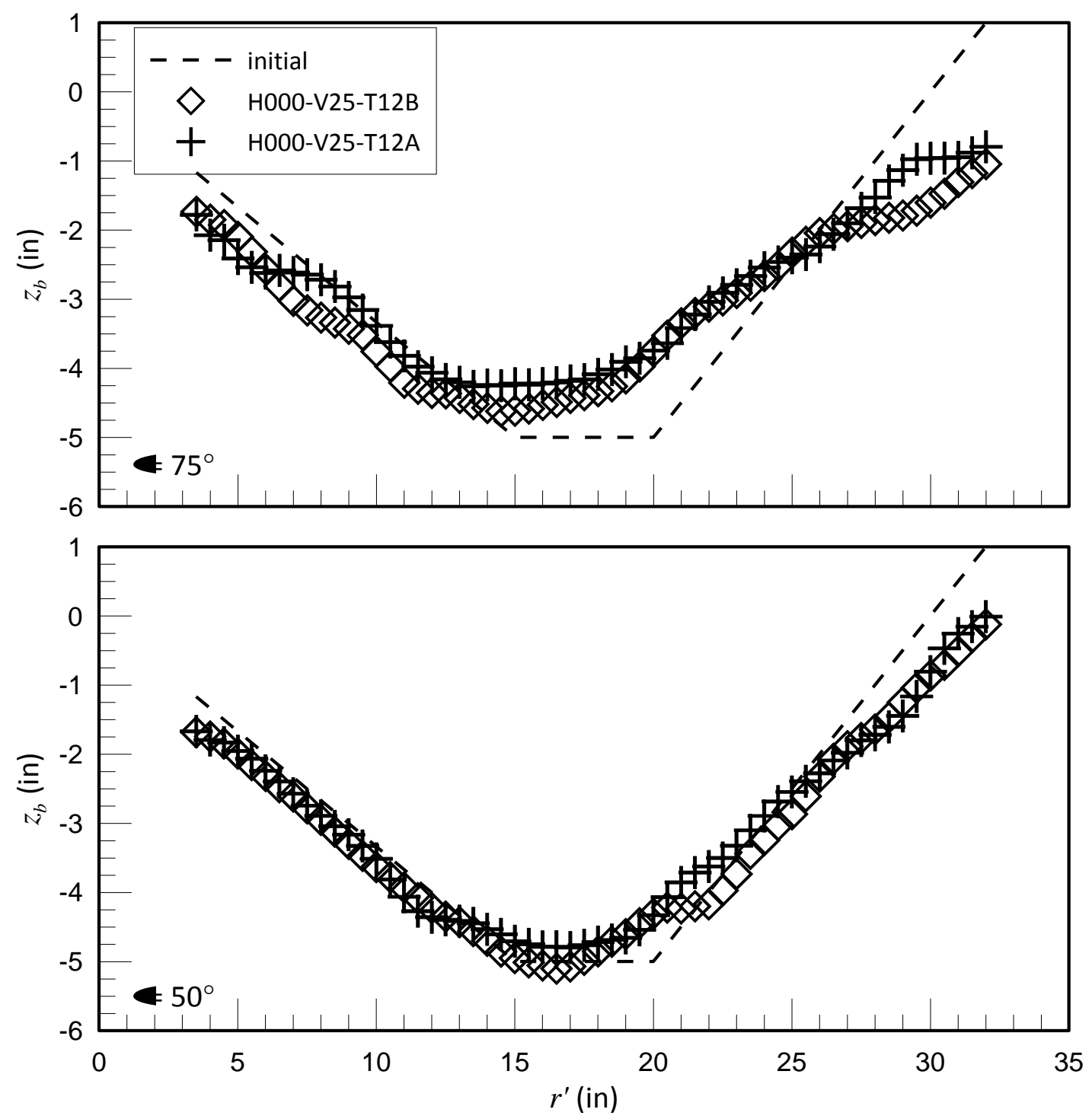

Fig. 4.4: Comparison of cross-sectional profiles of erodible-surface elevation $\left(z_{b}\right)$ measurements from two replicates for H000-V25-T12 conditions at two sections (angles, $\theta=75^{\circ}$ and $\theta=50^{\circ}$ ) 
least be partially attributed to the effect of mobile bed forms. Otherwise, the agreement between the replicate results is quite good, especially so in the outer-bank region that is of particular importance in the present context. If the outer-bank region is taken as the region, $r^{\prime} \geq 20$-in, then the average difference in this region between the replicates for the $\theta=75^{\circ}$ section is 0.02 -in (standard deviation, 0.31-in) for the H000-V22-T24 series and 0.18-in (standard deviation, 0.27-in) for the H000-V25-T12 series. For longer-duration experiments with larger changes in bed elevations, the scatter might be expected to be correspondingly larger. Nevertheless, the results in Figs. 4.3 and 4.4 suggest that differences that are larger than \pm 0.5 -in may be interpreted with confidence as being statistically significant.

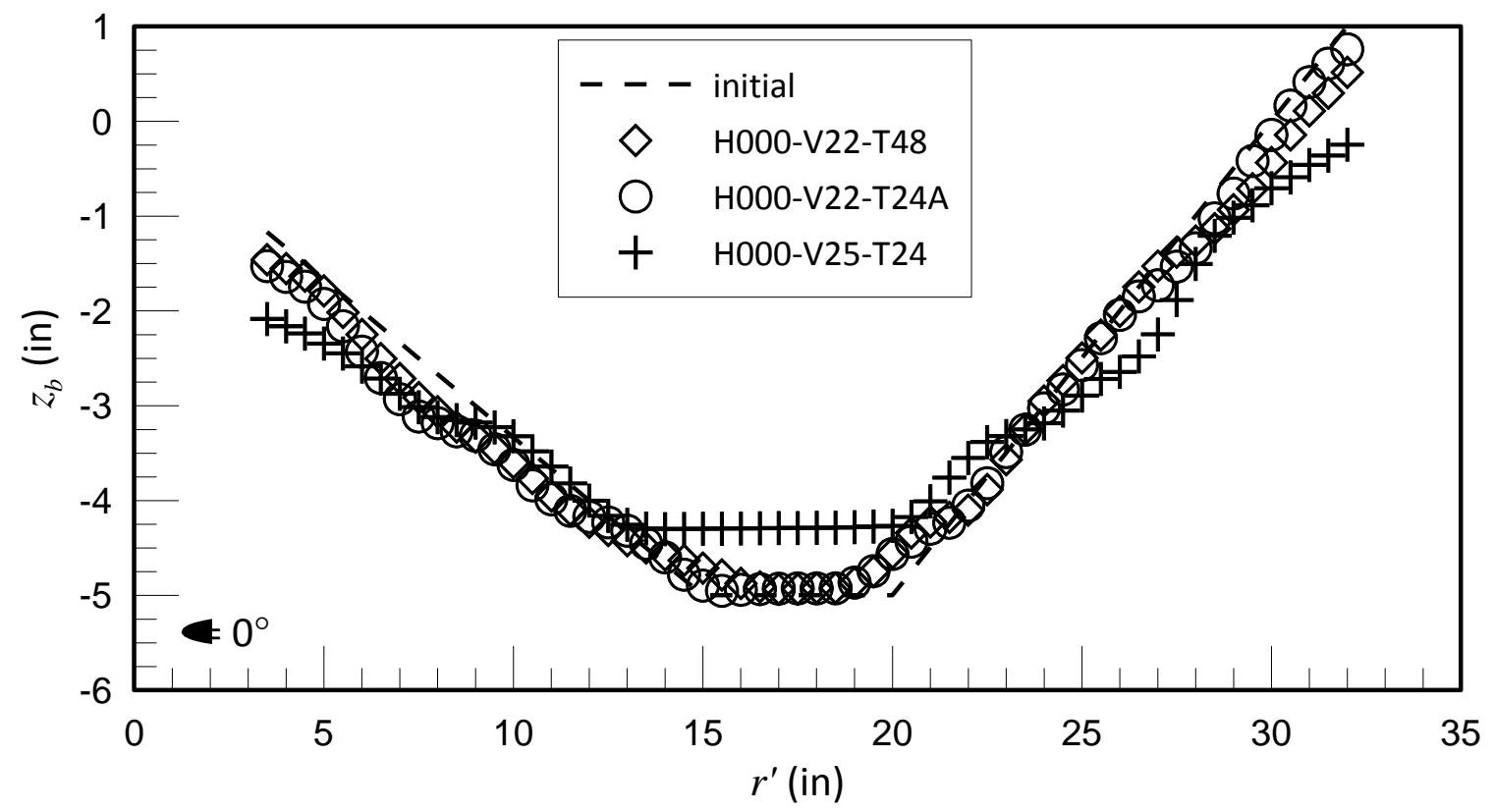

Fig. 4.5: Comparison of the inlet cross-sectional profiles at the end of three experiments with different velocities and durations

A stable clear-water condition is assumed to characterize the inlet to the bend. The inlet $\left(\theta=0^{\circ}\right)$ condition for experiments at two velocities and two durations is shown in Fig. 4.5. The profiles for the lower-velocity case for both (24-hr and 48-hr) durations have remained very close to the initial profile, so the assumption of a stable clear-water condition is clearly well justified. At the higher velocity, larger deviations from the initial profile are observed, and so the assumption becomes more questionable, which should be borne in mind in subsequent interpretation of the high-velocity results.

The effect of different velocities for the same experiment duration is considered in Fig. 4.6. For both lower- and higher-velocity cases, significant changes in cross-sectional profiles are seen after the 24-hr experiments, except (in both cases) in the inner bank region $\left(r^{\prime}<7\right.$-in). It is however evident that larger changes from the initial profile have resulted under the higher velocity condition, where the outer bank has receded beyond the range of measurements (though not necessarily the fixed vertical wall that is located at $r^{\prime}=36$-in), and a rather horizontal central region has become established through a combination of outer-bank scour and central-region deposition. The horizontal central region suggests that the profile is still far from any 'equilibrium' bend cross-sectional profile which is usually characterized by a distinct transverse slope (see Fig. 2.1). Because of the severe bank erosion at this section after $24 \mathrm{hrs}$, a longer-duration experiment at the higher velocity was not attempted. 


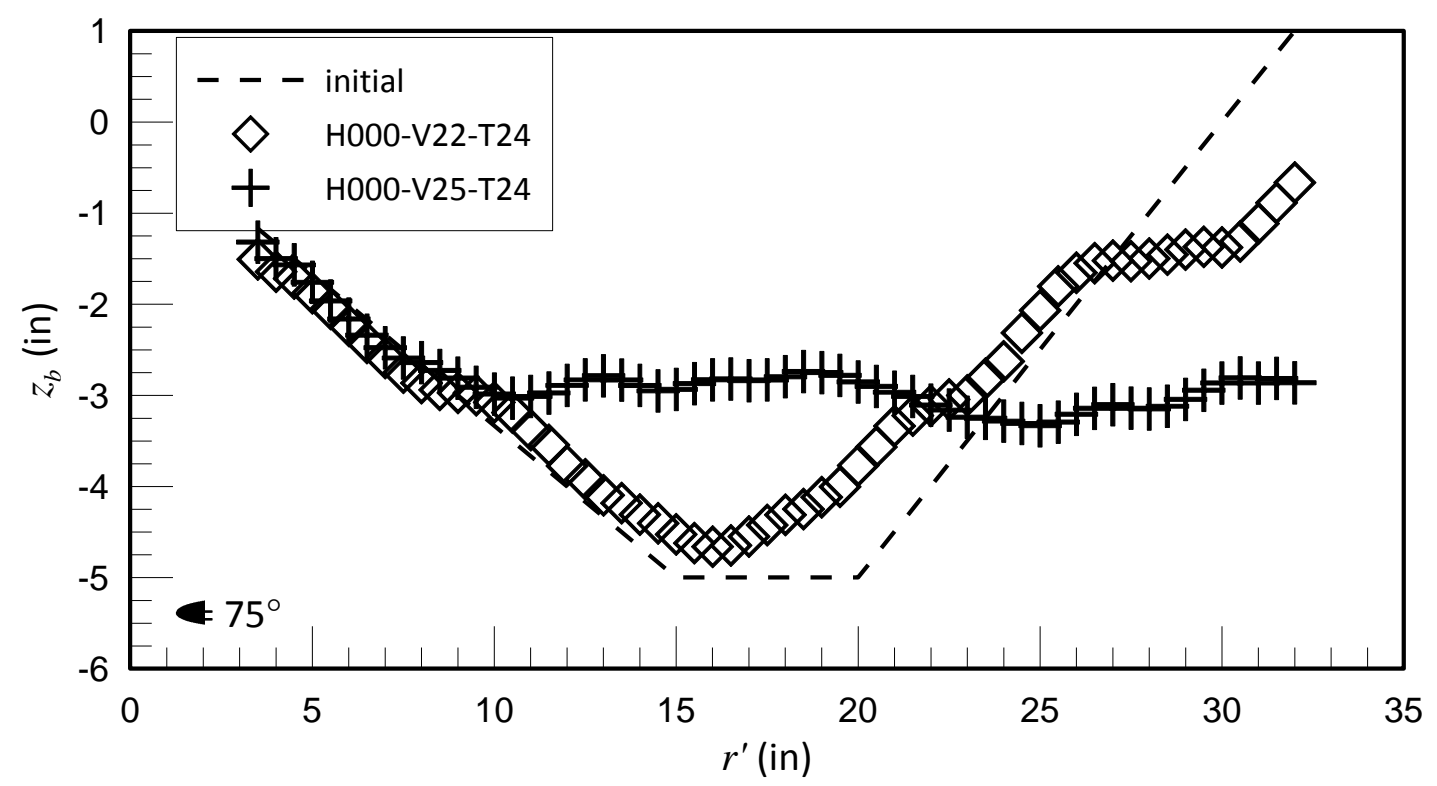

Fig. 4.6: Cross-sectional profiles at $\theta=75^{\circ}$ after $24 \mathrm{hrs}$ with two different values of $U_{0}=22 \mathrm{~cm} / \mathrm{s}$ and $25 \mathrm{~cm} / \mathrm{s}$.

Finally, the effect of experiment duration is illustrated again in Fig. 4.7 from the perspective of cross-sectional profiles with $U_{0}=22 \mathrm{~cm} / \mathrm{s}$. The longer-duration $(48 \mathrm{hr}$ ) experiment has allowed additional deposition in the central region, and additional erosion of the outer bank.

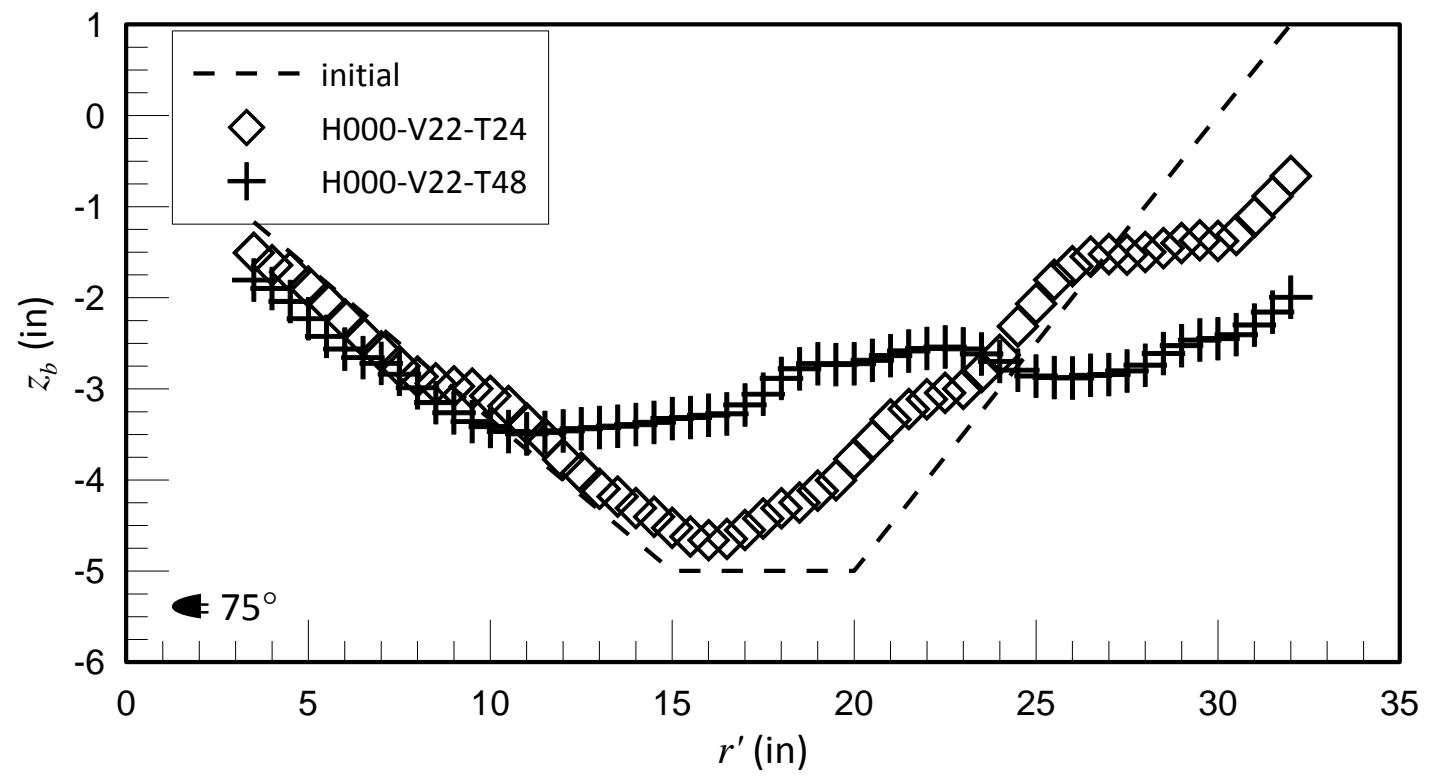

Fig. 4.7: Cross-sectional profiles at $\theta=75^{\circ}$ for the same velocity $\left(U_{0}=22 \mathrm{~cm} / \mathrm{s}\right)$ over two different experiment durations

\subsection{Results with model bendway weirs installed}

\subsubsection{Overall features}

The 'initial' geometry of the bank/weir can be seen in Fig. 4.8a, which was taken at the end of H050-V22-T24, but depicts the most upstream weir (W1) that has been negligibly affected in terms of 
the basic geometry. Its degree of exposure to the flow or the extent to which it protrudes into the flow is relatively small, as the upper sloping part is flush with the bank. The water mark gives a rough indication of the lateral extent of the flow at the inlet. Fig. 4.8b shows the most upstream four weirs at the end of H050-V22-T48. Due to local scour, particularly farther downstream, the weir becomes increasingly exposed, including to some extent the upper sloping part. Some scouring of the upper parts of the banks (below the water mark) between the weirs may also be seen, with ledge-like features seeming to form. Some slight deposition on the weir crests is also observed.

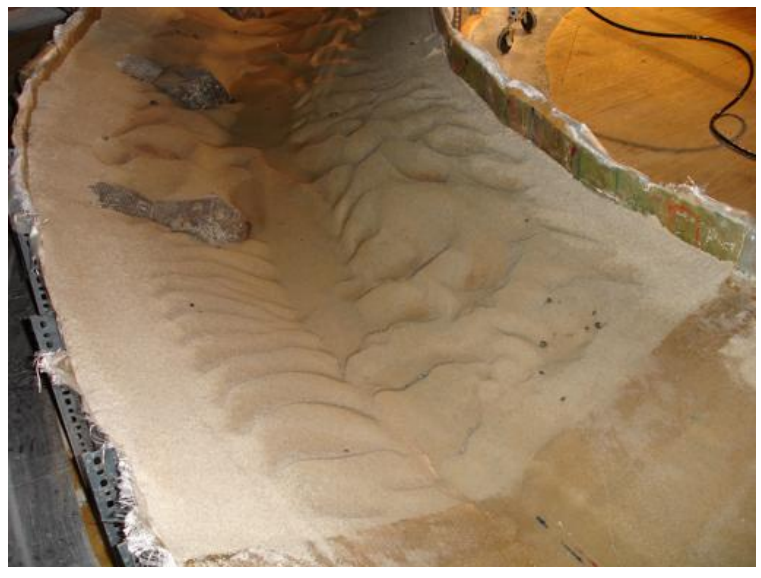

(a)

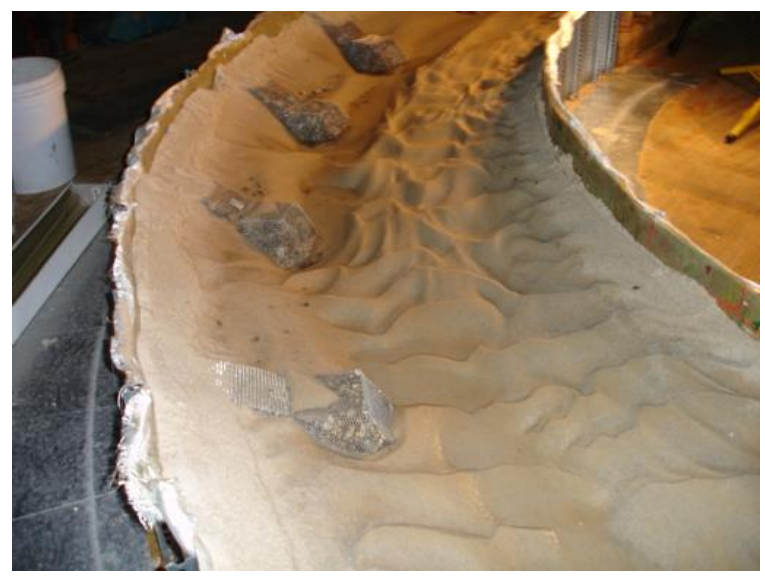

(b)

Fig. 4.8: Photographs of bendway weirs at end of a) H050-V22-T24, and b) H050-V22T48.

Contours plots of the erodible bend section for the three experiments of longest durations (48hrs) with the same 'initial' inlet velocity $\left(U_{0}=22 \mathrm{~cm} / \mathrm{s}\right)$ but with varying weir crest heights (H050-V22T48, H075-V22-T48, and H100-V22-T48) are shown in Fig. 4.9. Each case is presented in two 'difference' forms: on the left, the difference from the 'initial' condition is plotted, while on the right, the difference from the corresponding 'no weir' case is plotted. The left form can be directly interpreted in terms of scour and deposition, while the right form should be interpreted in terms of changes from the corresponding no-weir case. The weir regions have been blanked out, as are regions beyond the range of measurements.

The $\mathrm{H} 050$ series (Fig. 4.9a) is the closest to the HEC-23 guidelines with a weir crest height $50 \%$ of the initial undisturbed flow depth. The region upstream of the W2 experiences minor or negligible scour or deposition, and negligible change from the no-weir case. Between W2 and W3, the upper part of the outer bank begins to scour, the lower part sees neither scour nor deposition, while the central part of the channel begins to experience deposition. These effects are enhanced in the downstream direction, such that, in the outer-bank region between W4 and W5, there is quite severe scour (between 1.5-in and 2.5-in), and even increased deposition in the central region. The region at the toe of the outer bank does seem well protected in that a region of varying size experiencing little change (from the initial geometry) is always observed. A region of scour towards the inner bank opposite to the W5 also seems to develop. Compared to the no-weir case, very little definite improvement in outer-bank stability in the presence of the weirs is observed, except possibly between W2 and W3, where scour was reduced (though not entirely prevented). Where some deposition had occurred in the no-weir case, either no deposition or some measurable scour occurred. Overall, the results of Fig. 4.9a suggest that the HEC-23 design guidelines as implemented in this case may not be effective in stabilizing the outer bank in the long term. A weir crest height of $50 \%$ of design flow depth is at the upper bound of the recommended 
HEC-23 guidelines, and an even lower crest height might be expected, based on the present results, to perform even worse.

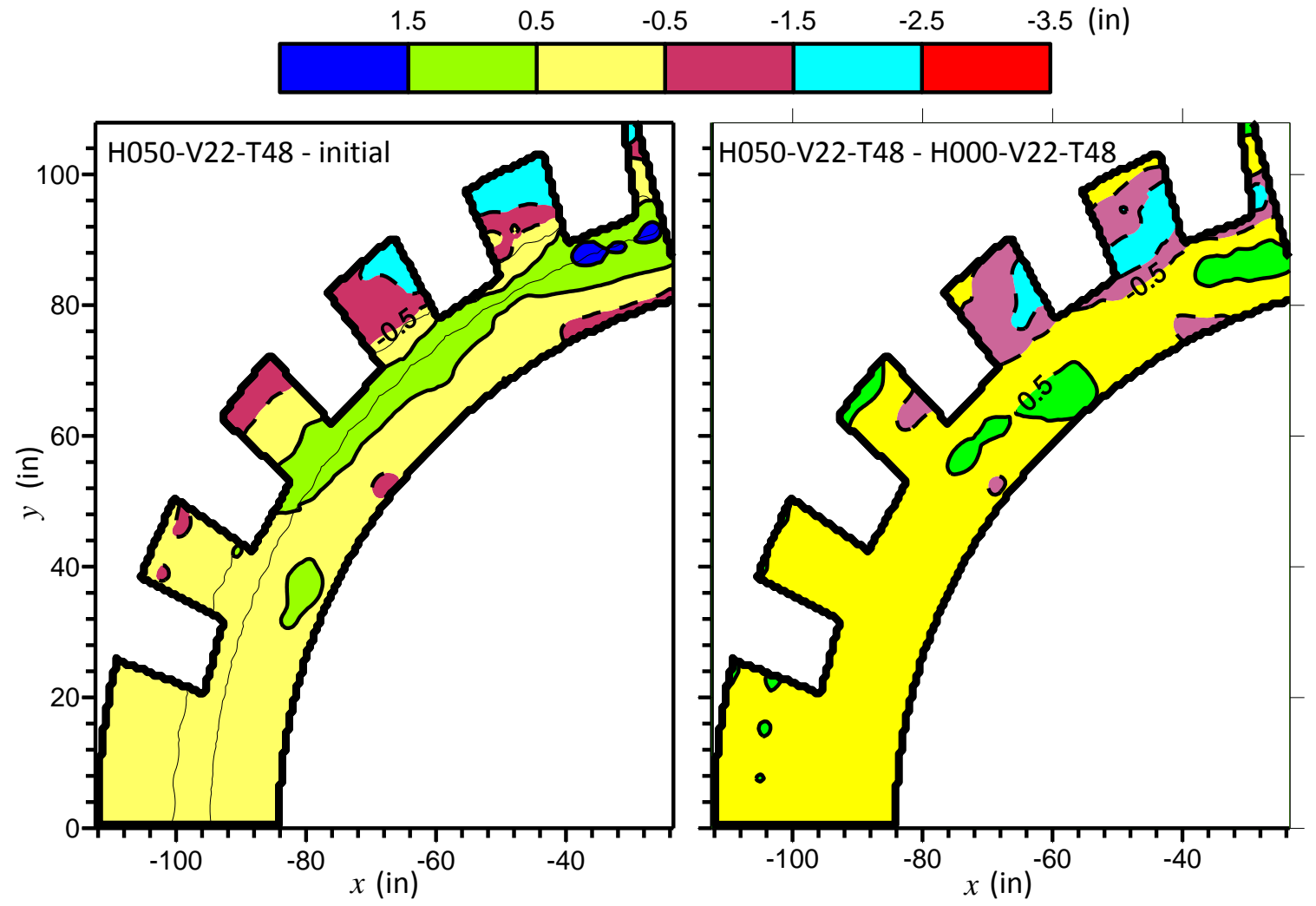

(a)
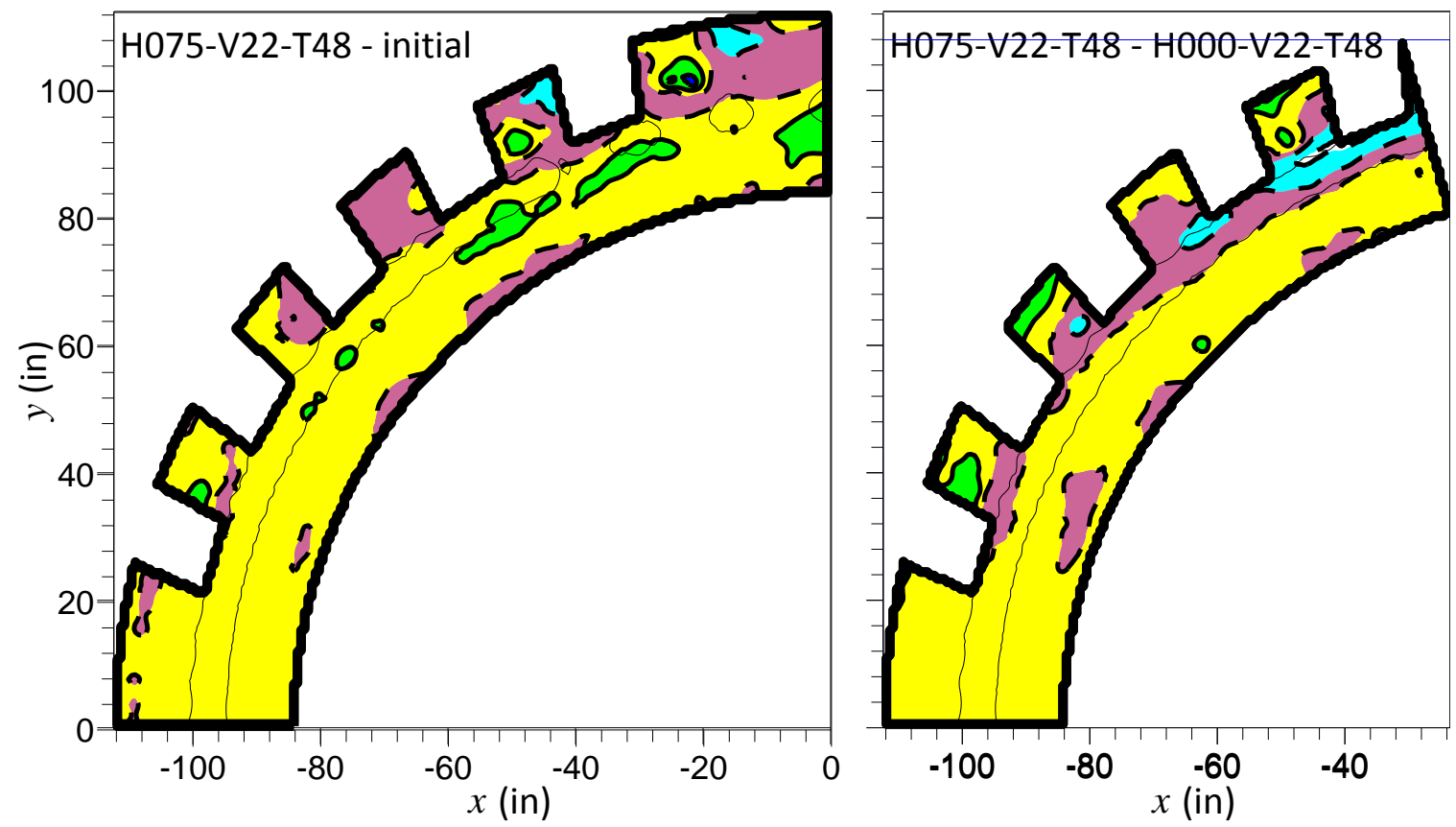

(b) 

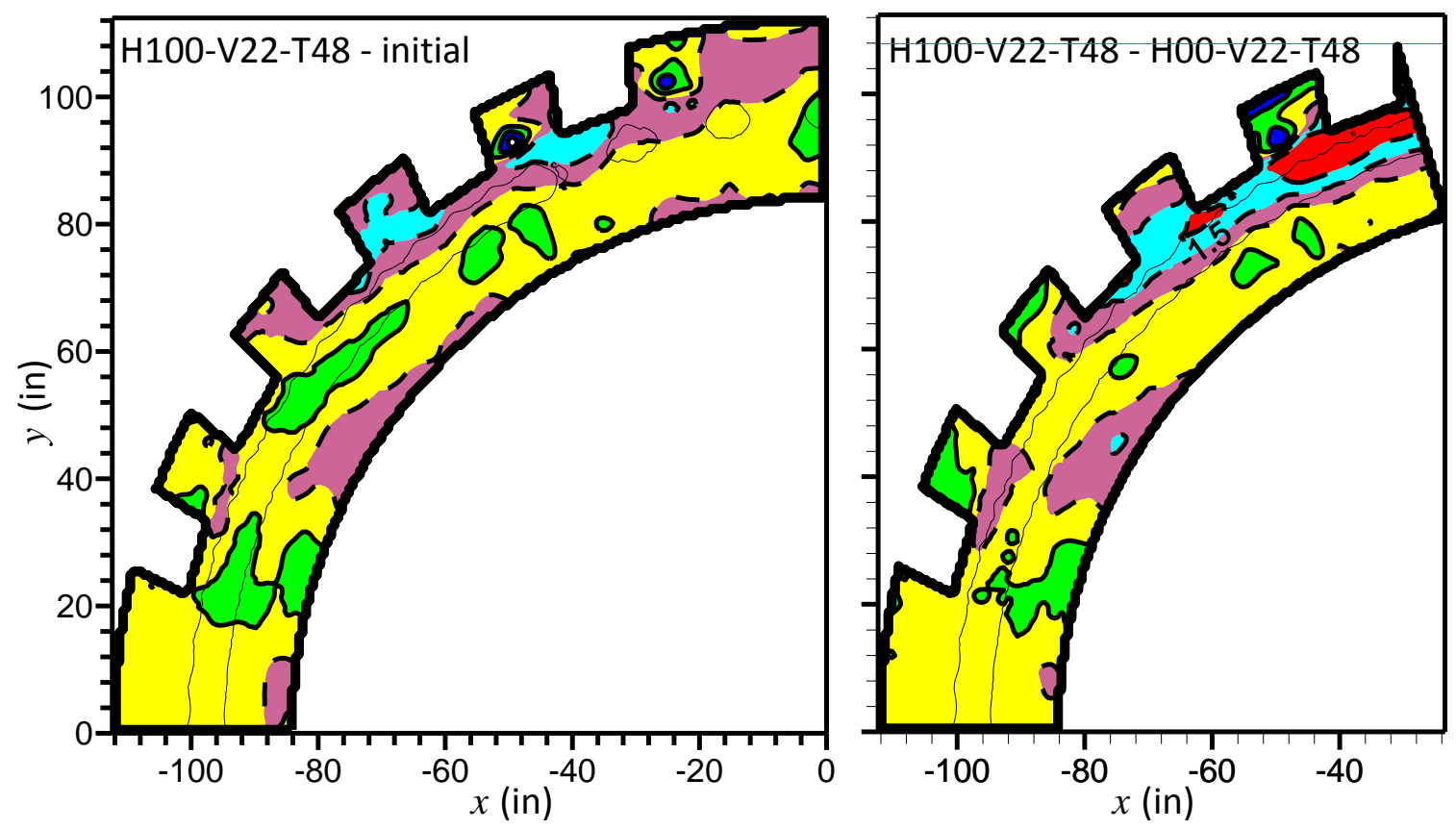

(c)

Fig. 4.9: Contour plots of boundary elevations relative to the initial profile (on the left) and relative to the corresponding no-weir case (on the right) for different cases of the same duration and iinlet velocity, a) H050-V22-T48, b) H075-V22-T48, and c) H100V22-T48.

The effect of increasing the weir crest height, $H_{w}$, while keeping the 'initial' inlet depth constant, is examined in Figs.4.9b and c, with the cases H075-V22-T48 and H100-V22-T48. Because the total length of the weir, $L_{w}$, is kept constant, the extent of the lateral protrusion of the weir into the flow and the flow 'blockage' are actually decreased (see Table 3.3). Also for both of these cases, an increased number of cross-sectional profiles was measured, so the appearance of some finer scale features in Figs. $4.9 \mathrm{~b}$ and $\mathrm{c}$ may be due to the greater density of measurements rather than to any actual physical change. As will be discussed with regards to Fig. 4.13, there is some uncertainty regarding the angular position recorded in the higher-density profile measurements of H075-V22-T48 and H100-V22-T48.

A comparison of Figs. 4.9a on the one hand and Figs. 4.9b and c on the other does suggest that the increased $H_{w}$ leads to some noticeable additional outer-bank protection. Whereas a region of severe scour (between 1.5-in and 2.5-in of scour) extends the entire distance between W4 and W5 in H050-V22-T48, such a region is much more limited in H075-V22-T48 and does not appear at all in H100V22-T48. Outer-bank scour still occurs but is reduced. Deposition in the central region is also noticeably reduced, but the weir-tip region becomes associated with significant scour, particularly in H100-V22-T48. This is not entirely surprising as, in this case, the structure acts practically as a spur, and specifically a spur that does not extend to the toe of the bank, and so offers not protection to that region. Higher effective local velocities and turbulence due to flow separation might also be expected to result in local scour in that region. The improved outer-bank protection may however come at the cost of increased scour potential in the inner-bank region. Though some inner-bank erosion was already seen in $\mathrm{H050}$ V22-T48, this is seen to increase in H075-V22-T48 and especially in H100-V22-T48, perhaps somewhat surprisingly in the more upstream sections. 
Fig. 4.10 presents results from two cases (H050-V25-T12 and H050-V22-T24) with different $U_{0}$ (but different durations) with the same weir configuration. Only the difference from the initial profile is shown in both cases. Although the lower velocity case is twice the duration of the higher-velocity case, the effects, both in scour and deposition are more extensive and more marked in the latter case. The basic features, previously noted in H050-V22-T48, are also seen in these two cases: a reasonably wellprotected outer-bank toe with however the upper part of the outer bank being susceptible to significant scour, and a central region where deposition takes place. These results argue strongly for a significant velocity effect for this ( $\mathrm{H050}$ ) weir configuration, and presumably for any other that has a weir crest height lower than $50 \%$ of design flow depth, i.e., larger velocities at the same flow depth will lead to greater outer-bank erosion for the same duration.

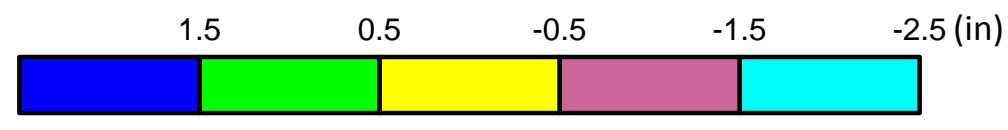

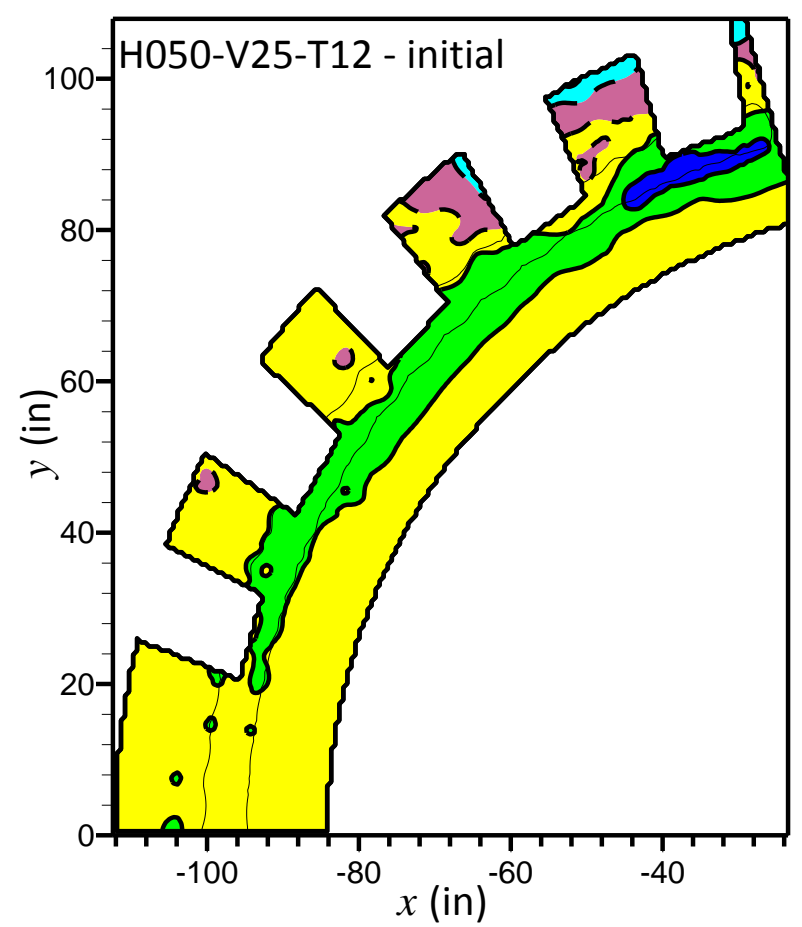

(a)

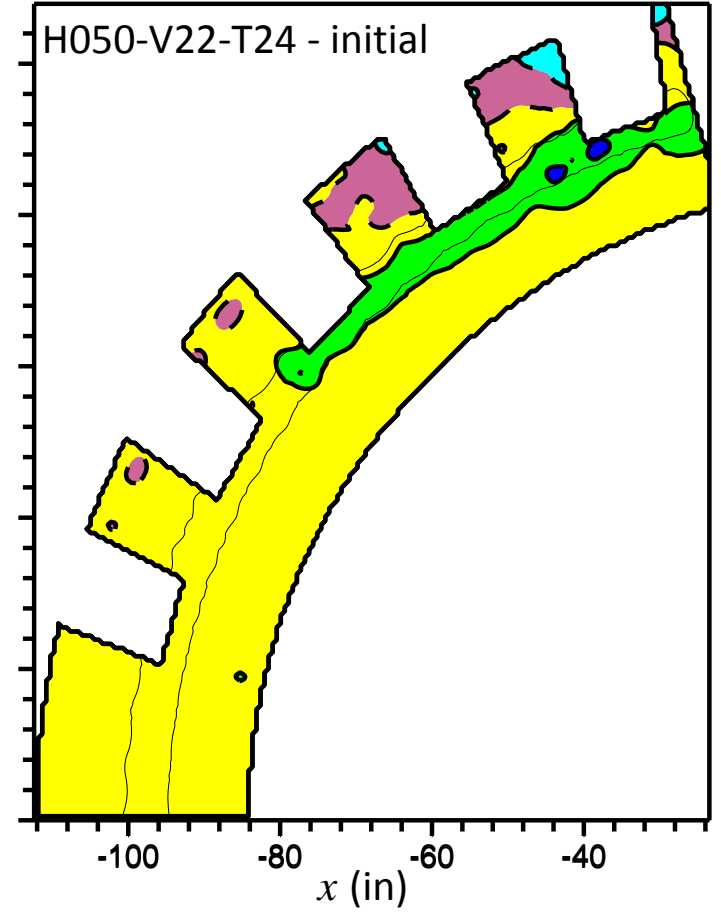

(b)

Fig. 4.10: Comparison of effect of initial inlet velocity on erodible-boundary elevations for the same weir, but different durations, a) H050-V25-T12, and b) H050-V22-T24

The effect of duration can also be assessed by comparing Fig. 4.10b with Fig. 4.9a, since these cases differ nominally only in the experiment duration (24-hr and 48-hr). As seen earlier in the no-weir cases, the process of scour and deposition continues well beyond 24-hr after the start of the experiment, with marked changes between the two durations. Caution should therefore be exercised in making any conclusions about the effectiveness of any bank-protection measure from short-term observations, either in the laboratory or in the field, though what should be considered short-term in the field may be debated. 


\subsubsection{More detailed cross-sectional profiles in weir cases}

Measured cross-sectional profiles in the erodible bend reach for the 'standard' weir configuration $(\mathrm{H} 050)$ at two sections well into the bend $\left(\theta=50^{\circ}\right.$ and $\left.\theta=62.5^{\circ}\right)$, between W3 and W4 and between $\mathrm{W} 4$ and $\mathrm{W} 5$ are shown in Fig. 4.11. The replicated experiments (H050-V22-T24) again indicate that the measurements, particularly on the banks, are quite reproducible. At the $\theta=50^{\circ}$ section (between W3 and W4), the inner bank seems quite stable without significant erosion or deposition even after $48 \mathrm{hrs}$. In contrast, the outer bank, particularly the upper part, experienced noticeable scour. Even quite close to the nominal water surface (the zero level), erosion has occurred. A ledge-like structure develops, about midway up the outer bank, and there is also scour at the toe of initial outer bank, but otherwise the lower outer bank is relatively well protected. At the more downstream $(\theta=$
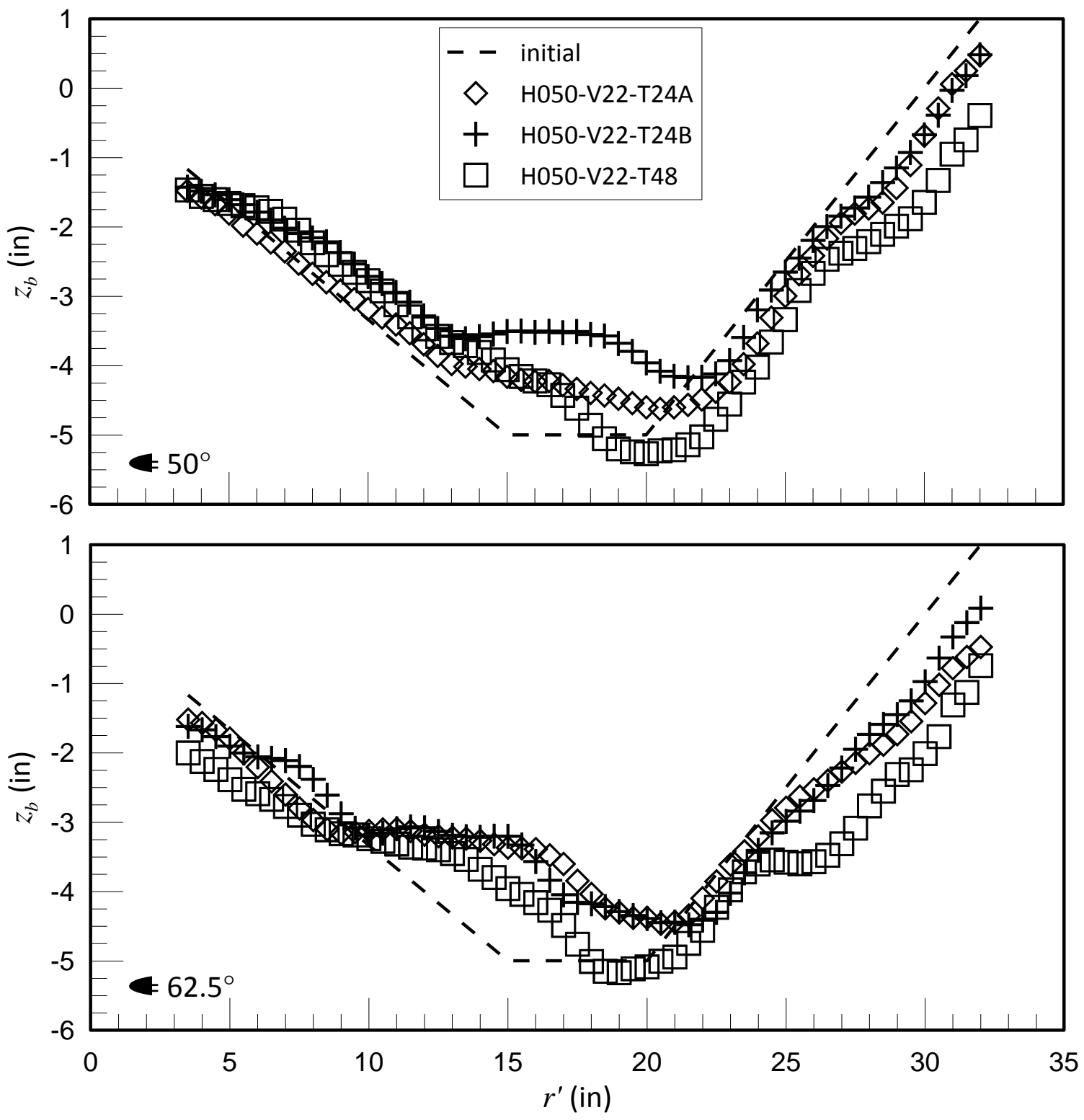

Fig. 4.11: Measured cross-sectional profiles of the erodible bend reach at two sections $\left(\theta=50^{\circ}\right.$ and $\theta=62.5^{\circ}$, respectively between W3 and W4 and between W4 and W5) for the H050 series 
$62.5^{\circ}$ ) section between $W 4$ and $W 5$, the same features may be seen though in some respects enhanced, with a much more pronounced ledge structure at a somewhat lower elevation, and a surprisingly well protected lower outer bank. In comparison with the cases without a weir (in Figs. 4.6 and 4.7, though at $\theta=75^{\circ}$; note that for the $\mathrm{H} 050$ series, the largest angle at which a profile was measured was $\theta \approx 74^{\circ}$, which was immediately downstream of $\mathrm{W} 5$ and so too close to the weir to be comparable), the presence of the weir has definitely had a positive effect, but their overall effectiveness in preventing outer-bank erosion, particularly in the upper region, can be questioned.
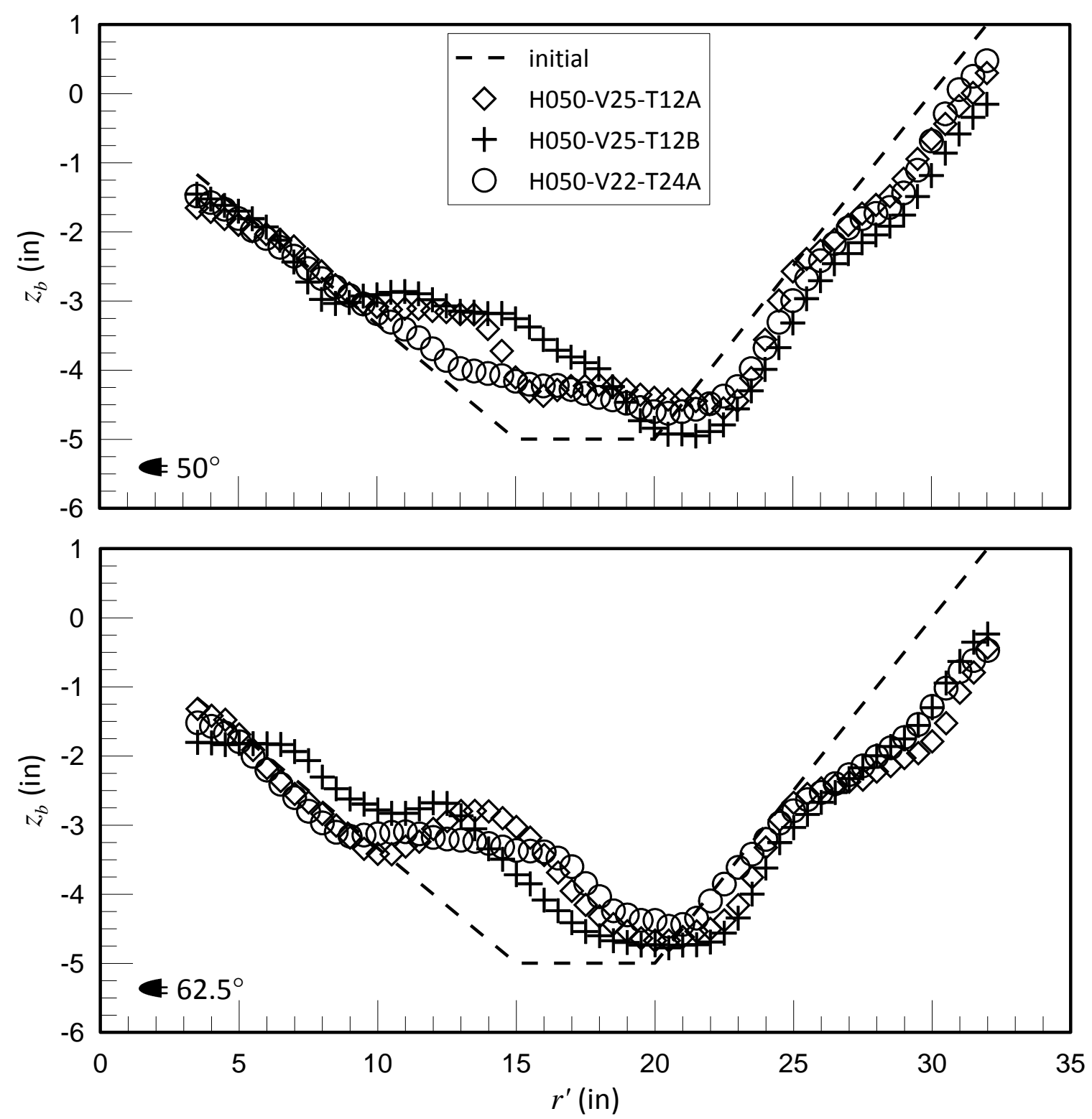

Fig. 4.12: Measured cross-sectional profiles of the erodible bend reach at two sections $\left(\theta=50^{\circ}\right.$ and $\theta=62.5^{\circ}$, respectively between W3 and W4 and between W4 and W5) for the H050 series

The results of replicate experiments (H050-V25-T12) with $U_{0}=25 \mathrm{~cm} / \mathrm{s}$, are compared in Fig. 4.12 with a lower-velocity case, H050-V22-T24, though with a different duration. As seen in Fig. 4.11 for the H050-V22 replicates, the reproducibility for the higher-velocity case is reasonable, especially at the 
upstream section and on the banks. The comparison with H050-V22-T24 also makes clear that the higher velocity case can result in comparable or even greater outer-bank scour than the lower-velocity longer-duration case. This underlines the possible velocity effect previously seen also in the no-weir cases, but which is not considered in the HEC-23 guidelines.
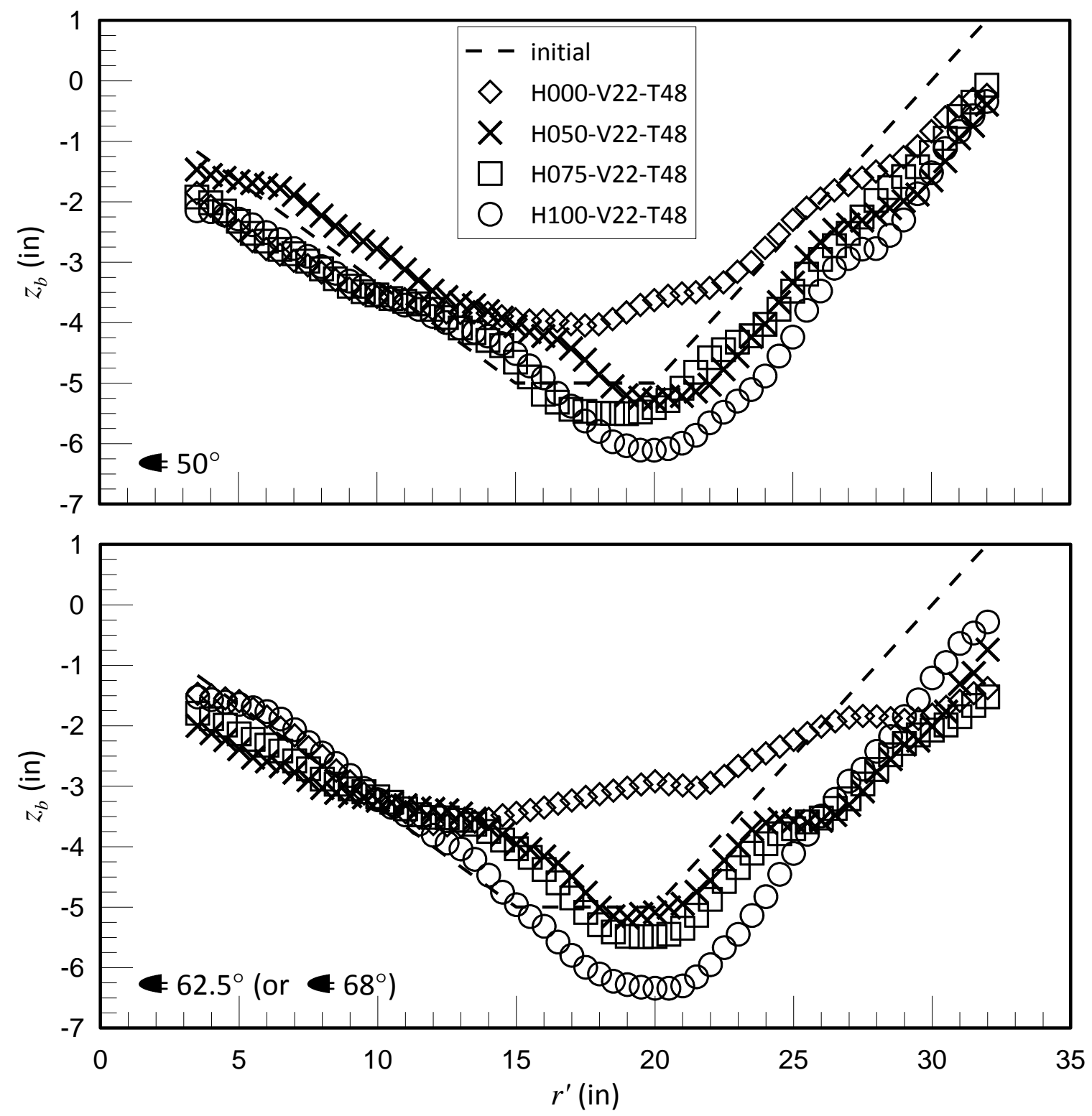

Fig. 4.13: Measured cross-sectional profiles of the erodible bend reach at two sections $\left(\theta=50^{\circ}\right.$ and $\theta=62.5^{\circ}$ or $\theta=68^{\circ}$, respectively between W3 and W4 and between W4 and W5) for the three weir heights

A higher weir crest height might be expected to provide additional protection to the upper part of the outer bank. In Fig. 4.13, where the results for the longest-duration experiments for all three weir heights, as well as the corresponding no-weir case, are compared, limited evidence for such a positive effect is found. At the $\theta=50^{\circ}$ section, the results for the outer-bank show only a very slight, practically negligible, improvement for the $\mathrm{H} 075$ over the $\mathrm{H} 050$ series, while the $\mathrm{H} 100$ series results are no better in the upper part, and worse in the lower part of the outer bank. Interestingly, for the outer bank, at the 
$\theta=50^{\circ}$ section, Fig. 4.13a suggests that, compared to the no-weir case, the presence of a weir of any weir height may even lead to slightly greater erosion. Differences are somewhat larger at the $\theta=62.5^{\circ}$ section, but the effect is still rather mixed. For the $\mathrm{H} 075$ and $\mathrm{H} 100$ series, a profile at $\theta=62.5^{\circ}$ was not measured, and so the profile at $\theta=68^{\circ}$ was taken for the comparison. This choice was made for two reasons. The various profiles between $W 4$ and $W 5$ were examined, and the $\theta=68^{\circ}$ section had the most severe scour in the upper outer-bank region, though the results for $\theta=66^{\circ}$ section were similar. A second reason was some uncertainty regarding the angular position of the weirs, as will be discussed below with regards to Fig. 4.14. Compared to the no-weir case, a clear improvement can be seen in the uppermost part of the outer bank only for the $\mathrm{H} 100$ weir; for the other two weirs, the empirical support for any improvement is not strong, though this may to some extent be due to the limited lateral range of measurements. At mid-depths, compared to the no-weir case or to the initial profile, the effectiveness of any of the weirs in protecting the bank is questionable. The lower part of the outer bank seems to be well protected by both the $\mathrm{HO50}$ and $\mathrm{H075}$ weirs, as the resulting profiles remain close to the initial profile. Because of the significant deposition in the no-weir case, it does not provide a good basis for comparison concerning the effect on the lower outer bank.

In the $\mathrm{H} 100$ case, substantial scour at the initial outer-bank toe is observed at both the $\theta=50^{\circ}$ and the $\theta=62.5^{\circ}$ ( $\operatorname{or} \theta=68^{\circ}$ ); this is also seen to a lesser extent in the H075 case, especially compared to the $\mathrm{H} 050$ results. This increased scour at the toe of the outer bank compared to the standard $\mathrm{H} 050$ case is attributed mainly to the fact that the weir protruded less into the flow as the weir height increased (recall that the total length of weir was held constant as the height was varied), and therefore offered less direct protection to the toe of the outer bank. For the $\mathrm{H} 100$ case, the amount of toe scour is such as to raise concerns regarding the long-term stability of the bank, even if the performance might be considered from Fig. 4.13 to be the best for the uppermost outer bank. If the lateral extent of the $\mathrm{H} 075$ and especially $\mathrm{H} 100$ weirs were extended to the same point as the $\mathrm{H} 050$ weir, then the observed toe scour might have been lessened.

Cross-sectional profiles in the immediate vicinity of a weir were of interest in giving insight on the mechanisms involved in the scour process, particularly in the upper part of the outer bank. A comparison of the results is shown in Fig. 4.14. Here unfortunately some potential discrepancies were found in the data. In the long-duration $\mathrm{H} 075$ and $\mathrm{H} 100$ experiments, profiles were taken at $2^{\circ}$ increments starting at $50^{\circ}$ rather than only immediately downstream, on the 'centerline' angle, and immediately downstream of the weir as was done for the $\mathrm{H050}$ case. In the H050 results, a clear signature of W4 is seen at what was recorded as the $\theta=56.9^{\circ}$ section, with the weir protruding from the bank. The sloping part of the weir should however be flush with the initial bank, but in Fig. 4.14, this is not the case. A possible explanation is that the angular position of the profile is slightly less than that recorded, possibly due to the offset of the instrument mount relative to the carriage. Because of the upstream orientation of the weir, a radial profile at an angle just less than the centerline angle at the outer channel wall would cut across the weir (see Fig. 3.6a). The scoured upper region seen in Fig. 4.14 for the H050 case at $\theta=$ $56.9^{\circ}$ would therefore be the erodible region just upstream of the sloping part of the weir.

For the $\mathrm{H} 075$ and $\mathrm{H} 100$ cases, the signature of W4 should be found at the angle closest to $56.9^{\circ}$, e.g., $\theta=56^{\circ}$, but no such signature was found; the only clear signature of W4 was found in the profile at $\theta=62^{\circ}$, as seen in Fig. 4.14. Thus, in Fig. 4.14, it has been assumed that, for the H075 and H10O cases, the 'centerline' angle of W4 is associated with what was recorded as $\theta=62^{\circ}$. The sloping part of this assumed weir is quite close to the initial bank, which lends further support to this assumption. The $\approx 5^{\circ}$ discrepancy is also found at W5, in that a weir signature is found at what was recorded as the $\theta=76^{\circ}$ section, rather than the $\theta=70.4^{\circ}$ section where it was supposed to be. This provided a second reason for the choice of the $\theta=68^{\circ}$ section for comparison with the $\theta=62.5^{\circ}$ section in Fig. 4.12 because $\theta=$ 

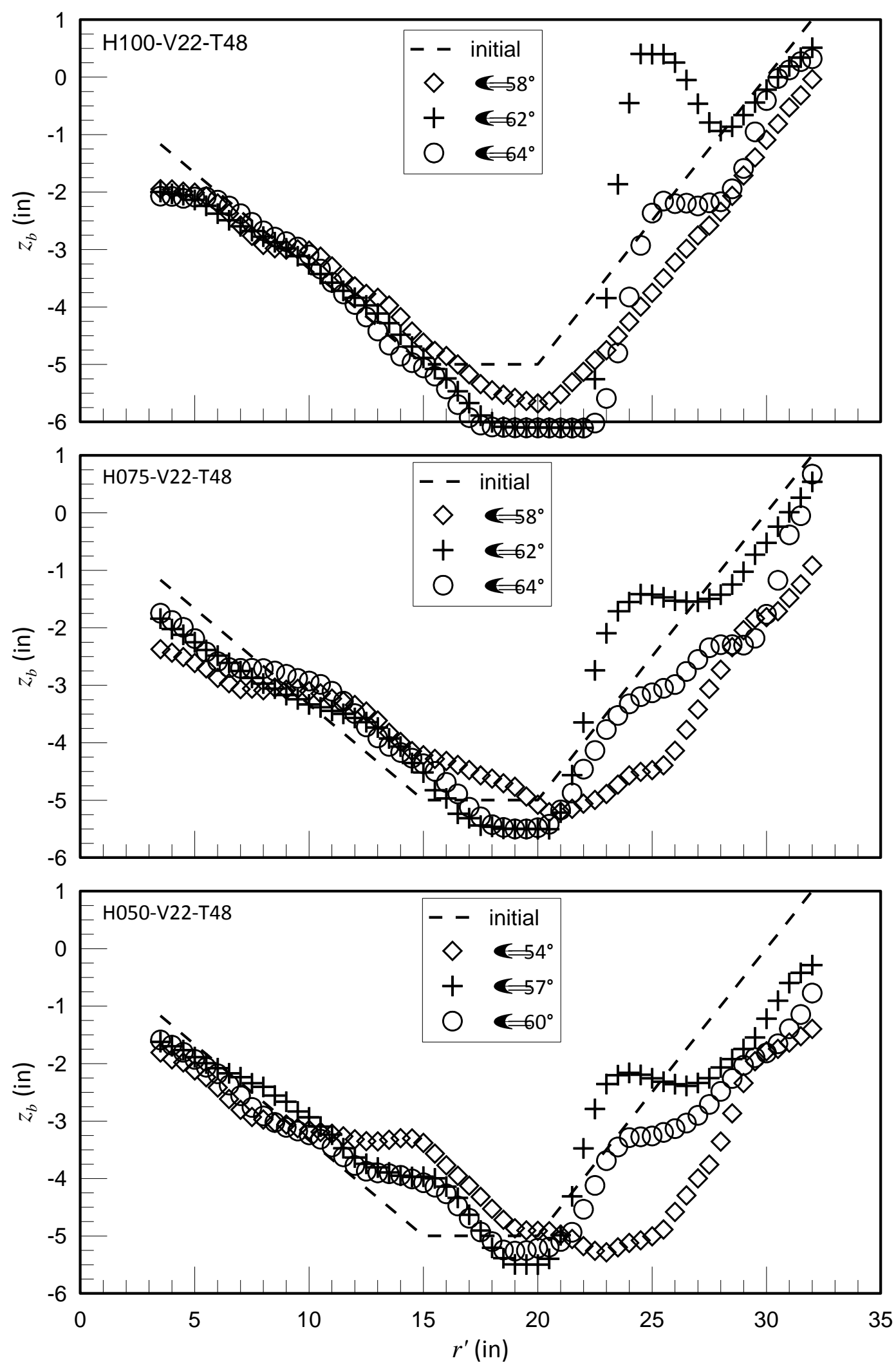

Fig. 4.14: Cross-sectional profiles of the erodible bend reach just upstream, at, and just downstream of W4 for the three different weir height cases 
$68^{\circ}$ lies more nearly to the midpoint between $\theta=62^{\circ}$ and $\theta=76^{\circ}$ where a clear weir signature was found.

In all three cases, a substantial difference between the profile just upstream and that just downstream of the weir is seen. The upstream profile exhibits considerably more scour, especially in the lower bank region, whereas in the upper bank region, even for $\mathrm{H} 100$, both profiles are more comparable. The ledge-like structure, seen in earlier profiles, is evident in the downstream profiles, somewhat surprisingly even in the $\mathrm{H} 100$ case, whereas it is strikingly absent in the upstream profiles. This suggests that overtopping of the weir may not be essential to the formation of the ledge-like structure, since it is also observed in the $\mathrm{H} 100$ case. The $\mathrm{H} 100$ weir crest was not entirely horizontal to the sloping part (see Fig. 3.6), as reflected in the weir profile in Fig. 4.14, where a local minimum elevation below the zero level can be seen. As such, some small amount of flow did go around the bank side, similar to flanking, but this minimal flow is unlikely to contribute significantly to the observed scour, leading to the ledgelike structure. On the other hand, the disappearance or the absence of the ledge-like structure at the upstream profile suggests that the upstream face of the weir was directly attacked by the main channel flow, as is perhaps implicitly assumed in the underlying theory that the flow direction over the weir is

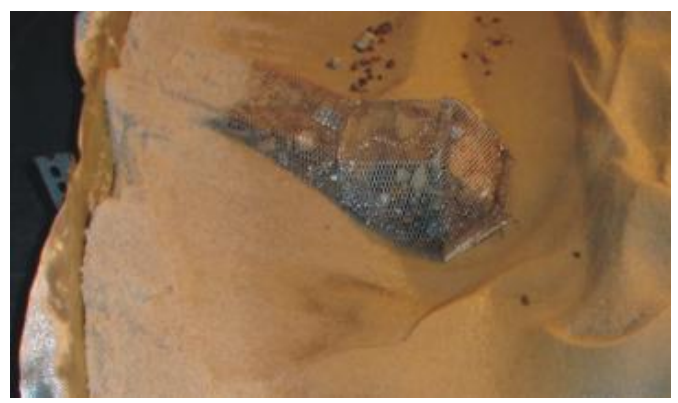

(a)
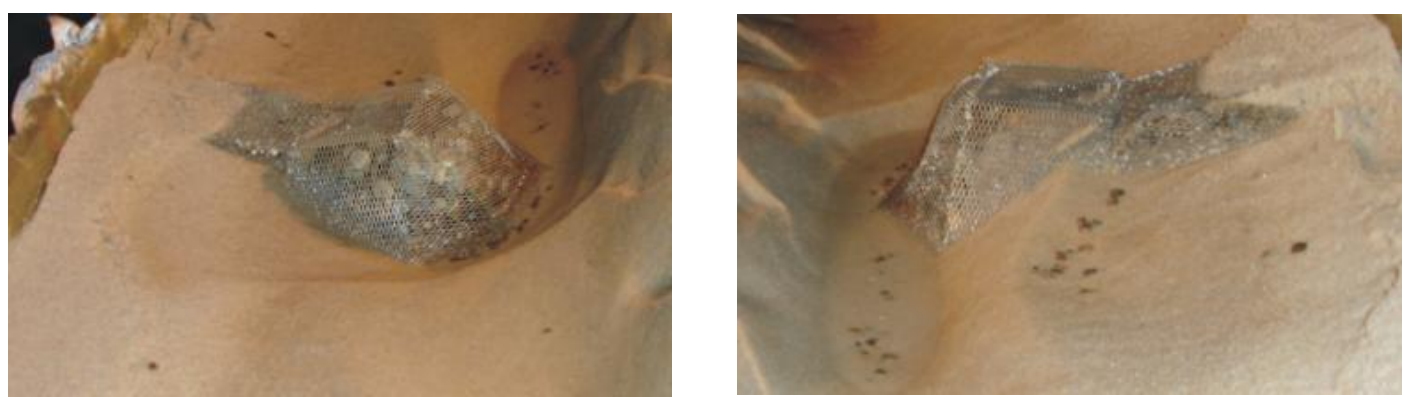

(b)
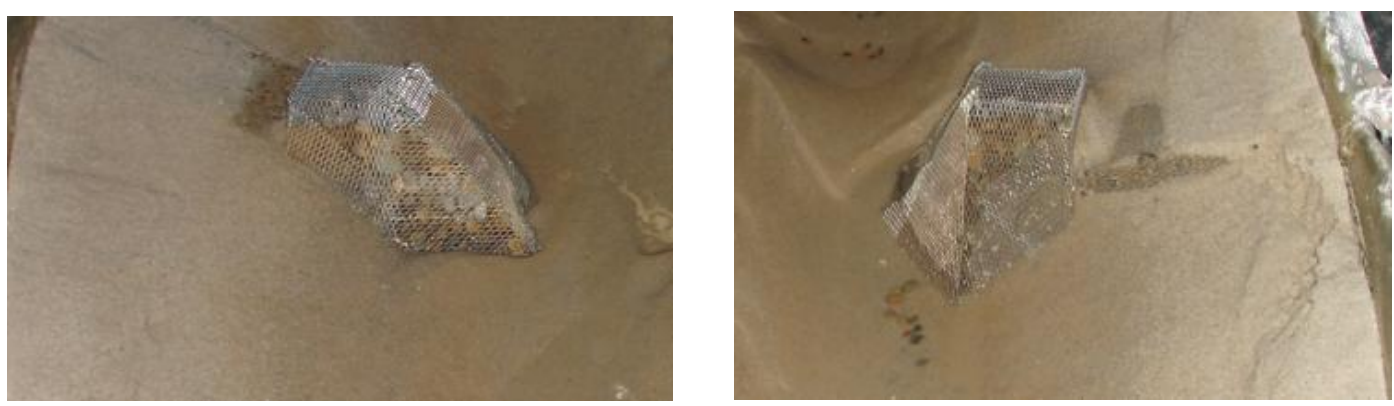

(c)

Fig. 4.15: Downstream (left) and upstream (right) views of W4, a) H050-V22-T48, b) H075-V22-T48, and c) H100-V22-T48 at end of experiment 
perpendicular to the axis of the weir. Nevertheless, it raises the question whether the lateral extent of the weir was sufficient, or possibly whether the spacing of the weirs was optimal (the length and spacing are, e.g., by the HEC-23 guidelines, related). Photographs of the regions just upstream and just downstream of W4 at the end of H050-V22-T48, H075-V22-T48, and H100-V22-T48 experiments provide a more concrete picture of the flow effects around W4.

\subsection{Further comments}

The preceding results have shown that the presence of a field of bendway weirs (or in the limit, spurs) may change substantially the pattern of scour and deposition in an alluvial bend. Yet do such structures protect the outer bank against erosion? The evidence from the present study is rather mixed. The $\mathrm{H050}$ and $\mathrm{H} 075$ weirs seemed to have 'protected' the lower part of the outer bank, such that the toe of the outer bank remained essentially as it initially was. Note however that in the no-weir case, there was actually deposition in the same region over the same duration, so that this region was in fact not subject to scour during the experiment. Whether the action of the weirs in this region should be termed 'protection' might be debated. On the other hand, in the region where the no-weir cases exhibited definite scour, namely in the upper third of the outer bank, the protection afforded by the H050 and even the H075 weir was limited, if any. The only structure for which the scour in this region was noticeably reduced was the $\mathrm{H} 100$ structure, which acted basically as a spur, with minimal over-topping, rather than as a weir.

The possibility of scour above the crest level of bendway weirs was already noted by Rhoads (2003) in his Illinois field study. More particularly, the development of a ledge-like structure, as was also seen in the present study, was noted. Attributing this scour to the flow over the weir is intuitively attractive, and the numerical study of Abad et al. (2008) gives some support to this explanation. Thus, the fact that only the $\mathrm{H} 100$ structure resulted in reduced bank erosion would also be consistent with this view. If this view is correct, then the outlook for bendway weirs as a complete bank erosion countermeasure must be considered pessimistic, as the essential characteristic of these structures is that they be overtopped. Changing the structure length or the the structure spacing seems unlikely to substantially improve the performance for bank stabilization since they do not directly affect the overtopping flow. One parameter that might affect this flow would be the angle of orientation, $\alpha_{w}$. The present study cannot give indication of an effect of $\alpha_{w}$ as only a single $\alpha_{w}=75^{\circ}$ was investigated, and that only at the higher end of the HEC-23 recommended range $\left(60^{\circ}-80^{\circ}\right)$. In the literature review (Chap. 2), stream barbs and bank-attached vanes were noted to be designed at a much sharper angle, e.g., $\alpha_{w}<45^{\circ}$, and so the effect of smaller $\alpha_{w}$ may warrant further study.

The significant erosion observed even in the region close to the water surface points also to the likely importance of mass or gravitational failure as a mechanism for bank retreat. This region is unlikely to have experienced high boundary shear compared to any estimate of critical shear stress, and so the most likely explanation for the erosion observed is motion of sediment at a lower elevation that ultimately makes bank above that elevation unstable. Evidence of slumping of bank can be seen in time lapse photography during an experiment. The considerable deposition in the central part of the channel, particularly in the no-weir case, is attributed to both the result of sediment contribution from the bank slumping as well as a low sediment transport capacity of the base flow. In the presence of weirs, because the toe of the bank is to some extent protected by the weirs, the mass failure is triggered at a higher elevation, and presumably results in the observed ledge-like structure.

\subsection{Summary}

Measurements of boundary elevations were made in a bend flow over a erodible non-cohesive boundary with and without bendway weirs installed. Results from replicated experiments show that 
reproducibility was acceptable especially on the banks. Consistent with an initial inlet velocity significantly below critical velocity, the inlet boundary was quite stable on average, though bedforms were still prominent. Some minor erosion, even at the inlet, was observed for the higher-velocity case.

In the absence of weirs, at sections downstream of mid-bend, substantial deposition occurred in the central part of the channel, while the upper part of the outer banks exhibited considerable erosion. Even after 48 hours, it was not clear that any equilibrium steady state had been achieved. Under highervelocity conditions, boundary changes including outer bank erosion occurred at a quicker rate.

With the standard HEC-23 based bendway weir, little change from the initial channel geometry was seen upstream of the first two weirs. Farther downstream, the bendway weirs protected the lower part of the outer bank in the sense that this part experience no erosion compared to the initial channel geometry. Compared to the no-weir case, however, this part had in fact experienced deposition rather than scour. The upper part of the outer bank still exhibited approximately the same erosion as in the no-weir case, and so the presence of the HEC-23 bendway weirs did not offer any apparent protection to this part. An increase in the weir crest height improved the situation only modestly, and only the case where the weir was not overtopped enhanced significantly protection to the upper part. 


\section{Results on the velocity field}

The preceding chapter presented measurements of the erodible boundary in the bend for the various conditions studied. Only a limited number of different cases could be studied, and to understand better the physical processes leading to the observations, it was desired to examine in more detail the associated flow characteristics. The discussion in this chapter will be restricted to the time-averaged streamwise, i.e., tangential, velocity measurements, because these are believed to be most reliable, obtained with the acoustic Doppler velocimetry (ADV) technique.

\subsection{Results for no-weir cases}

An overall view of the streamwise variation of the downstream (tangential) velocity, $u$, is given in Fig. 5.1, which shows the contours of the near-surface $(\approx 0.5$-in below the free surface) value, denoted as $u_{-0.5}$, along the erodible bend reach. For the no-weir cases, measurements were made at only four cross-sections (at $\theta=0^{\circ}, 25^{\circ}, 50^{\circ}$, and $75^{\circ}$ ), and hence contour plots like Fig. 5.1 rely heavily on interpolation of sparse data. In particular, small-scale features should be interpreted cautiously as they may be artifacts of the interpolation. The thick-line boundary indicates the limits of the erodible-boundary measurements, similar to those seen in Chap. 4, and does not indicate the limits of the flow. In general, velocity measurements satisfying the quality criteria that the average three-beam ADV correlation should exceed $50 \%$ and that the \%valid data (as determined by the WinADV processing software) should also exceed $50 \%$ were only obtained within a restricted region, often only in the central part of the flow. As also in Chap. 4, the thin lines indicate the limits of the sloping banks of the initial channel.

From Fig. 5.1, the inlet $\left(\theta=0^{\circ}\right)$ velocity distribution is rather surprisingly laterally quite nonuniform even in the central part of the flow. Unlike flows in straight channels where the highest velocities are found in mid-channel, the highest velocities in Fig. 5.1 are observed towards the inner bank, which is more characteristic of bend flows, as reported in studies of fixed-bed bend flows (Ippen and Drinker, 1962; Hicks et al., 1990). This indicates that bend effects are already influencing the inlet flow. It might be expected that the inlet distribution of $u_{-0.5}$ for the H000-V22-T24 and H000-V22-T48 cases would be similar since the inlet boundary profiles are quite similar (Fig. 4.5). Some evidence for this is seen in Fig. 5.1, though the H000-V22-T24 distribution seems more non-uniform. While uncertainties in the velocity measurements may have contributed to this, differences in downstream boundary geometry (Fig. 4.7) may also explain to some extent the differences at $\theta=0^{\circ}$ seen in Fig. 5.1 , especially since bend effects seem to be already influencing this section.

Farther downstream, beyond mid-bend, another characteristic of bend flows is noted, namely the shift of the highest-velocity region to the outer bank, which is of primary concern with regards to traditional bank stability. There is also evidence in the shorter-duration experiments (H000-V22-T24 and H000-V25-T12) that regions farther downstream of that measured may experience even higher local velocities. Caution should however be exercised in interpreting the results of the shorter-duration experiments since it is difficult to separate out the effects of the shorter-duration. The results of both $\mathrm{H} 000-\mathrm{V} 22-\mathrm{T} 24$ and H000-V25-T12 share similarities in that the overall $u_{-0.5}$ distribution seem rather more non-uniform than that of the longer-duration H000-V22-T48, and the higher-velocity region in the latter seems to extend farther upstream.

More details of the measured local velocities at the different measured sections for the different experiments are presented in Figs. 5.2 - 5.4. For orientation, the corresponding cross-sectional profiles and 'initial' profile are also shown. Validated ADV results were obtained only for a rather restricted region within each section, estimated to be less than $50 \%$ of the total flow area (the 'initial' inlet flow area is $\approx 87.5-\mathrm{in}^{2}$ ), and unfortunately too often no validated measurements were obtained near the outer bank boundary. Table 5.1 lists the areas covered by validated ADV measurements in each section, 
with the corresponding average velocities, $\langle U\rangle$ (again based only on the areas covered by the ADV measurements). The number of validated ADV measurements for any given section varies from 42 to 68 ,

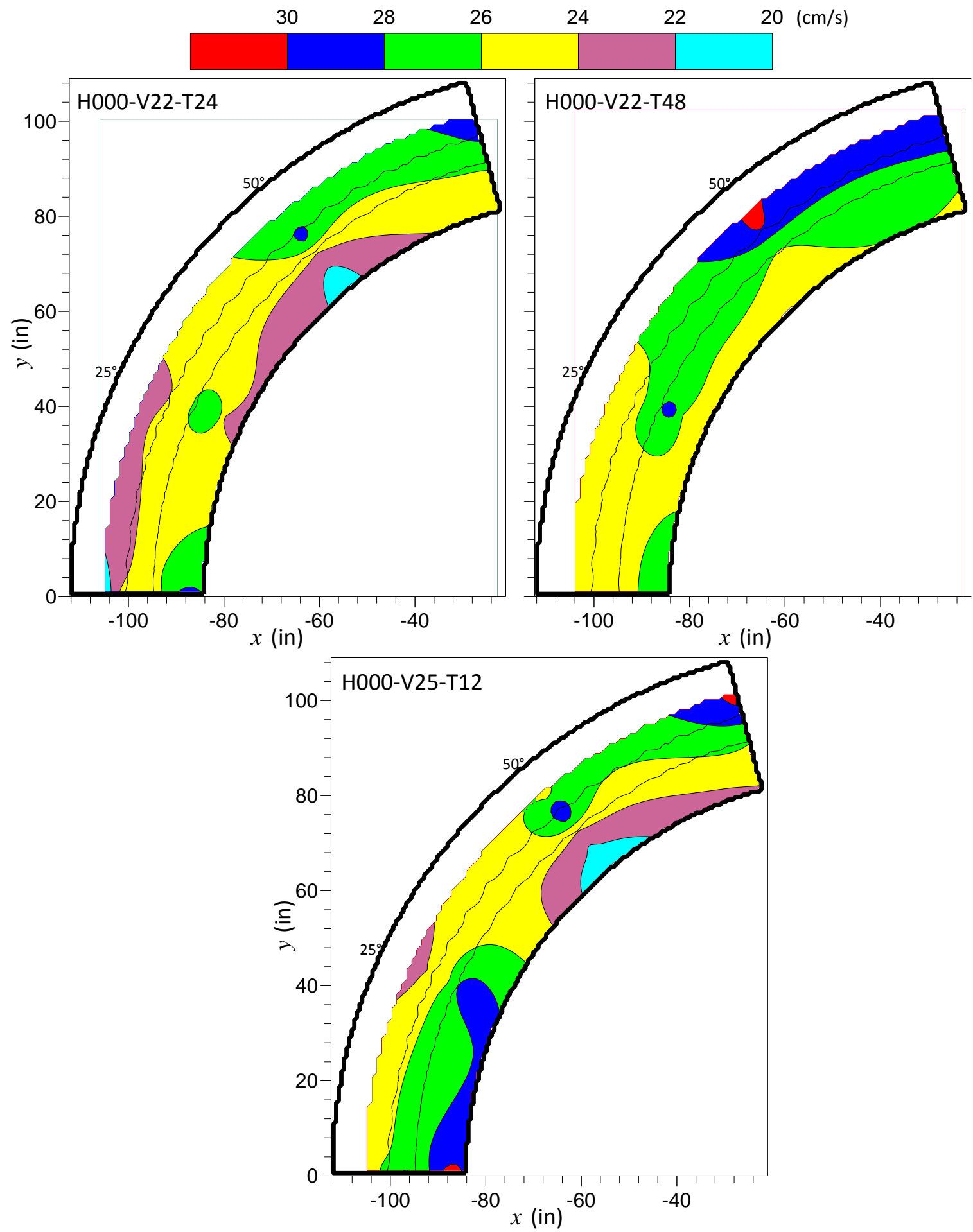

Fig. 5.1: Contour plots of downstream (tangential) near-surface $(\approx 0.5$-in below the free surface) velocity, $u_{-0.5}$, for the three no-weir cases. Thick lines show only the limit of erodible boundary measurements ( $\underline{\text { not }}$ the channel boundary), while thin lines show the limits of the sloping banks of the initial channel. 


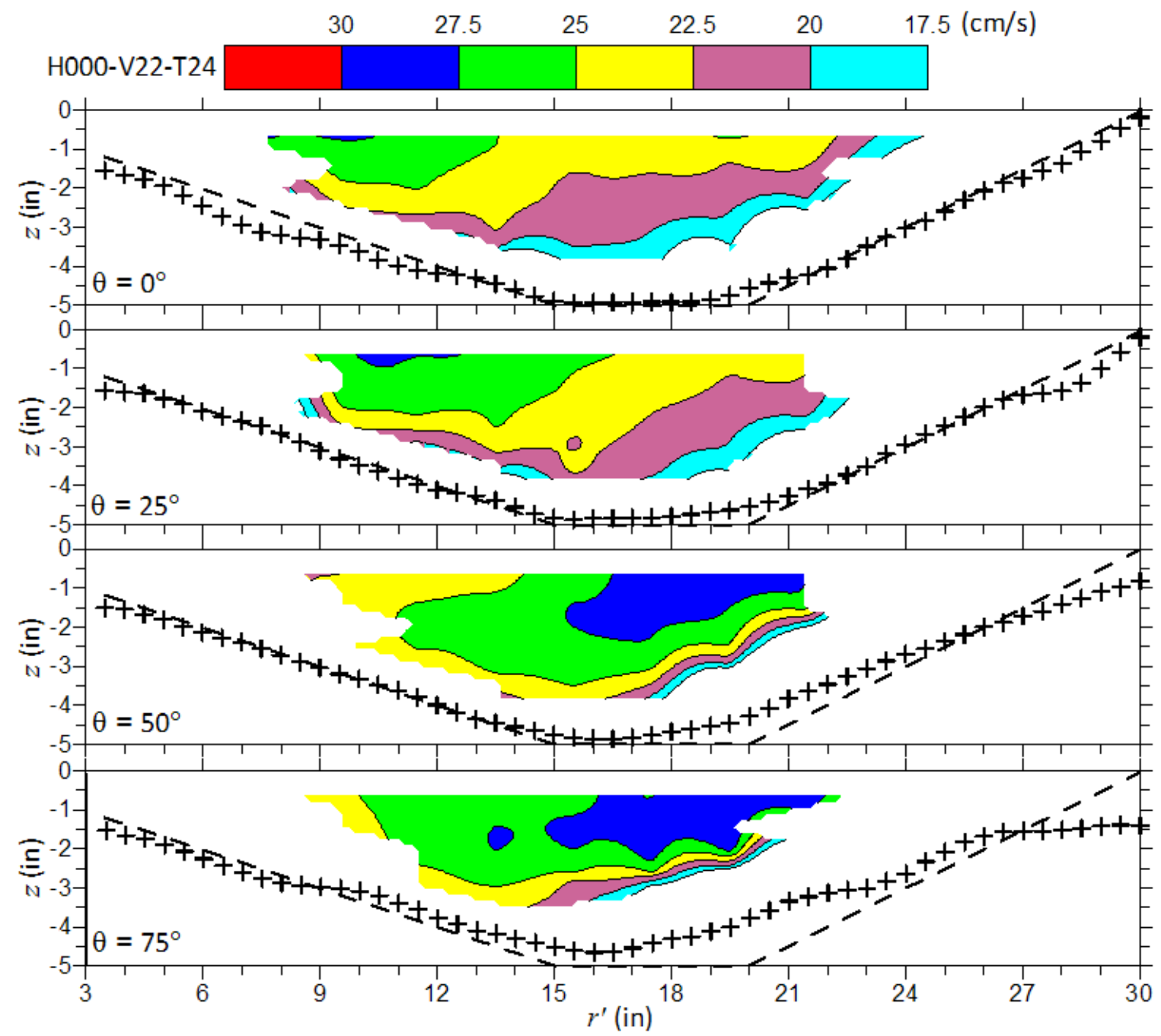

Fig. 5.2: Contours of local velocity at different sections for the H000-V22-T24 experiment; the symbols indicate the corresponding cross-sectional boundary profile, while the dashed line indicates the 'initial' boundary profile

Table 5.1: Estimated areas covered by ADV measurements and the corresponding average velocities

\begin{tabular}{|l|c|c|c|c|c|c|c|c|c|c|c|c|}
\hline Expt. & \multicolumn{4}{|c|}{ H000-V22-T24 } & \multicolumn{5}{c|}{ H000-V22-T48 } & \multicolumn{3}{c|}{ H000-V25-T12 } \\
\hline section & $\theta=0^{\circ}$ & $\theta=25^{\circ}$ & $\theta=50^{\circ}$ & $\theta=75^{\circ}$ & $\theta=0^{\circ}$ & $\theta=25^{\circ}$ & $\theta=50^{\circ}$ & $\theta=75^{\circ}$ & $\theta=0^{\circ}$ & $\theta=25^{\circ}$ & $\theta=50^{\circ}$ & $\theta=75^{\circ}$ \\
\hline $\begin{array}{l}\text { area }^{\dagger} \\
\text { (in }^{2}\end{array}$ & 36.7 & 34.4 & 32.4 & 26.4 & 36.2 & 33.4 & 29.2 & 24.3 & 39 & 31.7 & 39 & 38 \\
\hline $\begin{array}{l}\text { average } \\
\text { velocity } \\
\text { (cm/s) }\end{array}$ & 24.5 & 24.9 & 26.3 & 27.0 & 24.1 & 25.5 & 26.8 & 25.8 & 27.6 & 26.6 & 29.1 & 30 \\
\hline
\end{tabular}

'based only on area covered by ADV measurements 
with an average of $\approx 56$. Because the measurements do not include most of the low-velocity nearboundary regions, $\langle U\rangle$ is as might be expected larger than the nominal initial inlet velocities $(22 \mathrm{~cm} / \mathrm{s}$ and $25 \mathrm{~cm} / \mathrm{s}$ ). Particularly with the shorter-duration experiments, as was noted in the discussion of Fig. 5.1 , an increase in $\langle U\rangle$ in the downstream direction is noted.

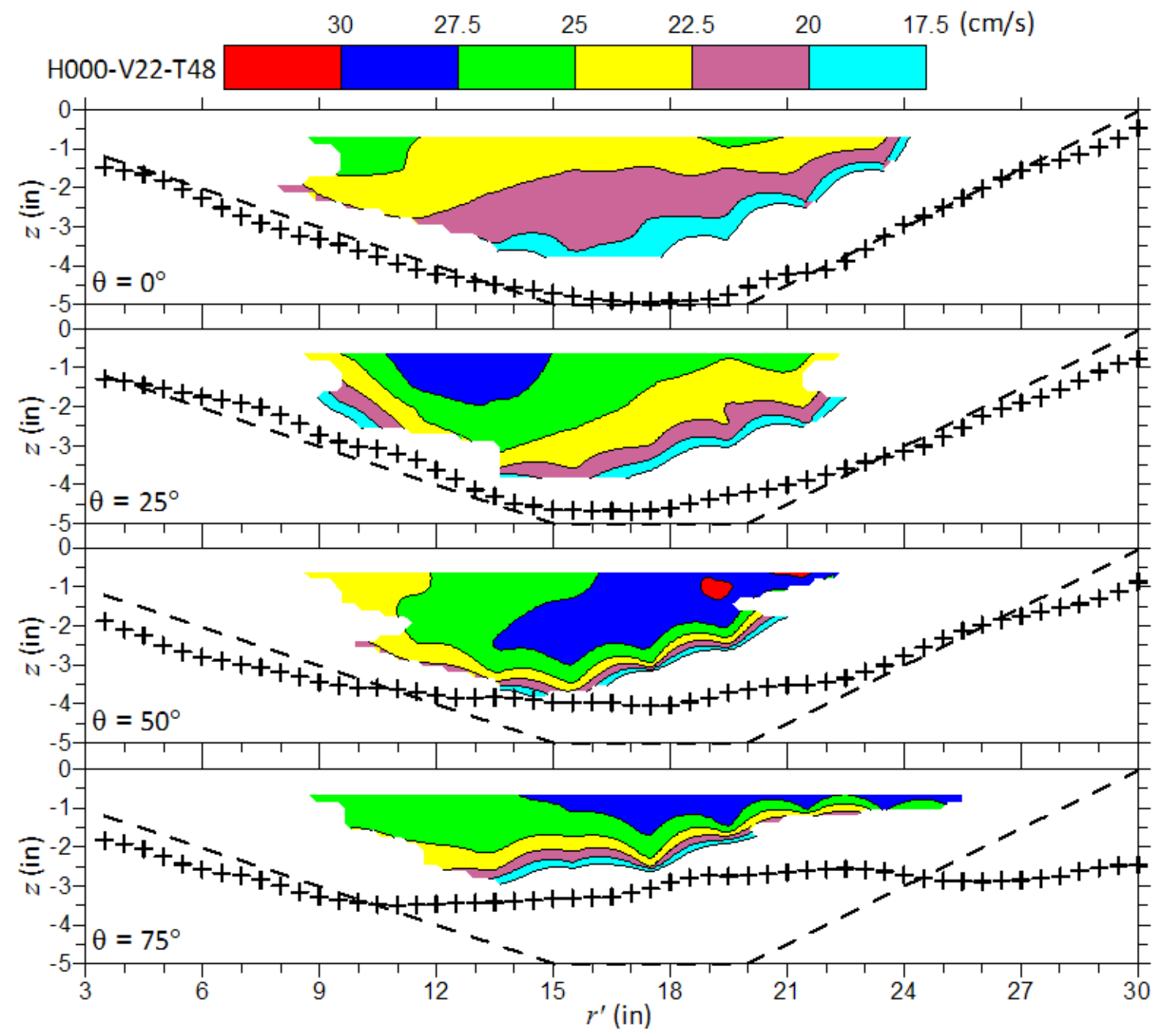

Fig. 5.3: Contours of local velocity at different sections for H000-V22-T48; the symbols indicate the corresponding cross-sectional boundary profile, while the dashed line indicates the 'initial' boundary profile

At the inlet, even though the largest velocities are found towards the inner-bank region, the vertical structure of the velocity distribution is similar to that expected in a straight-channel flow, with the largest velocities near the free surface. This remains essentially the case at the $\theta=25^{\circ}$ section, even as the maximum-velocity region begins to migrate laterally across the channel. At the $\theta=50^{\circ}$ section, this lateral migration seems to have proceeded more quickly near the free surface than at mid-depth, such that in mid-channel, say $r^{\prime}=15 \mathrm{in}$, maximum velocities are found below the free surface. A possible consequence of the downward shift in the maximum-velocity location is a larger bed shear stress due to the larger velocity gradients, and hence a larger sediment-transport capacity and erosion potential. 


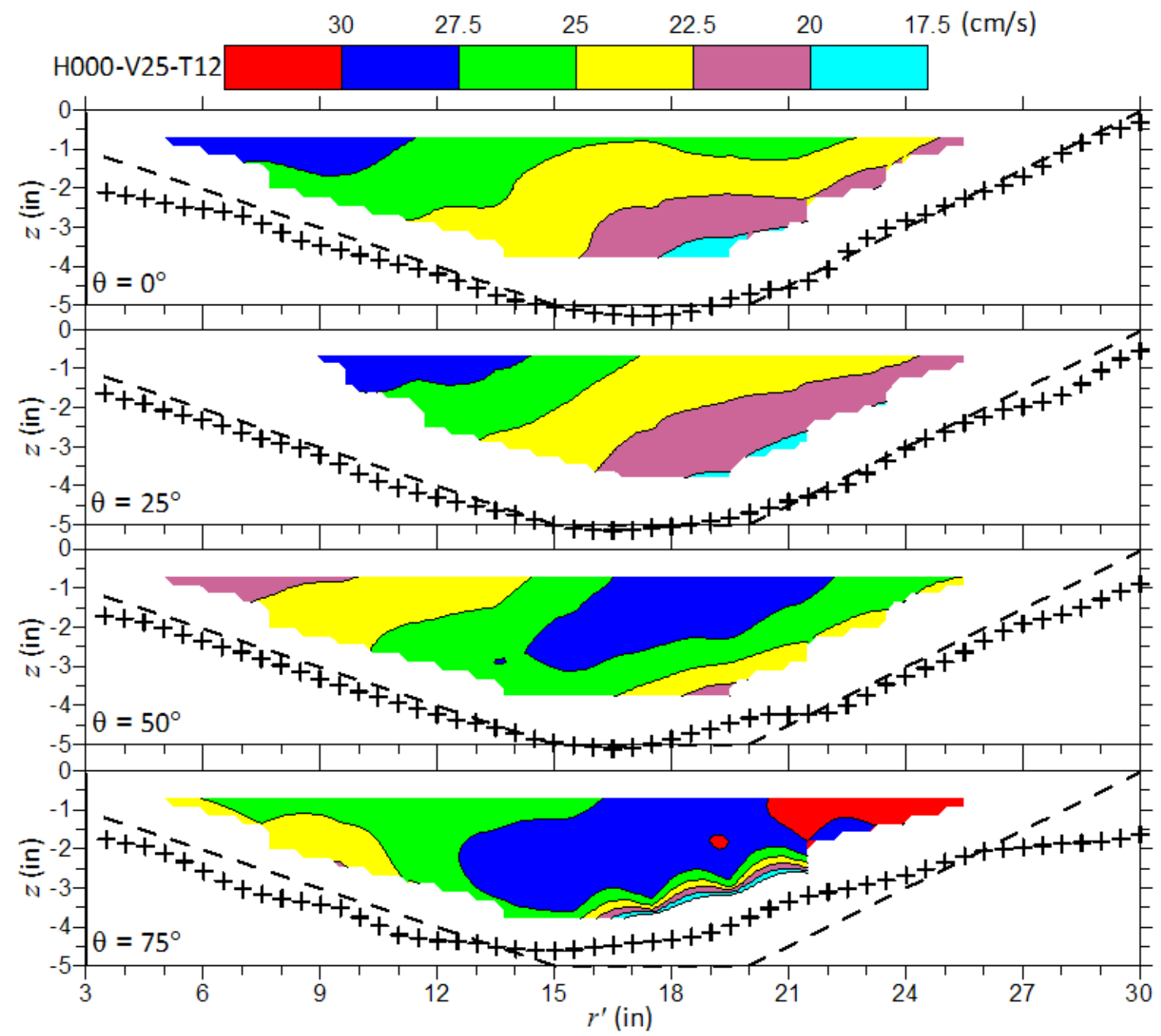

Fig. 5.4: Contours of local velocity at different sections for the H000-V25-T12 experiment; the symbols indicate the corresponding cross-sectional boundary profile, while the dashed line indicates the 'initial' boundary profile

A direct relationship between the local velocity field and the pattern of scour and deposition is not always evident. It is recalled that conventional estimates of critical velocities are $37 \mathrm{~cm} / \mathrm{s}, 30 \mathrm{~cm} / \mathrm{s}$, and $34 \mathrm{~cm} / \mathrm{s}$ for sediment in horizontal channel, on a side slope of $1 \mathrm{~V}: 2 \mathrm{H}$ (the initial slope of the outer bank), and on a side slope of $1 \mathrm{~V}: 3 \mathrm{H}$ (the initial slope of the inner bank). In the H000-V22-T24 case, the upstream sections do not exhibit any significant scour or deposition, which would be consistent with the maximum velocity, $u_{\max }$, being less than any critical velocity, and its location being towards the inner bank. At the downstream stations, as the location of $u_{\max }$ shifts to the central part of the channel and eventually over the initial outer bank region, a region of deposition is seen at the toe of the initial outer bank, with scour/erosion occurring only on the uppermost region of the outer bank, some distance away from the region of maximum velocities (some extrapolation of the measured velocities being made, since no measurements were obtained near the uppermost outer-bank region). Measured values of $u_{\max }$ varied only from $28 \mathrm{~cm} / \mathrm{s}$ to $29 \mathrm{~cm} / \mathrm{s}$ over the entire reach. The case of H000-V22-T48 is quite similar to H000-V22-T24 with however notably increased deposition in the central region and increased scour in the outer bank region, possibly extending farther upstream. The range of measured $u_{\max }$ over 
the entire reach is slightly wider $(27.6 \mathrm{~cm} / \mathrm{s}$ to $30.6 \mathrm{~cm} / \mathrm{s})$, and even some scour in the inner-bank region may be seen.

Unlike the inlet results for either H000-V22-T24 or H000-V22-T48, the inlet result for H000-V25T12 suggests some scour towards the inner bank, which would be consistent with the maximum velocities occurring in that region. Farther downstream however the results are similar to the other cases, with deposition in the central region and scour in the uppermost outer-bank region. Maximum measured velocities range $29 \mathrm{~cm} / \mathrm{s}$ to $31.5 \mathrm{~cm} / \mathrm{s}$.

\subsection{Results for cases with bendway weirs installed}

\subsubsection{The H050 series of experiments}

Contour plots of $u_{-0.5}$ for the H050 series of experiments, based on measurements at $\theta=0^{\circ}, 25^{\circ}$, $50^{\circ}$, and at sections just upstream, at, and just downstream of weir 4, are shown in Fig. 5.5. As with Fig. 5.1 , caution should be exercised in interpreting small-scale features. In general, although $u_{-0.5}$ is a nearfree-surface velocity and the bendway weirs are submerged (the weir crest height being at $50 \%$ of the initial inlet flow depth), comparison of Fig. 5.5 with Fig. 5.1 reveals that the presence of the weirs has led to notable changes. Upstream of the $\theta=50^{\circ}$ section, higher velocities are observed in a more extensive region towards the inner bank. As was the case for the no-weir cases, the results for the longer-duration H050-V22-T48 case differ somewhat from those of the other two cases, with reduced velocities not only towards the inner bank at sections downstream of $\theta=50^{\circ}$ but also towards the outer bank at upstream and downstream sections.

Table 5.2: Estimated areas covered by ADV measurements and the corresponding average velocities for the $\mathrm{H} 050$ experiment series

\begin{tabular}{|c|c|c|c|c|c|c|c|c|c|c|c|c|}
\hline Expt. & \multicolumn{4}{|c|}{ H050-V22-T24 } & \multicolumn{4}{|c|}{ H050-V22-T48 } & \multicolumn{4}{|c|}{ H050-V25-T12 } \\
\hline section & $\theta=0^{\circ}$ & $\theta=25^{\circ}$ & $\theta=50^{\circ}$ & $\mathrm{W} 4^{\dagger \dagger}$ & $\theta=0^{\circ}$ & $\theta=25^{\circ}$ & $\theta=50^{\circ}$ & W4 & $\theta=0^{\circ}$ & $\theta=25^{\circ}$ & $\theta=50^{\circ}$ & W4 \\
\hline $\operatorname{area}^{\dagger}\left(\mathrm{in}^{2}\right)$ & 35.4 & 32.3 & 27.4 & $\begin{array}{l}21.0, \\
20.8, \\
20.8 \\
\end{array}$ & 21.4 & 21.4 & 22 & $\begin{array}{l}21.2, \\
22.3, \\
21.2 \\
\end{array}$ & 24.0 & 24.0 & 24.0 & $\begin{array}{l}23.4, \\
23.6, \\
24.3\end{array}$ \\
\hline $\begin{array}{l}\text { average } \\
\text { velocity }^{\dagger} \\
(\mathrm{cm} / \mathrm{s})\end{array}$ & 24.4 & 25.3 & 27.5 & $\begin{array}{l}28.7, \\
29.2, \\
29.2\end{array}$ & 26.3 & 28.4 & 28.5 & $\begin{array}{l}28.1 \\
28.7 \\
27.6\end{array}$ & 30.0 & 32.5 & 35.6 & $\begin{array}{l}35.3, \\
32.9 \\
32.1\end{array}$ \\
\hline
\end{tabular}

'based only on area covered by ADV measurements

${ }^{\dagger}$ the three values are for the sections just upstream, at, and just downstream of W4

The areas covered by the ADV measurements in the $\mathrm{H} 050$ series of experiments and the corresponding average velocities are given in Table 5.2. The areas covered, often less than $30 \%$ of the initial inlet cross-sectional area, were less than those in the no-weir series, with fewer validated measurement points. This may have contributed to the larger velocities averaged over the areas covered, though as will be seen in Figs. $5.6-5.8$, the effect of the weirs on the increased velocities should not be discounted. The amount of 'blockage' of a single weir is relatively small, less than $12 \%$ (see Table 3.6), but their combined effect in deflecting flow towards the central part of the channel where validated measurements were more likely would tend to lead to a increased 'averaged' velocity. Except in the H050-V25-T12 case, no validated ADV measurements was obtained directly above W4, though some measurements were obtained in regions directly affected by the weirs. 


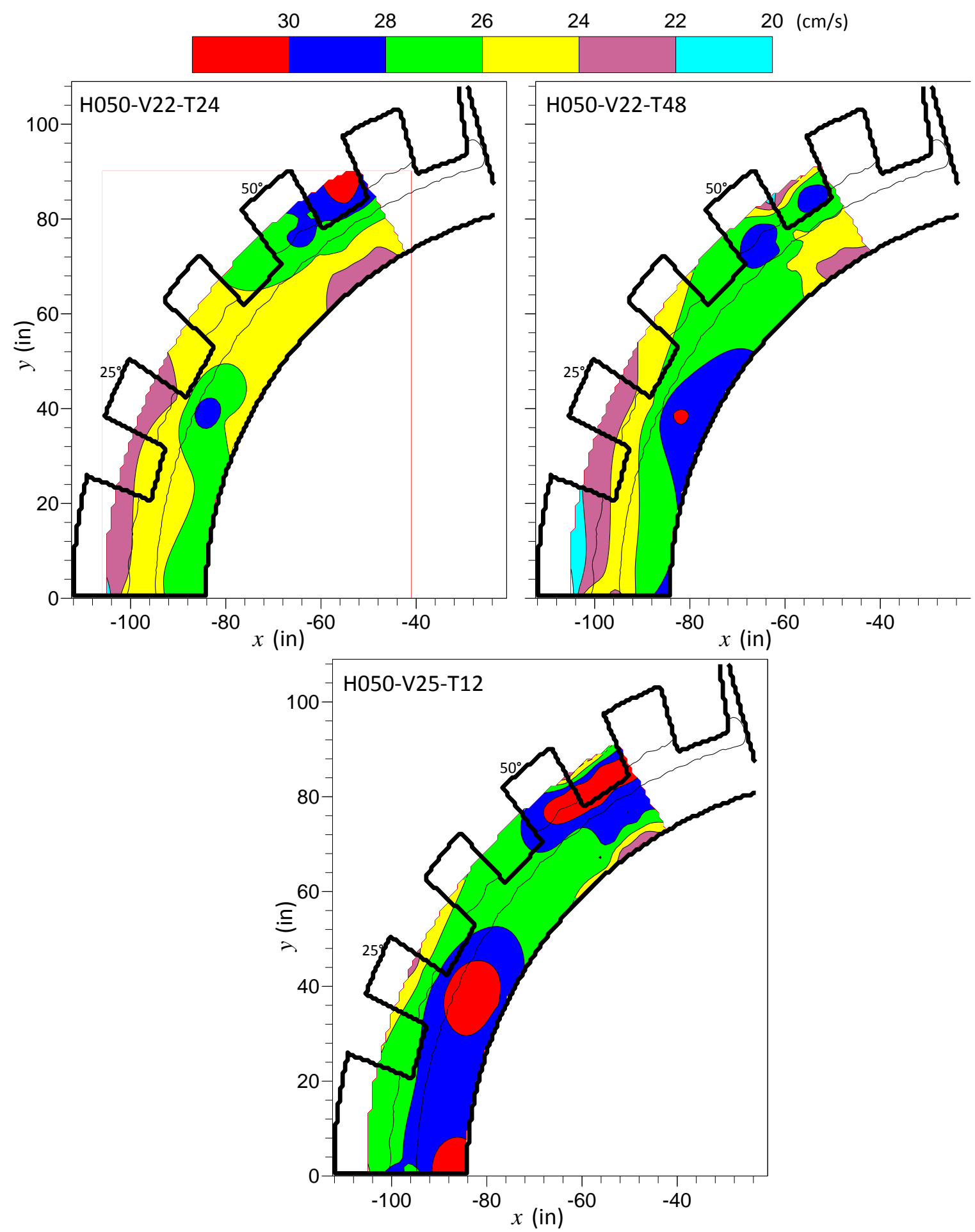

Fig. 5.5: Contour plots of downstream (tangential) near-surface $(\approx 0.5$-in below the free surface) velocity, $u_{-0.5}$, for three cases with the bendway weir crest at $50 \%$ of initial inlet flow depth. Thick lines show only the limit of erodible boundary measurements (not the channel boundary), while thin lines show the limits of the sloping banks of the initial channel. 


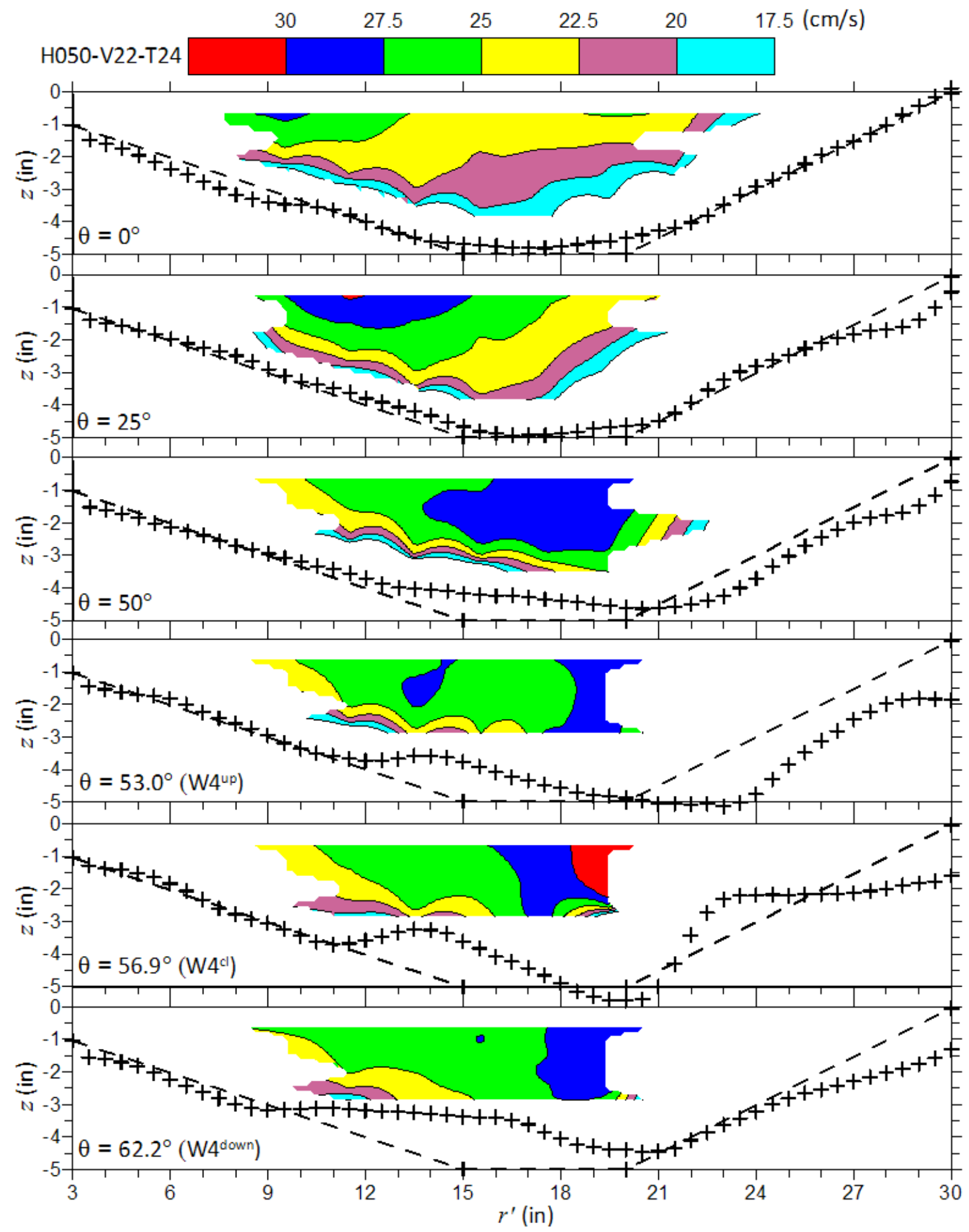

Fig. 5.6: Contours of local velocity at different sections (the last three are sections just upstream, at, and just downstream of W4) for the H050-V22-T24 experiment; the symbols indicate the corresponding cross-sectional boundary profile (angles may differ), while the dashed line indicates the 'initial' boundary profile (except at the weir) 


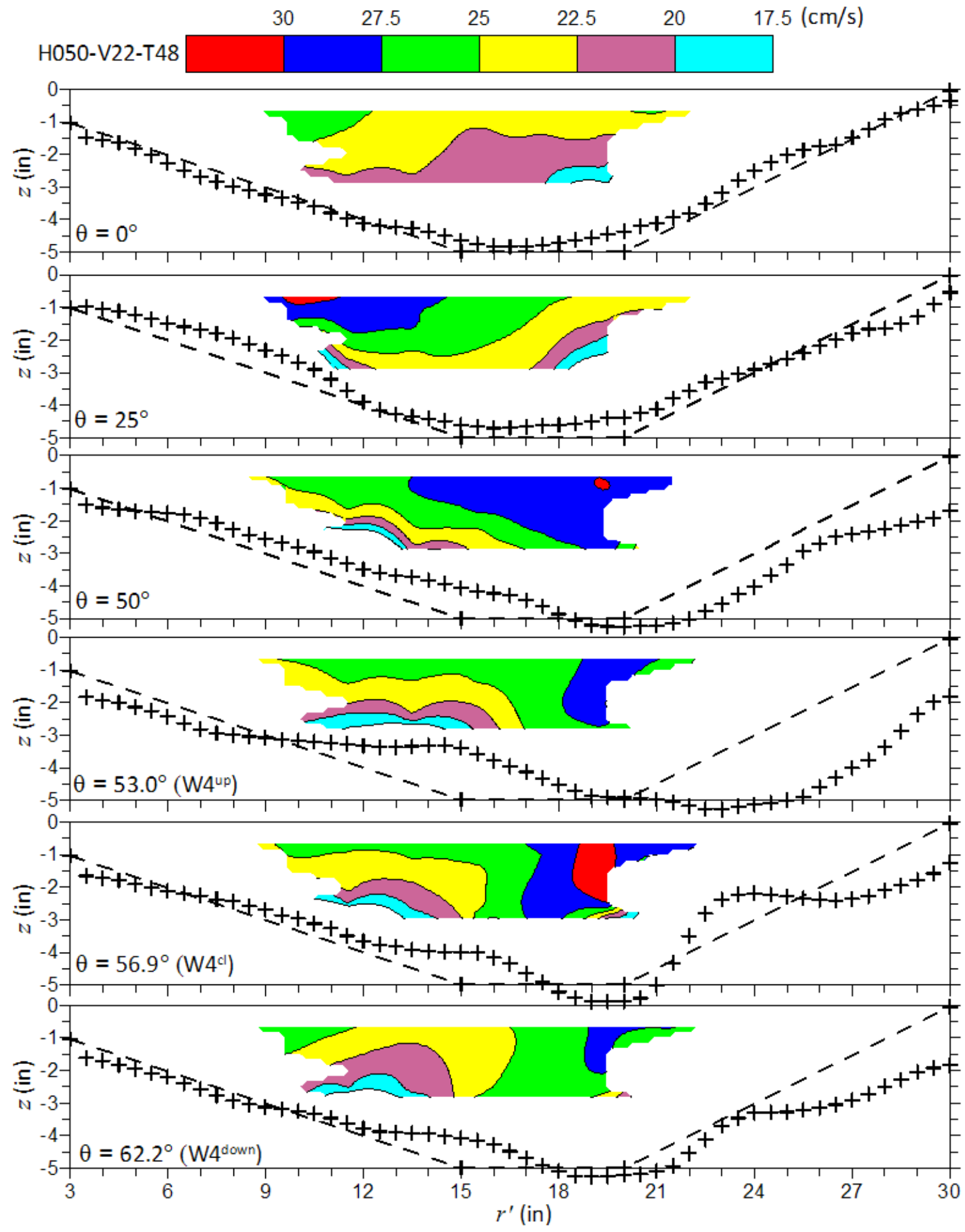

Fig. 5.7: Contours of local velocity at different sections (the last three are sections just upstream, at, and just downstream of W4) for the H050-V22-T48 experiment; the symbols indicate the corresponding cross-sectional boundary profile (angles may differ), while the dashed line indicates the 'initial' boundary profile (except at the weir) 


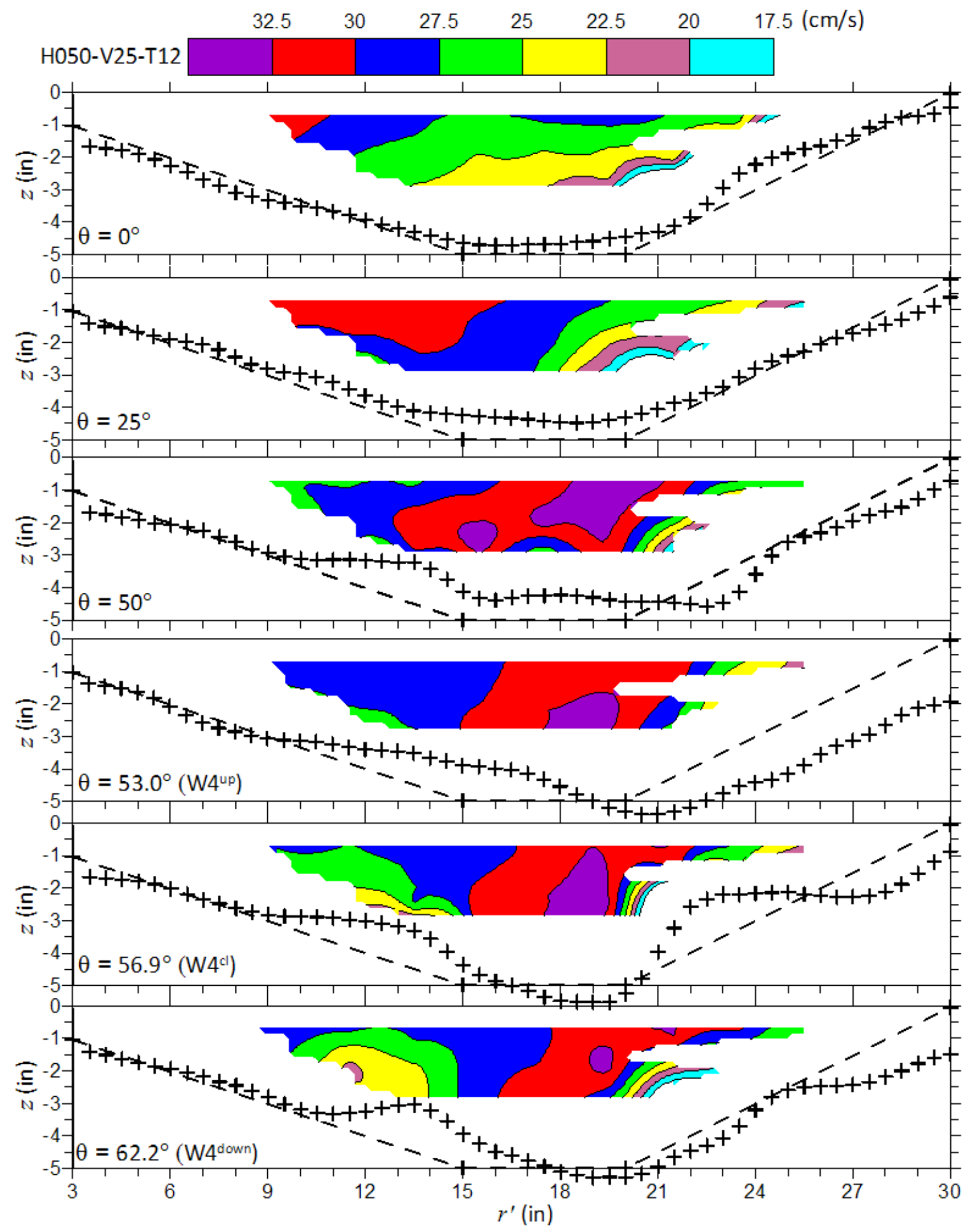

Fig. 5.8: Contours of local velocity at different sections (the last three are sections just upstream, at, and just downstream of W4) for the H050-V25-T12 experiment; the symbols indicate the corresponding cross-sectional boundary profile (angles may differ), while the dashed line indicates the 'initial' boundary profile (except the profile at the weir) 
Comparison of Fig. 5.6 with Fig. 5.2 shows an inlet flow (and boundary profile) very similar for the cases H050-V22-T24 and H000-V22-T24, but by the $\theta=25^{\circ}$ section, a noticeably more extensive high-velocity region is observed, interestingly still in the inner-bank region, i.e., away from the weirs. At this section, the boundary profiles remain quite similar, even including in both cases a region of scour in the uppermost outer-bank region. Differences in boundary profiles between the two cases become more evident at the $\theta=50^{\circ}$ section, where the region of deposition has shifted in the case of H050-V22T24 from the toe of outer bank where net scour occurs to the toe of inner bank. This is accompanied by a velocity distribution that is more 'horizontal' and less diagonally inclined, i.e., more like a straightchannel distribution. Such a distribution would be more conducive to deposition at the toe of the inner bank, while the more extensive high-velocity region over the toe of the outer bank would tend to lead to scour in that region. In the immediate vicinity of the weir, the velocity distribution becomes more vertically uniform, with a high-velocity region concentrated near the weir tip, presumably as the flow becomes dominated by the deflecting effect of the weir. Associated with this is the scour around the weir tip region. On the other hand, the lower velocities at the toe of the inner bank seem to further enhance the deposition.

The results for the H050-V22-T48 and H050-V25-T12 cases share the above features of the velocity distribution and the corresponding boundary profiles with the H050-V22-T24 cases, at least for the central and the inner-bank regions. Although quite limited, the H000-V25-T12 case offers the only validated velocity measurements that extend some distance over the outer bank, including over the weir. The few measurements available, mostly near the free surface, indicate that the velocities in the uppermost outer bank region where some scour is observed even at the upstream sections $\left(\theta=25^{\circ}\right.$ and $\theta=50^{\circ}$ - also see the similar results for H050-V22-T24 and H050-V22-T48) are quite modest, and do not attain values anywhere close to the equilibrium straight-channel critical value of $\approx 30 \mathrm{~cm} / \mathrm{s}$, except possibly at the $\theta=50^{\circ}$ and $\theta=60.3^{\circ}$ sections. This suggests that the erosion of the uppermost outer-bank region is more likely due to mass failure than to direct entrainment.

Table 5.3: Estimated areas covered by ADV measurements and the corresponding average velocities for the $\mathrm{H} 075$ and $\mathrm{H} 100$ experiment series

\begin{tabular}{|c|c|c|c|c|c|c|c|c|c|c|c|c|}
\hline Expt. & \multicolumn{4}{|c|}{ H075-V22-T24 } & \multicolumn{4}{|c|}{ H075-V22-T48 } & \multicolumn{4}{|c|}{ H100-V22-T48 } \\
\hline section & $\theta=0^{\circ}$ & $\theta=25^{\circ}$ & $\theta=50^{\circ}$ & $\mathrm{W} 4^{\dagger \dagger}$ & $\theta=0^{\circ}$ & $\theta=25^{\circ}$ & $\theta=50^{\circ}$ & W4 & $\theta=0^{\circ}$ & $\theta=25^{\circ}$ & $\theta=50^{\circ}$ & W4 \\
\hline $\operatorname{area}^{\dagger}\left(\mathrm{in}^{2}\right)$ & 29.3 & 29.7 & 29.7 & $\begin{array}{l}28.5, \\
29.3 \\
30.1\end{array}$ & 24.4 & 25.0 & 25.1 & $\begin{array}{l}25.0 \\
23.7 \\
25.0\end{array}$ & 25.9 & 25.3 & 25.3 & $\begin{array}{l}25.3 \\
25.3 \\
26.4\end{array}$ \\
\hline $\begin{array}{l}\text { average } \\
\text { velocity }^{\dagger} \\
(\mathrm{cm} / \mathrm{s})\end{array}$ & 24.1 & 28.6 & 28.7 & $\begin{array}{l}28.7 \\
30.3 \\
27.7\end{array}$ & 24.7 & 27.1 & 27.3 & $\begin{array}{l}27.6 \\
26.9 \\
27.3\end{array}$ & 25.9 & 28.8 & 29.0 & $\begin{array}{l}28.9 \\
29.7 \\
28.3\end{array}$ \\
\hline
\end{tabular}

'based only on area covered by ADV measurements

†the three values are for the sections just upstream, at, and just downstream of W4

\subsubsection{The H075 and H100 experiments}

For the other weir crest heights, velocity measurements were taken only for a single initial inlet velocity $(22 \mathrm{~cm} / \mathrm{s})$ and different durations were only studied with the $\mathrm{H} 075$ weir. The areas covered and 


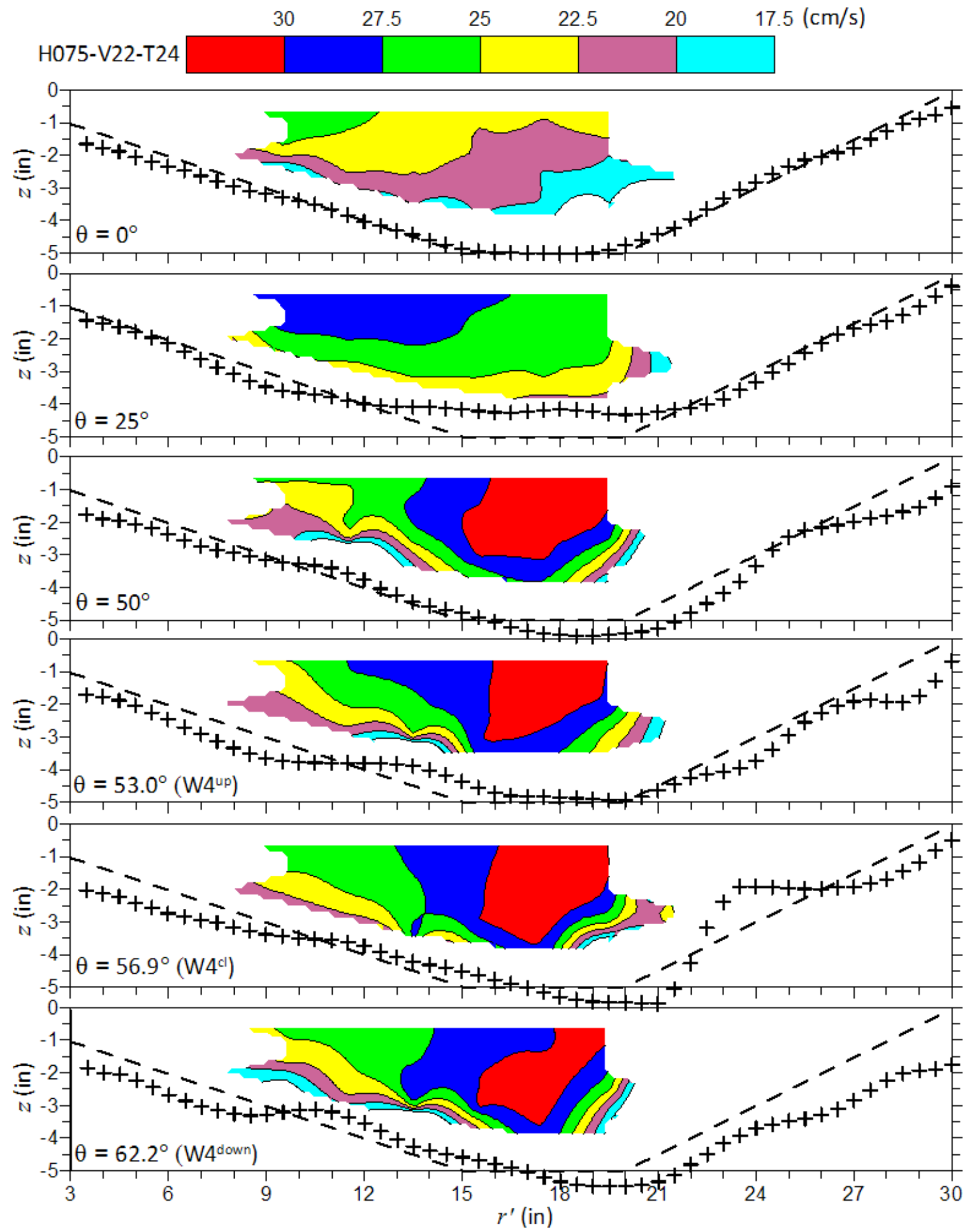

Fig. 5.9: Contours of local velocity at different sections (the last three are sections just upstream, at, and just downstream of W4) for the H075-V22-T24 experiment; the symbols indicate the corresponding cross-sectional boundary profile (angles may differ), while the dashed line indicates the 'initial' boundary profile (except the profile at the weir) 


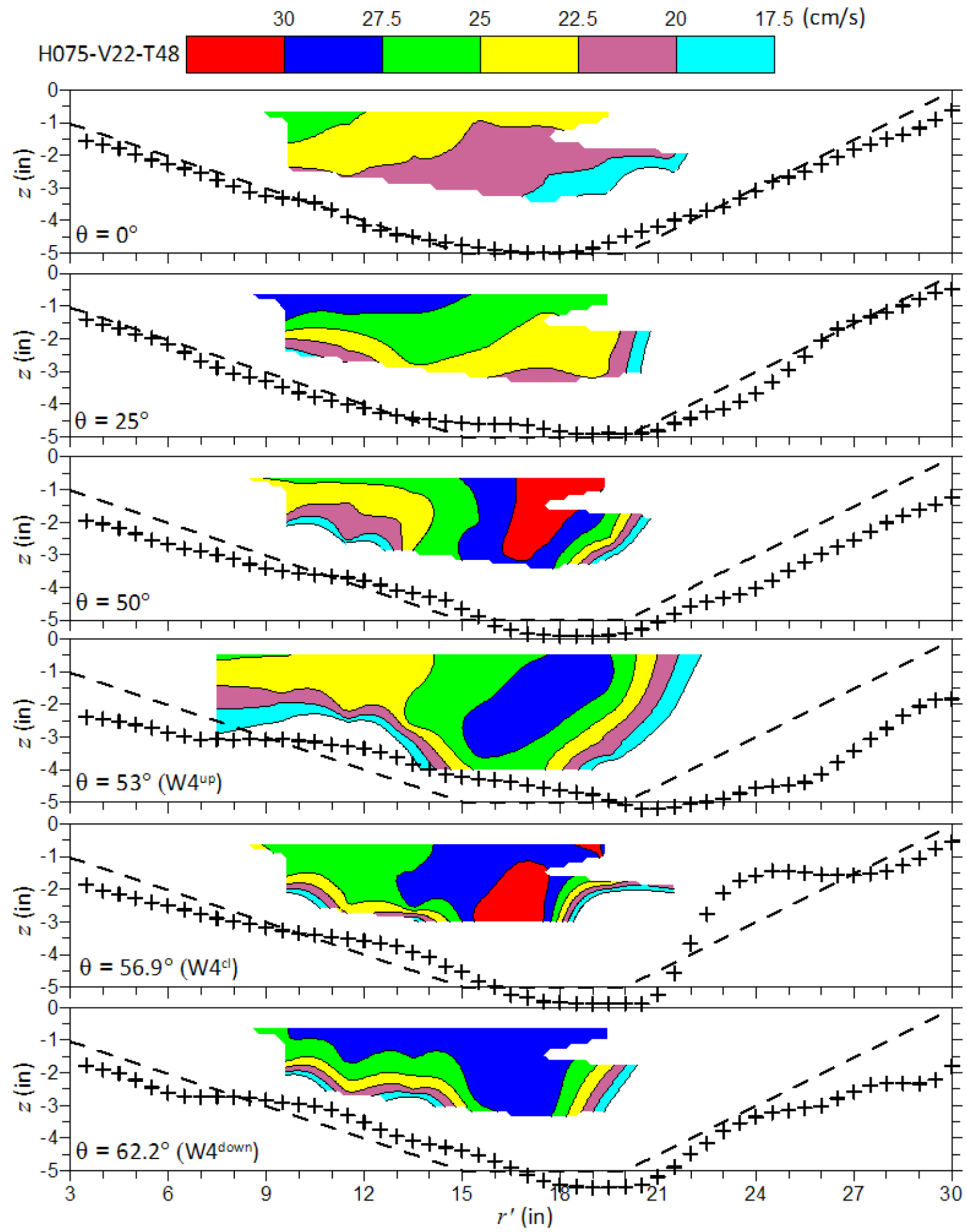

Fig. 5.10: Contours of local velocity at different sections (the last three are sections just upstream, at, and just downstream of W4) for the H075-V22-T48 experiment; the symbols indicate the corresponding cross-sectional boundary profile (angles may differ), while the dashed line indicates the 'initial' boundary profile (except the profile at the weir) 


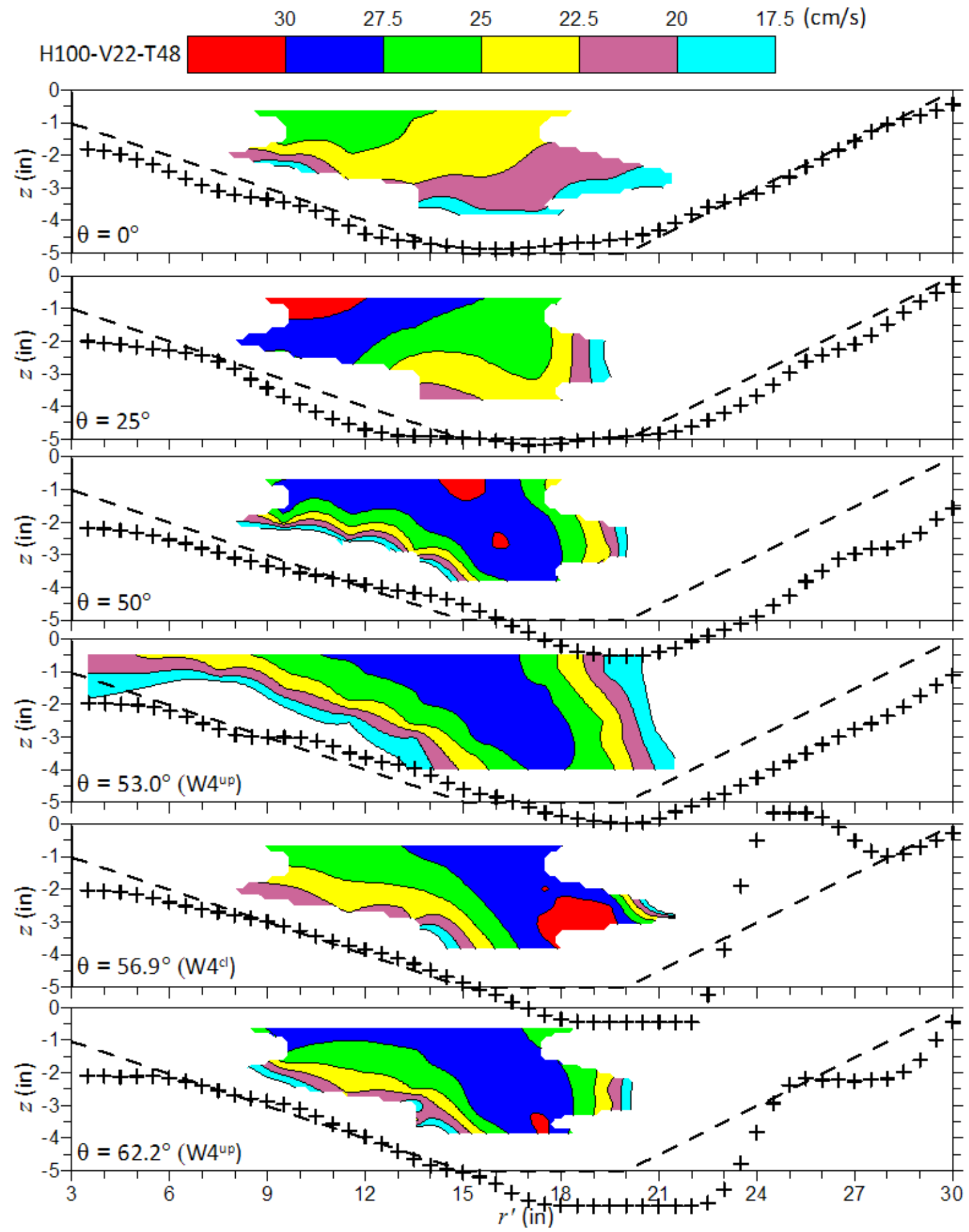

Fig. 5.11: Contours of local velocity at different sections (the last three are sections just upstream, at, and just downstream of W4) for the H100-V22-T48 experiment; the symbols indicate the corresponding cross-sectional boundary profile (angles may differ), while the dashed line indicates the 'initial' boundary profile (except the profile at the weir) 
the corresponding 'average' velocities are given in Table 5.3. The velocity contours at the different sections for the various cases are shown in Figs. 5.9 - 5.11. Compared to the H050 series, the inlet velocity distribution and cross-sectional profile for the higher-weir-crest cases are quite similar. At the $\theta$ $=25^{\circ}$ section, i.e., between W1 and W2, a more vertically oriented (contour lines tend to be vertical) structure is however seen towards the outer bank in the $\mathrm{H} 075$ and $\mathrm{H} 100$ cases. In the $\mathrm{H} 100$ case, this seems to have led to higher velocities and even some scour towards the inner bank. Again, it should be kept in mind that the flow blockage due to the higher weir crest height is actually slightly reduced. At the $\theta=50^{\circ}$ section, a notable difference in the velocity distribution is seen in the various cases, including the no-weir case. The contrast is particularly striking between the no-weir case (H000-V22-T48 in Fig. 5.3), where the high-velocity region extends diagonally from mid-depth at the toe of the inner bank to the free surface over the lower outer bank, and the spur-like case (H100-V22-T48 in Fig. 5.11) where the high-velocity region also extends diagonally, but in the other direction, namely at the free surface over the inner bank and towards the central channel at mid-depth. The differences in cross-sectional profiles between these two cases are also striking, with a rather uniform deposition over the central channel and scour confined to both upper bank regions in the case of H000-V22-T48, but with significantly greater scour at the toe and lower part of the outer bank. The latter would be consistent with the difference in the velocity distribution.

Comparison of the $\theta=50^{\circ}$ section contours of the $\mathrm{HOOO}, \mathrm{HO50}$, and $\mathrm{H} 100$ series (Figs. 5.3, 5.7, and 5.11) leads to the interpretation that the more horizontal $\mathrm{H} 050$ contours are intermediate between the two oppositely inclined contours of $\mathrm{H0OO}$ and $\mathrm{H} 100$. Whereas for H050-V22-T48 the high-velocity region at the free surface seems to extend farther towards the outer bank than H100-V22-T48, the highvelocity region of the latter may extend deeper, which may explain the larger scour at the toe and the lower part of the outer bank (though not necessarily the similar scour in the uppermost part of the outer bank). In the immediate vicinity of the weir (W4), the contours towards the outer bank take on a more vertically oriented character irrespective of weir height, though this character seems more pronounced for the higher-weir-crest cases.

\subsection{Further comments}

The relationship between the mean streamwise velocity field and the pattern of scour and deposition, especially when interpreted in terms of the estimate of critical velocity based on uniform equilibrium flow, is not straightforward. Interpretation of the velocity measurements is made difficult because the present measurements were often limited to regions rather far away from the bank regions where definite scour was observed. In the one case (H050-V25-T12) where velocity measurements were obtained in the flow over the weir, these were not found to be especially high, and the maximum velocities were in fact found in the deflected flow at some distance from the weir tip. Thus, whether the overtopping flow played the dominant role in the scour in the upper part of the outer bank observed between the weir remains unclear.

That substantial erosion is observed in regions where the local velocity and hence local boundary shear stress are likely to be quite small (compared to any estimate of a critical value) suggests strongly that that the main mechanism for this erosion is mass failure. Such mass failure would still need to be initiated at a lower elevation by direct fluvial entrainment. Whether this should be attributed primarily to the overtopping flow or to the deflected flow is not settled by the available velocity measurements. Nevertheless, because some erosion and even a ledge-like structure are observed in the $\mathrm{H} 100$ case, with its minimal overtopping flow, the possible importance of the deflected flow should be considered. 
It had been hoped to determine directly from measurements of the two components (tangential and radial) of velocity the extent to which the flow over the weir was directed perpendicular to the plane of the weir, the presumed basis of the bendway weir. Unfortunately, while the measurements of the mean streamwise component of velocity are considered quite reliable, the radial component is believed to be associated with a sufficiently large uncertainty so as to make any inferences about the direction of the flow over the weir questionable.

\subsection{Summary}

Point velocity measurements obtained with the acoustic Doppler technique in a bend flow over an erodible boundary with and without bendway weirs were presented. In the no-weir cases, the typical features of bend flows were observed, namely that at the entrance to the bend, the high-velocity region occurred towards the inner-bank region, while beyond mid-bend, the location of the high-velocity region shifts towards the outer-bank region. The rate of this lateral shift of the high-velocity region seems however to vary vertically within the water column, with the largest shift at the free surface, and a distinct lag at mid-depth. As a consequence, the high-velocity region has a notably diagonal orientation, and at mid-channel the maximum velocity is found at some distance below the free surface. Although some loose correlation between the measured velocity distribution and the pattern of scour and deposition might be inferred, the relationship is not straightforward. Erosion in the uppermost bank regions (both inner and outer) was noted where it seemed quite unlikely that the depth-averaged velocity approached, much less exceeded, the critical velocity. This points to the predominant erosion mechanism being mass failure.

In the presence of weirs, regardless of weir crest height, the inlet flow is not substantially changed. Farther downstream however the diagonal orientation of the high-velocity region seen in the no-weir case is much less marked, and in the vicinity of a weir, the velocity distribution becomes more uniform in the vertical direction, presumably reflecting the high-velocity flow being deflected laterally by the weir. This high-velocity flow is clearly associated with a scour region at the tip of the weir. Limited measurements were obtained in the flow over the weir only in a single case, but these do not give any strong indication of any high velocities that might be responsible for the scour observed in the uppermost part of the outer bank, and may not even be sufficient by themselves to initiate mass failure. 


\section{Conclusions and implementation}

The central question addressed in the present study concerns the effectiveness of bendway weirs as a bank erosion countermeasure. More specifically, a field of bendway weirs implemented following HEC-23 design guidelines was to be investigated in a laboratory model of a erodible-boundary bend flow. In addition, the effects of increasing the weir crest height and, to a more limited extent, the inlet velocity were also studied.

On the positive side, the weirs, particularly those that were overtopped, were found effective in protecting the lower part of the initial toe of the outer bank, to the extent that this region did not experience any substantial scour, compared to the initial channel geometry. Nevertheless, it should be pointed out that in the corresponding no-weir case, at the corresponding section, this region experienced considerable deposition rather than scour. The apparent protection may therefore be debatable.

The effectiveness of the weirs, specifically as implemented in the HEC-23 design guidelines, in protecting the upper part of the outer bank is even more questionable. In the no-weir case, this region did experience substantial erosion, and the presence of the 'standard' HEC-23 weirs did little to inhibit erosion. Increasing the weir crest height above that recommended in HEC-23 gave some improved protection, but only the limiting case where there was minimal overtopping flow, i.e., the structure acting essentially as a spur, resulted in noticeably reduced erosion of the upper part of the outer bank.

The HEC-23 guidelines for bendway weirs do not incorporate any effect of approach velocity. The limited study of the effects of velocity indicates however that these effects may be important in cases with and without weirs. Rates of erosion, or more generally, of evolution of the erodible boundary were higher with a higher inlet velocity, such that scour or deposition was comparable to that for a lower velocity over a much longer duration.

Mean streamwise velocity measurements for the no-weir case agree with the literature in showing a high-velocity region towards the inner bank at the bend inlet that migrates farther downstream towards the outer bank. A marked diagonal vertical orientation of the high-velocity region is seen at sections beyond mid-bend in the absence of weirs, but this seems to be moderated or eliminated in the presence of weirs. At the tip of the weirs, a high-velocity region that is quite vertically uniform is observed, but limited measurements of the flow over the weir do not give any strong evidence of high velocities that might be capable of causing the observed scour of the upper part of the outer bank.

As in any experimental study, only a restricted set of conditions could be examined, and it is conceivable that bendway weirs could prove more effective under conditions other than those covered in this study. For example, the possibility of improved performance with closer weir spacing or sharper upstream orientation should not be excluded. Other effects, such as the effect of sediment cohesion was not studied at all. Nevertheless, the study provides clear evidence that bendway weirs designed according to the HEC-23 guidelines may not prove entirely effective, and further research is needed to delineate more precisely those conditions, if any, under which such structures would be effective.

\subsection{Implementation implications for INDOT}

Due to the above somewhat negative conclusions regarding the performance of bendway weirs, designed according to HEC-23 guidelines, as a bank erosion countermeasure, the study makes the recommendations for implementation by INDOT: 
- for cases where no erosion can be tolerated for design flow conditions, bendway weirs, particularly as described in HEC-23, should not be chosen

- if an alternative to riprap is desired, spurs, i.e., structures that are not overtopped by the mean annual flow, would be preferable as the present results indicate that these offer greater protection to the upper part of the outer bank.

- to minimize problems of scour at the toe of the outer bank, the length of the spur should extend to or beyond the toe of the outer bank

- the spacing between spurs should probably be reduced from that $\left(S / L_{\mathrm{w}} \approx 4\right)$ in the present study, closer to that recommended in Copeland for spurs, namely, $2<S / L_{\mathrm{w}}<3$.

- if it is sufficient that the toe of the bank be protected, and that retreat of only the upper part of the outer bank can be tolerated, then bendway weirs may be more seriously considered, but their effectiveness would require close monitoring.

- further study may be needed regarding the effect of angle (with respect to the bank tangent)

- more conservative choices with regards to the HEC-23 recommended range of design values might also be seriously considered. 


\section{References}

1. Abad, J. D., Rhoads, B. L., Guneralp, I. and Garcia, M. H. (2008). Flow structure at different stages in a meander bend with bendway weirs, J. Hydraulic Eng., v. 134, no. 8, Aug., pp. 1052-1063.

2. Biedenharn, D. S., Elliott, C. M. and Watson, C. C. (1997). THE WES Stream Investigation and Streambank Stabilization Handbook,

3. Blanckaert, K. and Graf, W. H. (2002). Mean flow and turbulence in open-channel bend, J. Hydraulic Eng., vol. 127, no. 10, Oct., pp. 835-847.

4. Bhuiyan, F., Hey, R. D., and Wormleaton, P. R. (2010). Bank-attached vanes for bank-erosion control and restoration of river meanders, accepted for publication, J. Hydraulic Eng.

5. Brown, S. A. (1985). Design of spur-type streambank stabilization structures, Rept. no. FHWA/RD84-10, Federal Highway Administration, U. S. Dept. of Transportation, Washington, D. C.

6. Brown, S. A. and Clyde, E. S. (1989). Design of Riprap revetment, HEC-11, FHWA-IP-89-016, Federal Highway Administration, U. S. Dept. of Transportation, Washington, D. C.

7. Chang, H. H. (1992). Fluvial Processes in River Engineering, Krieger, Malabar, Florida.

8. Chow, V.-T. (1959). Open channel Hydraulics, McGraw-Hill, New York.

9. Copeland, R. R. (1983). Bank protection techniques using spur dikes, Waterways Experiment Station, Hydraulics Laboratory, HL-83-1, Vicksburg, Miss.

10. Darrow, J. D., Thornton, C. I., Abt, S. R., Lipscomb, C. M., Watson C. C., and Robeson, M. D. (2004). Effects of Bendway Weir Characteristics on Resulting Flow Conditions, Colorado State University, Engineering Research Center, Fort Collins, Colorado.

11. Derrick, D. L., Boyd, M. B., Crutchfield, J. P., Henderson, R. R. and Pokrefke, T. J. (1994). Design and development of bendway weirs for the Dogtooth Bend reach, Mississippi River, hydraulic model investigation, Waterways Experiment Station, Vicksburg, Miss., Technical Rept. HL-94-10.

12. Fischenich, J. C. (2003). Effects of Riprap on Riverine and Riparian Ecosystems, Rept. ERDC/EL TR03-4, U.S. Army Corps of Engineers, Engineer Research and Development Center Environmental Laboratory, Vicksburg, Miss.

13. Fox, J. F., Papanicolaou, A. N., Hobbs, B., Kramer, C., and Kjos, L. (2005). Fluid-sediment dynamics around a barb: an experimental case study of a hydraulic structure for the Pacific Northwest, Can. J. Civil Eng., vol. 32, pp. 853-867.

14. Henderson, F. M. (1966). Open Channel Flow, Prentice-Hall, New Jersey.

15. Heintz, M. L., Thornton, C. I., Abt, S. R., Lipscomb, C. M., Watson C. C., Darrow, J. D., and Robeson, M. D. (2002). Investigation of Bendway Weir Spacing, Colorado State University, Engineering Research Center, Fort Collins, Colorado.

16. Hickin, E. J. and Nanson, G. C. (1984). Lateral migration rates of river bends, J. Hydraulic Eng., vol. 110, no. 11, pp. 1557-1567.

17. Hicks, F. E., Jin, Y. C., and Steffler, P. M. (1990). Flow near sloped bank in curved channel, J. Hydraulic Eng., vol. 116, no. 1, Jan., pp. 55-70.

18. Ippen, A. T. and Drinker, P. A. (1962). Boundary shear stress in curved trapezoidal channels, J. Hydraulics Div., vol. 88, no. HY5, pp. 143-179.

19. Kraus, N. C., Lohrmann, A., and Cabrera, R. (1994). New acoustic meter for measuring laboratory flows, J. Hydraulic Eng., vo. 120, no. 3, March, pp. $406-412$.

20. Lagasse, P. F., Schall, J. D., and Richardson, E. V. (2001). Stream stability at highway structures, $3^{\text {rd }}$ ed., HEC-20, FHWA-NHI-01-002, Federal Highway Administration, U. S. Dept. of Transportation, Washington, D. C.

21. Lagasse, P. F., Clopper, P. E., Pagan-Ortiz, J. E., Zeverbergen, L. W., Arneson, L. A., Schall, J. D., and Girard, L. G. (2009). Bridge scour and stream stability countermeasures, $3^{\text {rd }}$ ed., vols. 1 and 2, 
HEC-23, FHWA-NHI-09-111, Federal Highway Administration, U. S. Dept. of Transportation, Washington, D. C.

22. Matsuura, T. and Townsend, R. (2004). Stream-barb installations for narrow channel bends - a laboratory study, Can. J. Civ. Eng., vol. 31, pp. $478-486$.

23. Maynord, S. R. (1988). Stable riprap size for open channel flow, Hydraulics Lab. Rept. HL-88-4, Dept. of the Army, Waterways Experiment Station, Vicksburg, Miss.

24. National Resources Conservation Service (2007). Stream Restoration Design Handbook, National Engineering Handbook, NEH-654, U.S. Dept. of Agriculture, Washington, D. C.

25. Odgaard, A. J. (2009). River Training and Sediment Management with Submerged Vanes, ASCE Press, Reston, Virginia.

26. Rhoads, B. L. (2003). Protocols for geomorphic characterization of meander bends in Illinois, Dept. of Geography, Univ. Illinois Urbana-Champaign.

27. Richardson, E.V. and Davis, .S. R. (2001). Evaluating scour at bridges, $4^{\text {th }}$ ed., HEC-18, FHWA-NHI01-001, Federal Highway Administration, U. S. Dept. of Transportation, Washington, D. C.

28. Sontek (2001). Acoustic Doppler Velocimeter Principles of Operation, Sontek, San Diego, Calif.

29. U.S. Army Corps of Engineering (USACE) (1991). Hydraulic Design of Flood Control Channels, EM 1110-2-1601, Dept. of the Army, U.S. Corps of Engineers, Washington, D. C. 